\title{
MODELING, SIMULATION AND DESIGN SPACE \\ EXPLORATION OF A MTV 5.0 TON CARGO TRUCK IN MSC-ADAMS
}

\author{
A Thesis \\ Presented in Partial Fulfillment of the Requirements for \\ the Degree Master of Science in the
} Graduate School of The Ohio State University

By

Mohit Verma, B.E.

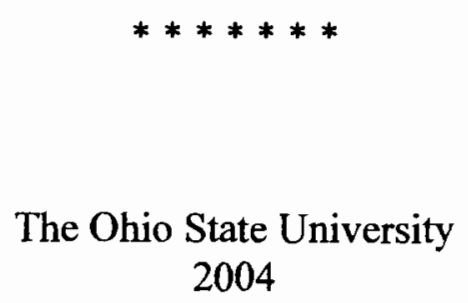

Master's Examination Committee:

Dr. Giorgio Rizzoni, Adviser

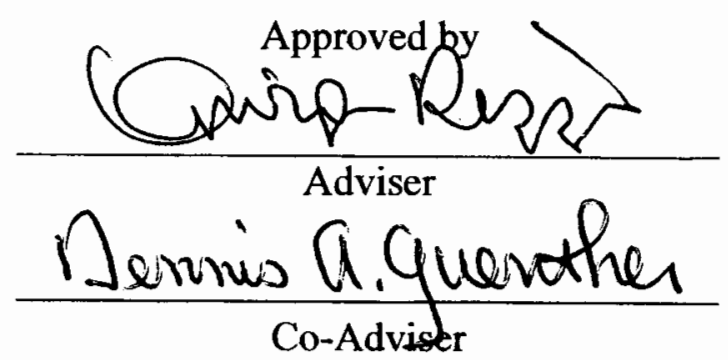

Department of Mechanical Engineering 


\section{ABSTRACT}

Ride and handling of heavy duty trucks are an important issue in the automotive industry. Design, simulation and optimization are key steps in the process of creating optimized prototypes of the truck. Testing of physical prototypes to optimize ride and handling requires substantial amount of manpower, time and financial resources. This thesis uses a methodology for ride and handling optimization of an MTV (Medium Tactical Vehicles) 5.0 Ton truck with modified suspension for U.S.Army.

ADAMS (Automatic Dynamic Analysis of Mechanical System) is used as the multibody dynamics software to model the vehicle. Inputs and outputs (responses) are selected to evaluate ride and handling of the truck. Dynamic simulations of the truck are run for the chosen maneuvers for selected suspension and tire parametric variations. Performance measures for ride and handling evaluation along with the design parameters form the design space. This design space is then exported to the flexible optimization architecture. Dominance filtering is used to filter out the designs which are dominated by the other designs in the design space with respect to the all the selected performance measures. The visualization environment provides two dimensional scatter plots for the 
performance measures and/or design parameters to help the user to find complex relationships between them.

The final optimized design selection is dependent on the criteria's selected to optimize ride and handling for the truck by making desired tradeoffs. Appropriate tire pressure are found for a given sprung mass to optimize ride and handling for the truck. 
Dedicated to my family 


\section{ACKNOWLEDGMENTS}

I would like to thank my adviser, Dr. Giorgio Rizzoni, for his guidance, support and help throughout my graduate study at The Ohio State University.

I thank Dr. Dennis A. Guenther for helping me in writing this thesis and for guiding me in the right direction. I would like to thank my friends at CAR-IT for their help and support for this thesis.

I express my gratitude to Mark Carroll, John Josephson and James Russell for their help with the flexible optimization architecture used in this thesis. I am thankful to Eric Pesheck, Tim Gartland, Jan Van Oosten and Jesper Slättengren from Mechanical Dynamics, Inc. for their help in solving problems related to MSC-ADAMS.

I thank Heather Molitoris and Thomas Udvare from the U.S.Army TACOM for providing help with modeling and simulation data used for the MTV cargo truck. I would like to thank Fred Wheeler from Michelin America in providing the data used for the tire used in the cargo truck. I want to thank Dr. Kamel Salaani from NHTSA in providing help and guidance for the tire modeling.

Many thanks to my parents, brother, cousins and friends for their ongoing support through out my life and I feel blessed to have them in my life. 


\section{VITA}

November 25, 1979................... Born - New Delhi, India

October $2001 \ldots \ldots \ldots \ldots \ldots \ldots \ldots \ldots \ldots \ldots \ldots \ldots \ldots \ldots \ldots$ B.E, Mechanical Engineering,

R.V.College of Engineering,

Bangalore, Bangalore University

January 2003 - May 2003............... Graduate Teaching Associate, Department of Mechanical Engineering, The Ohio State University

June $2003-2004$

Graduate Research Associate, Center for Automotive Research and Intelligent Transportation (CAR-IT), The Ohio State University

\section{FIELDS OF STUDY}

Major Field: Mechanical Engineering 


\section{TABLE OF CONTENTS}

\section{Page}

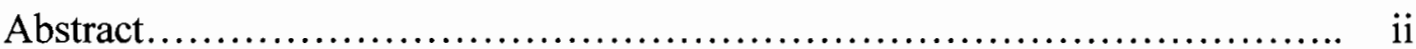

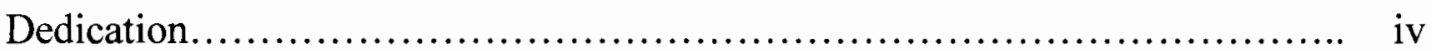

Acknowledgements................................................ v

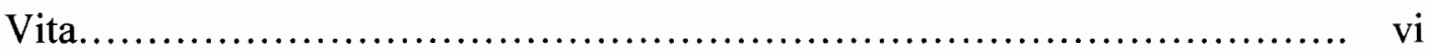

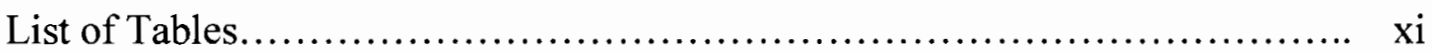

List of Figures............................................................... xii

\section{CHAPTERS:}

1. Introduction...................................................... 1

$1.1 \quad$ Motivation..................................................... 1

1.2 Objective................................................... 3

$1.3 \quad$ Literature Review................................................. 5

1.3.1 Vehicle Dynamics Simulation.......................... 5

1.3.2 Ride................................................ 5

1.3.3 Handling............................................. 7

1.4 Thesis Chapter Organization.................................. 7

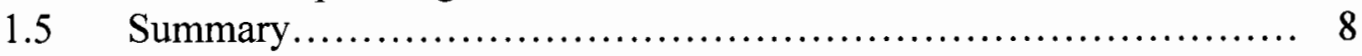

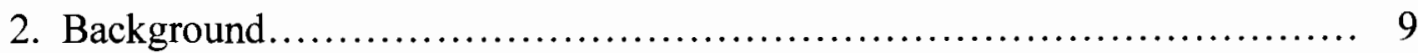

$2.1 \quad$ Multi-Body Dynamics........................................... 9

2.1.1 D' Alembert's Principle.............................. 9

2.1.2 Lagrange's Equation.................................. 10 
$2.2 \quad$ Vehicle Dynamics................................................. 12

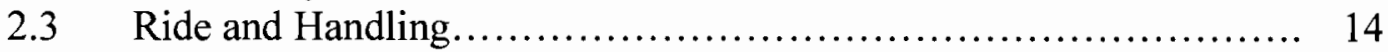

$2.4 \quad$ Real World Vehicle Dynamics Testing ............................... 16

2.4.1 Handling Testing Procedures............................ 17

2.4.1.1 Constant Radius Test........................... 17

2.4.1.2 Step Steer Test................................ 18

2.4.1.3 NHTSA J-Turn Maneuver........................ 18

2.4.1.4 NHTSA Fish Hook Maneuver.................... 20

2.4.2 Ride Testing Procedures................................... 23

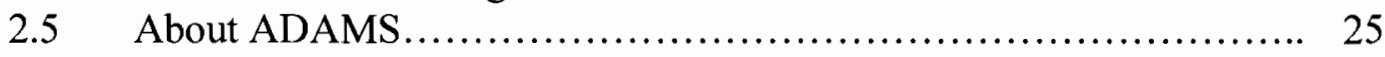

2.5.1 ADAMS/Car........................................... 26

2.5.2 Hardpoints.............................................. 27

2.5.3 Construction frames..................................... 27

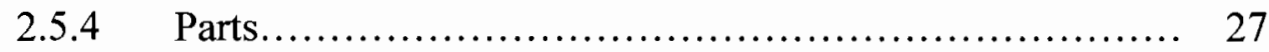

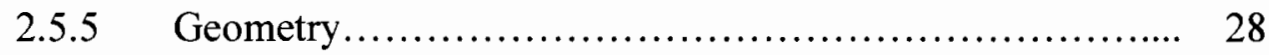

2.5.6 Templates............................................. 28

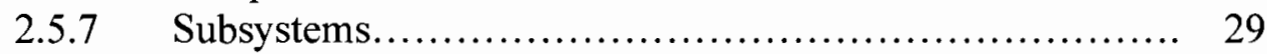

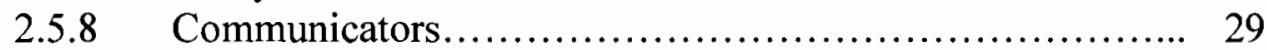

2.5.9 Assemblies............................................. 30

2.5.10 ADAMS/Insight..................................... 30

2.6 General Modeling Approach.................................... 31

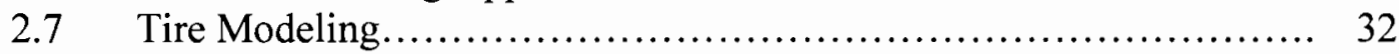

$2.8 \quad$ Vehicle Design Optimization................................... 33

2.8.1 Design Seeker.................................................. 35

2.8.2 Filter...................................................... 35

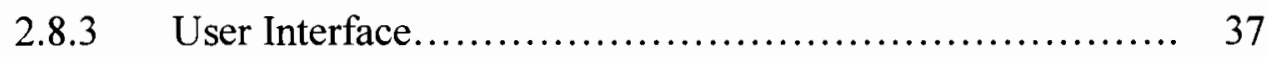

3. Modeling, Simulation and Verification.................................. 38

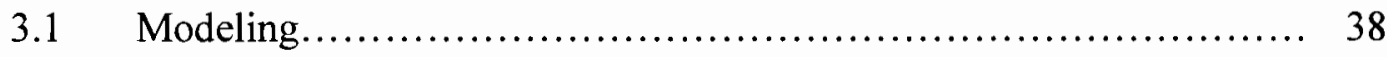

3.2 Modeling in ADAMS/Car........................................ 39

3.3 Truck Modeling ................................................... 41

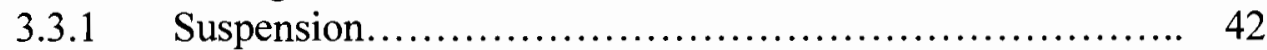

3.3.1.1 Front Steering Axle......................... 43

3.3.1.2 Tandem Axle Suspension......................... 45

3.3.2 Chassis.................................................. 48

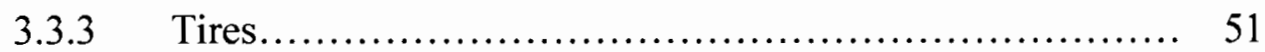

3.3.4 Steering ................................................. 53

3.3.5 Anti-roll bar............................................ 54 
$3.4 \quad$ Verification.................................................... 56

3.5 Verification of Truck Model..................................... 57

3.5.1 Step Steer Analysis for Model Validation................... 57

3.5.1.1 Results of Step Steer Analysis ................. 57

3.5.1.2 Validation of Lateral Acceleration ............... 61

3.5.1.3 Validation of Normal Loads on Tire ............. 62

3.5.1.4 Validation of Lateral Tire Forces .............. 63

3.5.2 Constant Radius Cornering Analysis for Model Validation... 65

4. Analysis, Results and Optimization................................... 68

4.1 Design Space Exploration Procedure.............................. 68

4.2 Selection of the vehicle from the FMTV ........................... 69

4.3 Selection of the Design Parameters for the Modified Vehicle.......... 70

$4.4 \quad$ Selection of Inputs for the Design Study.......................... 78

4.5 Selection of Responses used to evaluate the Design Candidates....... 80

4.6 Generation of Different Configurations for the Modified Vehicle..... 90

4.6.1 Defining Factors..................................... 90

4.6.2 Specifying Responses for the Simulations................. 92

4.6.3 Specification of the Design Space........................ 92

4.6.4 Generating Workspace................................... 93

4.7 Simulation of the Generated Configurations...................... 95

4.8 Design Space transfer to the Flexible Optimization Architecture...... 97

4.9 Dominance Filtering for the Design Space......................... 98

4.10 Selection of the Final Optimized Design based on the desired performance of the vehicle in the viewer.......................... 101

4.11 Selection of the Final Optimized Design for the Curb Vehicle Weight in the viewer................................................. 106

4.12 Selection of the Final Optimized Design for the Intermediate Vehicle Weight in the viewer........................................... 110

4.13 Summary ................................................... 117

5. Conclusion and Future Work ....................................... 118

$5.1 \quad$ Conclusion................................................... 118

$5.2 \quad$ Future Work................................................ 122

5.2.1 Air Spring Stiffness as the Design Parameter.............. 122 
5.2.2 Optimization the Damping and Spring Stiffness for a given 122

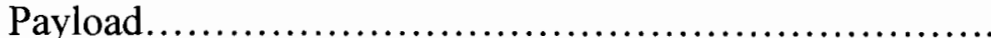

5.2.3 Leaf Spring Modeling using Auto/Flex................... 122

5.2.4 Powertrain and Drivetrain Modeling..................... 123

$5.2 .5 \quad$ ADAMS/ Ride......................................... 123

$5.2 .6 \quad$ Flexible Chassis...................................... 123

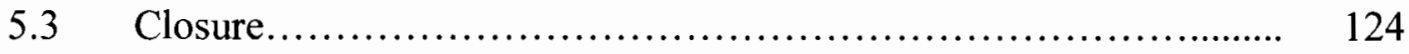

References...................................................... 125

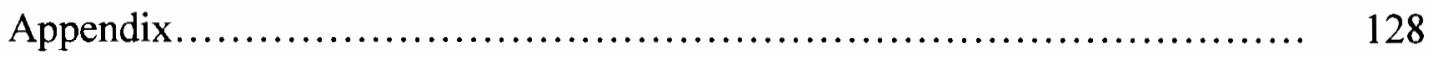




\section{LIST OF TABLES}

Table

Page

Table $4.1 \quad$ Air Spring Preloads......................................... 71

Table 4.2 Scale Values for Damping Variations....................... 75

Table 4.3 Parametric Values for Auxiliary Roll Stiffness for Suspension.... 76

Table 4.4 Ride Metrics to evaluate Design Candidates................... 89

Table 4.5 Handling Metrics to evaluate Design Candidates................ 89

Table 4.6 Combined Design Matrix for Ride and Handling Maneuvers..... 96

Table 4.7 Performance Measures selected for Filtering of the Design 99

Space.......................................................

Table 4.8 Optimized Configuration for Gross Vehicle Weight (GVW)..... 105

Table 4.9 Optimized Configuration for Curb Vehicle Weight (CVW)...... 110

Table 4.10 Optimized Configuration for Intermediate Vehicle Weight....... 116

Table 4.11 Optimized Configuration for Different Sprung Masses.......... 116

Table 5.1 Optimized Configuration for Different Sprung Masses.......... 121 


\section{LIST OF FIGURES}

Figure

Page

Figure $1.1 \quad$ Schematic Flow Chart of Methodology........................ 2

Figure 2.1 SAE Vehicle Axis System.................................. 13

Figure 2.2 Vibration Flow Diagram in a Typical Vehicle................ 15

Figure 2.3 Handwheel Angle vs. Time for a NHTSA J-turn Maneuver..... 19

Figure $2.4 \quad$ NHTSA Fishhook Maneuver ............................. 22

Figure 2.5 Major Components of the Optimization Architecture.......... 34

Figure 2.6 Filtering Technique Working Illustration................... 36

Figure 3.1 Front Axle Air Suspension Assembly for the Vehicle......... 43

Figure 3.2 Tandem Axle Air Suspension Assembly for the Vehicle ........ 46

Figure 3.3 Illustration of Leaf Spring and Air Spring Suspension

Design......................................................................... 47

Figure $3.4 \quad$ Rigid Chassis for the Truck............................. 50

Figure $3.5 \quad$ Fiala Tire Model........................................ 52

Figure $3.6 \quad$ Pitman Arm Steering................................... 53

Figure $3.7 \quad$ Anti-Roll bar.................................................. 55

Figure 3.8 Lateral vs. Longitudinal Displacement in a Step Steer Analysis for Validation................................. 58

Figure 3.9 Steering Wheel Input and Longitudinal Velocity in a Step 59

Steer Analysis for Validation...................................

Figure 3.10 Chassis Lateral Acceleration in a Step Steer Analysis.......... 59

Figure 3.11 Chassis Roll Angle in a Step Steer Analysis................. 60

Figure 3.12 Tire Normal Forces in a Step Steer Analysis................... 62 
Figure 3.13 Left Tire Lateral Forces in a Step Steer Analysis............. 63

Figure 3.14 Constant Radius Cornering Track......................... 65

Figure 3.15 Vehicle Forward Speed and Lateral Acceleration in a Constant 66 Radius Cornering Analysis for Validation.

Figure 4.1 Two Degrees of Freedom Model (Quarter Car Model)......... 72

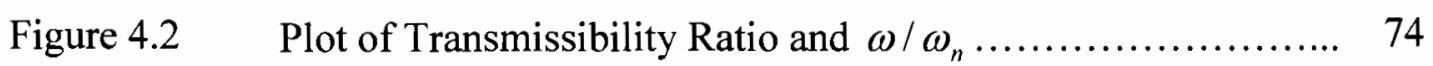

Figure 4.3 Flow Chart for an Experiment in ADAMS/Insight............ 77

Figure 4.4 Road Profile for Ride Analysis............................ 79

Figure 4.5 Road Profile for Left and Right Track....................... 80

Figure 4.6 Chassis Vertical Acceleration for illustration purpose............ 82

Figure $4.7 \quad$ Vehicle Layout..................................... 85

Figure 4.8 Tire Normal Forces in ISO Lane Change for GVW - for 87

$\begin{array}{lll} & \text { illustration purpose ....................................... } & \\ \text { Figure 4.9 } & \text { Tire Lateral Slip in Step Steer Analysis for GVW - for }\end{array}$ illustration purpose.

Figure 4.10 Ties and Factors for the Work Space...................... 91

Figure 4.11 Design Specification.................................... 92

Figure 4.12 Work Space for Ride Analysis................................. 94

Figure 4.13 Design Space for Gross Vehicle Weight in Visualization 97

Figure 4.14 Filtered Design Space for the Gross Vehicle Weight in the 100

Figure 4.15 Viewer: User Selection based on RMS Chassis Vertical 103 Acceleration and Peak Lateral Load Transfer for Gross Vehicle Weight.........................................

Figure 4.16 Viewer: User Selection based on Chassis Roll Angle and 104 Lateral Load Transfer for Gross Vehicle Weight...............

Figure 4.17 Filtered Design Space for the Curb Vehicle Weight (CVW) in the Viewer............................................ 106 
Figure 4.18 Viewer: User Selection based on RMS Chassis Vertical Acceleration and Peak Lateral Load Transfer for Curb Vehicle Weight.

Figure 4.19 Viewer: User Selection based on Chassis Roll Angle and Lateral Load Transfer for Curb Vehicle Weight

Figure 4.20 Viewer: User Selection based on Chassis Pitch Acceleration and Chassis Roll Acceleration for Curb Vehicle Weight.........

Figure 4.21 Filtered Design Space for the Intermediate Vehicle Weight in the Viewer.

Figure 4.22 Viewer: User Selection based on RMS Chassis Vertical Acceleration and Peak Lateral Load Transfer for Intermediate Vehicle Weight.

Figure 4.23 Viewer: User Selection based on Chassis Vertical

Acceleration and Chassis Roll Acceleration for Intermediate Vehicle Weight.

Figure 4.24 Viewer: User Selection based on Chassis Roll Angle and Peak Lateral Load Transfer for Intermediate Vehicle Weight..........

Figure 4.25 Viewer: User Selection based on Chassis Roll Acceleration for Intermediate Vehicle Weight 


\section{CHAPTER 1}

\section{INTRODUCTION}

\subsection{Motivation}

Experimental vehicle testing used to obtain knowledge of vehicle dynamics involves significant time and expense. Indeed, just the sensors needed to collect the data on a full vehicle are expensive and set up time is arduous and lengthy. Furthermore, the complexity and size of large trucks also hinders the making of an accurate dynamic vehicle model.

Ride and handling form the important characteristics for any vehicle. Ride is a subjective perception and is normally associated with the level of comfort experienced when traveling in a vehicle. Handling, on the other hand, is a term used to characterize the directional response behavior of the vehicle [1]. To be able to analyze ride and handling of a vehicle one needs to set-up the real truck with all the required instrumentation and do real world testing on a proving ground.

Computer simulations are very powerful in today's world and once we have a validated model for the vehicle, we can make changes in the parameter values and then examine the effect of those variations on the performance (including ride and handling) 
of the full vehicle. In this research, this concept is used to explore different configurations obtained by variations in suspension and tire parameters. For example, one can observe the effect of payload and tire pressure changes for the full scale vehicle model in ADAMS (Automatic Dynamic Analysis of Mechanical Systems). ADAMS is an industry acknowledged multibody dynamics simulation software which is used widely for modeling and simulations of vehicles. The schematic flow of the method used for the research is illustrated in the Figure 1.1.

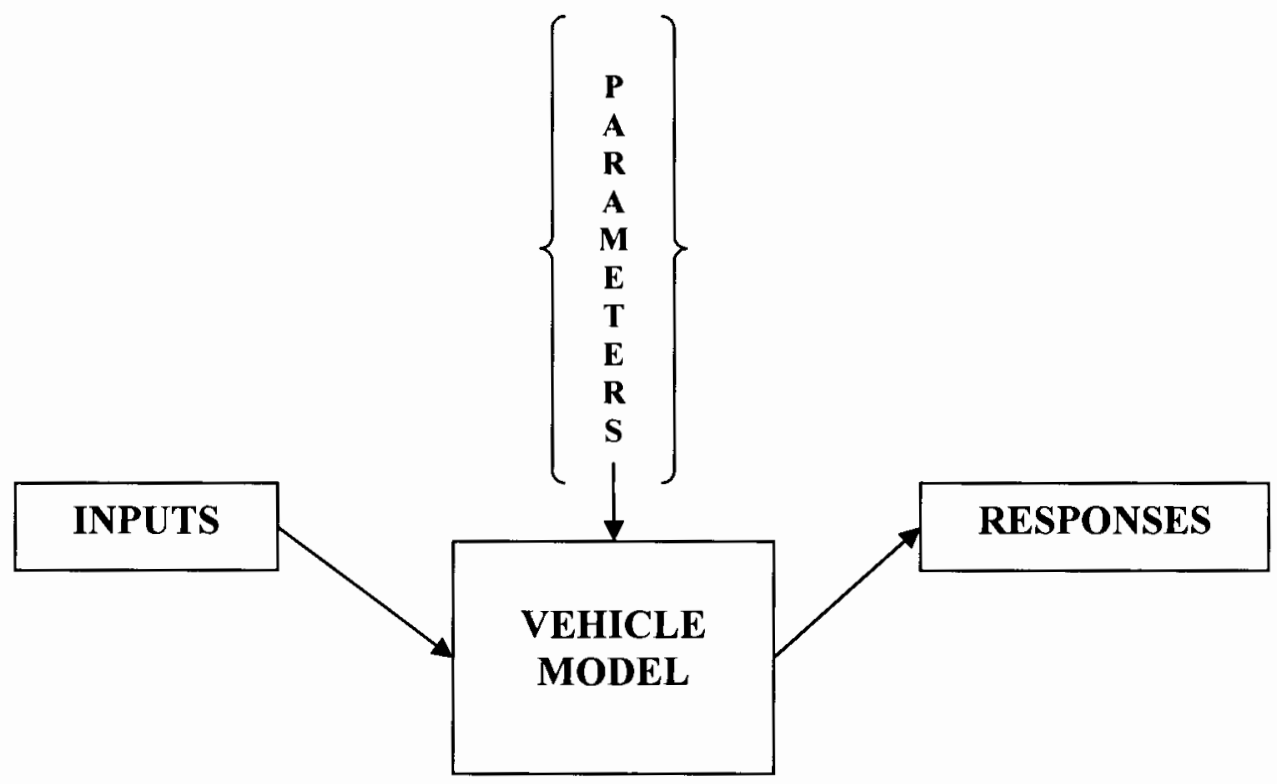

Figure 1.1: Schematic Flow Chart of methodology 


\subsection{Objective}

This thesis focuses on the design space exploration of a MTV (Medium Tactical Vehicle) 5.0 Ton U.S.Army truck with modified suspensions. Suspension and tire variations are considered to examine the effect on the ride and handling of the truck. A design space exploration is conducted using ADAMS/Car and ADAMS/Insight to consider parametric design changes in the modified suspension. This research work uses ADAMS (Automatic Dynamic Analysis of Mechanical Systems) and flexible optimization algorithm architecture to explore large design spaces. This thesis is a portion of the sponsored research performed for the U.S.Army TACOM (Tank Automotive and Armaments Command) at the Center for Automotive Research and Intelligent Transportation (CAR-IT) at the Ohio State University.

The method used in this research is described below:

1. Modeling of the MTV 5.0 Ton cargo truck in MSC-ADAMS.

2. Selection of mission profiles (inputs) to evaluate ride and handling.

3. Suspension and tire parameter selection which results in different truck configurations.

4. Responses (or measures) selection which will help in evaluating the ride and handling of the truck.

5. Performing the simulations and generating results using ADAMS/Car with ADAMS/Insight. 
6. Exporting the results from ADAMS/Insight to the flexible optimization architecture for further analysis.

7. Using dominance filtering in the viewer to filter out the dominated designs out of the design space.

8. Narrowing down in the viewer to the optimized vehicle based on the selected performance criteria's.

In the first part of this work, modeling and verification of the modified truck model with air springs is done in MSC-ADAMS. Subsequently, parametric changes in the model are performed by ADAMS/Insight resulting in different configurations for the truck. These different configurations are run for selected dynamic maneuvers which result in a large design space consisting of performance measures and design parameters. The final step involves selection of a particular design with desired characteristics from the design space using the visual analysis in flexible optimization architecture. This final design corresponds to appropriate tire pressure for a given sprung load. Tire pressures are very important for any terrain and effect ride and handling of the cargo truck.

As we know, Central Tire Inflation Systems (CTIS) can be used to control the tire pressures for a vehicle based on the terrain and loading conditions. Depending on the terrain such as snow, mud, sand and rocks, the tire inflations can be adjusted to provide the appropriate contact patch for the tires and good ride on a given terrain. Correct tire pressures for a given terrain and loading condition results in improved mobility, 
increased tractive effort and greater safety for the off-road vehicle. The approach used in this thesis is applicable for finding the correct tire pressures for different loading conditions. CTIS can be used to provide the appropriate tire pressure for appropriate ride and handling of the truck on a given terrain.

\subsection{Literature Review}

\subsubsection{Vehicle Dynamics Simulation}

In today's fast track vehicle production market, in-house modeling and simulation software is a common tool. Every company wants to design better products and in a short time. To achieve this fast paced development effort, it is mandatory to rely on fast computing devices and software technologies. Computer simulations give a great flexibility and accessibility to designers to design a better product. Multi-body systems (MBS) consist of rigid or flexible bodies, springs, dampers, joints, etc. In modeling and designing of these systems, computer simulations provide tools to inspect the dynamic behavior of the system [2]. Computer simulations provide an environment to better understand the vehicle dynamic behavior long before the actual testing and can significantly reduce the product cycle time and cost.

\subsubsection{Ride}

Ride is a subjective perception and is normally associated with the level of 
comfort experienced when traveling in a vehicle. It is commonly used in reference to tactile and visual vibrations, where visual vibrations correspond to noise [1]. More about ride will be discussed in the second chapter of this thesis. Ride quality of trucks is getting more attention in the recent years due to the demand of more comfortable ride of the passengers. Army vehicles are designed for, and exposed to, rough roads and are mainly used on off-roads. Severe conditions experienced in the field provide high acceleration and frequencies of road inputs which result in discomfort of the driver as well as the passengers in the truck.

Ride plays a major role in the driver's comfort and their capability to drive for a long distance and thus serves as a major area of concern. A significant amount of work has been done in this area to provide better ride for the heavy and medium duty truck. El-Demerdash discusses the importance of semi-active suspensions to improve the truck ride dynamics [3]. Ledesma shows three different designs of trailer suspension to compare its ride performance [4]. Nagueira talks about the design and tuning of tractor air suspensions to improve comfort [5]. Springs, dampers, payload and tire pressures all play a significant role in the determining the ride of a vehicle [7]. Lee et al. studied the ride quality of medium duty trucks with varying characteristics of suspension design parameters [6]. As can be seen, ride is one of the critical factors in design of any truck and thus, in this thesis, one of the main areas of study. 


\subsubsection{Handling}

Handling is a term used to characterize the "directional response" behavior of the vehicle [1]. It is a term normally used to imply the responsiveness of a vehicle to driver inputs. Handling includes both driver and vehicle interaction and thus is called a closed-loop system. The modeling of vehicle/driver interaction involves the behavior of vehicle systems and the driver response to achieve the closed loop stability. Vehicle behavior is considered in the open-loop and thus the difference is that no driver is present [1]. Specific steering inputs are applied and the response is measured and there is no corrective measure taken by the driver. It is equivalent to applying input and measuring the output for a vehicle system.

The Army has always put a substantial amount of research and effort in the area of vehicle dynamics to enhance the maneuverability of its vehicles $[8,9]$. Handling is the other major area of study for this research work and will be discussed in more detail in the second chapter.

\subsection{Thesis Chapter Organization}

Chapter 1 provides the introduction about the research work and also presents relative literature in the area of vehicle dynamics modeling and simulation.

Chapter 2 discusses the background related to this thesis work. Real world testing procedures are discussed in detail along with information on MSC-ADAMS and the flexible optimization architecture used for this research. 
Chapter 3 gives details about the modeling and verification of the MTV 5.0 Ton cargo truck with air springs in MSC-ADAMS.

Chapter 4 presents the details about the dynamic simulation runs in ADAMS and the procedure used to find the optimized vehicle using the flexible optimization architecture.

Chapter 5 covers the conclusions for this research work and also present the suggested future work.

\subsection{Summary}

The motivation for this research work is to explore the effects of variations of suspension and tire parameters on the performance of the truck. Also, to find the appropriate design parameters for the truck to optimize ride and handling of the cargo truck for different loading conditions. MSC-ADAMS is used for modeling and simulation of the MTV 5.0 Ton cargo truck and a flexible optimization algorithm is used to explore the design space to find the optimized vehicle. 


\section{CHAPTER 2}

\section{BACKGROUND}

\subsection{Multi-Body Dynamics}

Multi-body dynamics includes elements or components held together by joints, gears, bushings etc. Modeling of multi-body dynamic mechanical systems involves modeling of these components, as well as the modeling of constraints between the components.

Newton's law is used to develop the equations of motion for mechanical systems. Interestingly, in the real world application, it is not always the most convenient method of developing equations of motion. There are other methods like D' Alembert's principle and Lagrange's method which are discussed briefly below.

\subsubsection{D' Alembert's Principle}

J. d'Alembert suggested that the mass times acceleration and inertia times angular acceleration terms be taken to the left side of Newton's second law (eq. 2.1). They are considered as the force and moment quantities of the equations of motion. In other words, a particle with a mass $m$ and acceleration $a$ in an inertial frame I experiences an inertial force $F^{*}$ which is proportional to $m$ and $a$ and 
directly opposite to $a$. The sum of the applied and inertial forces is zero. Equation 2.2 corresponds to Newton's seconds law of motion which states that "the acceleration of a particle is proportional to the force applied to the particle and inversely proportional to the mass of the particle".

$$
\begin{gathered}
F^{*}=-m a \\
F^{*}+F=0
\end{gathered}
$$

The importance of D' Alembert approach is more apparent in problems involving combined mechanical components and in cases where rotational motions occur. Furthermore, the advantage of the d' Alembert principle is that moments can be taken about any point. Also, while solving the problem we are no longer restricted to the center of mass or a fixed axis of rotation [16]. It clearly provides us an advantage in solving problems in fewer equations, which is beneficial from the perspective of computational time required for solving large systems of equation.

\subsubsection{Lagrange's Equation}

Newton's law and D' Alembert's method of developing equations requires that any mechanical system consisting of several components must be taken apart and all the forces acting on the parts be identified on the free body diagram (FBD) of each element. However, there are many situations when we are not interested in the forces at the interconnections and in that case it is better to be able to derive the equations of motion with regard to the overall standpoint of the system. 
J.L. Lagrange (French Mathematician, 1717-83) showed that the consideration of energies in the system allows us to achieve such a derivation [16]. If necessary, it is also possible to find constraint forces through this formulation also. This is a very general method of formulating the rigid body dynamic simulations and is used extensively in engineering. Lagrange's equations in general form is given below:

$$
\frac{d}{d t}\left(\frac{\partial K}{\partial \dot{q}_{r}}\right)-\frac{\partial K}{\partial q_{r}}=F q_{r} \quad(r=1,2, \ldots \ldots, n)
$$

Equation 2.4 is used for a "conservative system" such that a potential energy function $P$ exists so that $F q_{r}$ may be expressed as $-\partial P / \partial q_{r}$.

$$
\frac{d}{d t}\left(\frac{\partial L}{\partial \dot{q}_{r}}\right)-\frac{\partial L}{\partial q_{r}}=0 \quad(r=1,2, \ldots \ldots ., n)
$$

where;

$K: \quad$ Total kinetic energy of the system

$q_{r}: \quad \quad$ rgeneralized coordinates

$F q_{r}$ : $\quad$ r generalized applied forces corresponding to $q_{r}$

$L: \quad$ Lagrangian function given by $K-P$

$P$ : $\quad$ Potential energy of the system 


\subsection{Vehicle Dynamics}

Vehicle dynamics as the name suggests deals with the motions (dynamics) of the vehicle. The motion can be primarily divided in to longitudinal, lateral and vertical components [1]. Vehicle Dynamics involves motions such as acceleration, braking, ride and handling. Acceleration motion normally corresponds to the longitudinal direction, ride is concerned with the vertical motion and handling is related to the lateral direction. The behaviors for any vehicle is influenced by the road loads, tire - road interaction, gravity and aerodynamics. The motion for the vehicle can be studied using the classical approaches discussed in section 2.1. For modeling of the vehicle we must define the global co-ordinate system and the local co-ordinate system and both can be defined using Euler angles etc. 
The SAE (Society of Automotive Engineers) vehicle axis coordinate system is shown in Figure 2.1 [14].

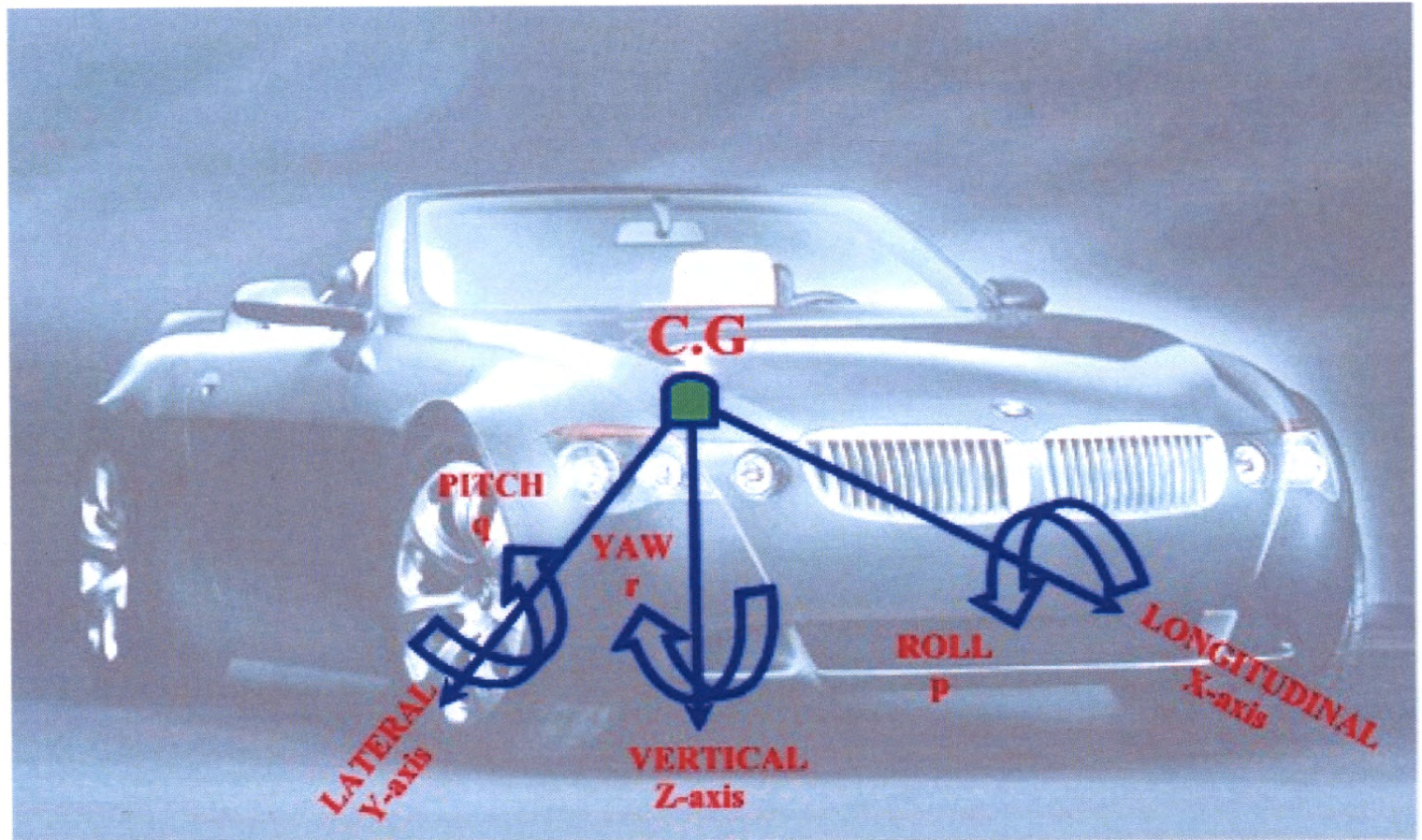

Figure 2.1: SAE Vehicle Axis System (background picture taken from BMW website [23])

By standard SAE convention [1] the coordinates are given as:

$\mathrm{x}$ - Pointing forward and on the longitudinal plane of symmetry

$\mathrm{y}$ - Lateral out the right side of the vehicle

$\mathrm{Z}$ - Vertically downward with respect to the vehicle

$\mathrm{p}$ - Roll velocity about the $\mathrm{x}$-axis

$q$ - Pitch velocity about the $y$-axis

$\mathrm{r}-$ Yaw velocity about the z-axis 


\subsection{Ride and Handling}

As discussed before in chapter- 1 of this thesis, ride is a subjective perception and is normally associated with the level of comfort experienced when traveling in a vehicle. Ride is mainly associated with the vertical motion of the vehicle. Ride quality is concerned with the feel of the passenger in the environment of a moving vehicle. Ride problems are mainly due to the vibrations of the vehicle body which may be induced by a variety of sources like irregular surfaces, engine vibration, aerodynamic forces, and imbalance in the tire/wheel assembly. Typically, surface irregularities from potholes to random vibrations of the surface elevation profile act as a major source that excites the vibration of the vehicle body through the suspension system and the tire/wheel assembly [17]. A flow diagram for the vibration in a typical vehicle is shown in Figure 2.2 (for the seat and steering channel): 


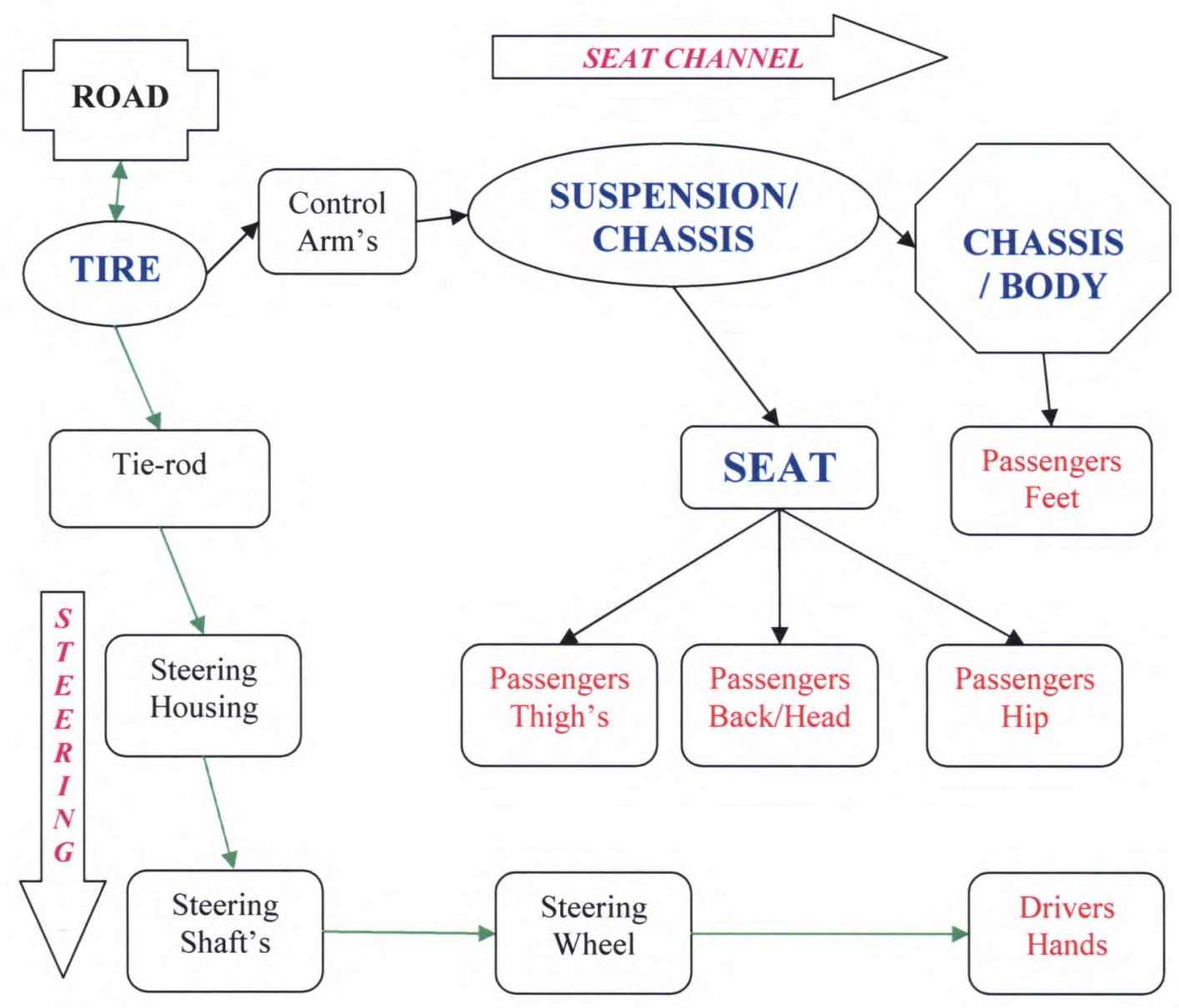

Figure 2.2: Vibration Flow Diagram in a Typical Vehicle

$>$ In the Figure 2.2, only one way flow of vibration from the road-tire interaction to the driver of the vehicle is shown, but actually there is a two way flow between any two interacting bodies/systems/components of the vehicle.

$>$ For the passengers of the vehicle (other than driver), the steering wheel interaction is not there, other channels of flow for vibration remains the same.

$>$ Typically, steering vibrations are not significant and do not form a major source of excitation for discomfort. 
The objective of the ride study in a vehicle is to provide guiding principles for the control of the vibrations of the vehicle so that the passenger's sensation of discomfort does not exceed a certain level. Human response to vibration, the vibration behavior of the vehicle, and the characteristics of surface irregularities are important in ride studies [17].

Handling characteristics of a road vehicle refers to its response to steering commands and as well as to environmental inputs like cross-winds and road disturbances that affect its direction of motion. There are two issues in vehicle handling performance: one is the control of the direction of motion of the vehicle and the other is the ability of the vehicle to stabilize its direction of motion against external disturbances. The roll motion in a vehicle can cause the wheels to steer and thus affect the handling behavior of the vehicle. Bounce and pitch motion also affect the steering response of the vehicle. These motions are important when we want to look at the limits of the handling characteristics of the vehicle [17].

\subsection{Real World Vehicle Dynamics Testing}

Real world testing is done to examine the behavior of the vehicle on roads and to characterize the ride and handling behavior of the vehicle. As mentioned earlier, to gather the data from an instrumented truck, we need to install a large number of sensors, load cells, etc. As with most instruments, they are subject to errors in measurement. The results are often filtered to assist in analysis. Different types of maneuvers used for handling and ride evaluation of a vehicle will be discussed next. 


\subsubsection{Handling Testing Procedures}

\subsubsection{Constant Radius Test}

In the constant radius test, the vehicle is driven along a curve with a constant radius at various speeds. The steer angle required to maintain the vehicle on the course for various speeds is measured. Also, the corresponding lateral accelerations are measured for the increasing speeds.

The steady state lateral acceleration can also be derived using the vehicle forward speed and the turning radius during the maneuver. Plots are made between steer angle and lateral acceleration obtained during the test and using the slope of the curve we can comment about the understeer, oversteer or neutral steer characteristics of the vehicle. The slope of the curve represents the value of the understeer coefficient. If the slope is positive, the vehicle understeers; if the slope is negative, it oversteers and if the slope is zero, it is a neutral steer vehicle. It is possible for a vehicle to have understeer characteristics at low accelerations and oversteer characteristics at high lateral accelerations [17]. 


\subsubsection{Step Steer Test}

A step steer analysis involves increasing steering input from a initial value to a final value in a specified amount of time. This test is primarily used to yield time-domain transient response metrics for the vehicle. The following metrics are typically considered to be important to measure during the step steer test [18].

- Speed of the vehicle during the test

- Steering wheel angle (from initial to final steer applied)

- Yaw rate

- Lateral acceleration

\subsubsection{NHTSA J-Turn Maneuver}

The NHTSA (National Highway Traffic Safety Administration) J-Turn maneuver represents an avoidance maneuver in which a vehicle is steered away from an obstacle using a single input (handwheel angle). In the maneuver, the vehicle is driven in a straight line at a speed slightly greater than the desired entrance speed. The driver releases the throttle, coasts to the target speed, and then triggers the controlled handwheel input. The nominal maneuver entrance speeds used in the J-Turn maneuver ranged from 35 to $60 \mathrm{mph}$, increased in $5 \mathrm{mph}$ increments until a termination condition is achieved. Termination conditions are simultaneous two inches or greater lift of a vehicle's inside tires (two-wheel lift) or 
completion of a test performed at the maximum maneuver entrance speed without two-wheel lift. If two-wheel lift is observed, a downward iteration of vehicle speed is used in $1 \mathrm{mph}$ increments until such lift is no longer detected. Once the lowest speed for which two-wheel lift could be detected is isolated, two additional tests were performed at that speed to monitor two-wheel lift repeatability [20]. Figure 2.3 illustrates the plot between handwheel angle and the time for a NHTSA J-turn maneuver.

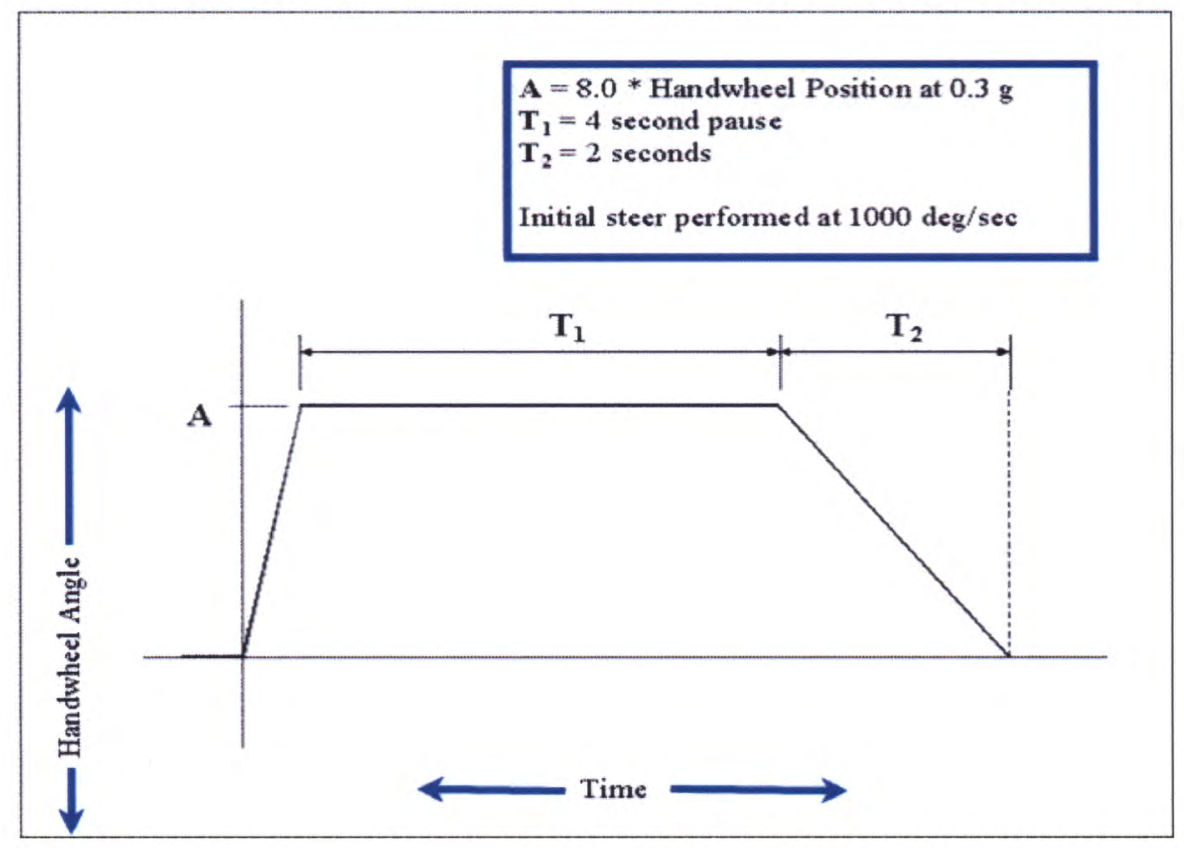

NHTSA J-Turn maneuver

Figure 2.3 Handwheel Angle vs. Time for a NHTSA J-turn Maneuver.(NHTSA website) 


\subsubsection{NHTSA Fish Hook Maneuver}

NHTSA's Fishhook maneuver uses steering inputs that approximate the steering a driver in panic situation might use in an effort to regain lane position after dropping two wheels off the roadway onto the shoulder. Interestingly, the test is performed on a smooth pavement rather than at a road edge drop-off, but its rapid steering input followed by an over-correction is representative of a general loss of control situation. The original version of the fishhook test was developed by Toyota, and variations of it were suggested by Nissan and Honda. The initial steering magnitude and countersteer magnitudes are symmetric, and are calculated by multiplying the handwheel angle that would produce a steady state lateral acceleration of $0.3 \mathrm{~g}$ at $50 \mathrm{mph}$ on level pavement. The average steering input is equivalent to the 270 degree handwheel angle used in earlier forms of the maneuver but, as in the case of the J-Turn, the procedure above is an objective way of compensating for differences in steering gear ratio, wheelbase and understeer properties between vehicles. The fishhook maneuver dwell times (the time between completion of the initial steering ramp and the initiation of the countersteer) are defined by the roll motion of the vehicle being evaluated, and can vary on a test-to-test basis. This is made possible by having a steering machine monitor roll rate (roll velocity). If an initial steer is to the left, the steering reversal following completion of the first handwheel ramp occurs when the roll rate 
of the vehicle first equals or goes below 1.5 degrees per second. If an initial steer is to the right, the steering reversal following completion of the first handwheel ramp occurs when the roll rate of the vehicle first equals or exceeds -1.5 degrees per second. The handwheel rates of the initial steer and countersteer ramps are 720 degrees per second [20].

To begin the maneuver, the vehicle is driven in a straight line at a speed slightly greater than the desired entrance speed. The driver releases the throttle, coasts to the target speed, and then triggers the commanded handwheel input. The nominal maneuver entrance speeds used in the fishhook maneuver ranged from 35 to $50 \mathrm{mph}$, increased in $5 \mathrm{mph}$ increments until a termination condition was achieved. Termination conditions includes simultaneous two inch or greater lift of a vehicle's inside tires (two-wheel lift) or completion of a test performed at the maximum maneuver entrance speed without two-wheel lift. If two-wheel lift is observed, a downward iteration of vehicle speed is used in

$1 \mathrm{mph}$ increments until such lift is no longer detected. Once the lowest speed for which two-wheel lift could be detected is isolated, two additional tests are performed at that speed to check two-wheel lift repeatability [20]. Figure 2.4 illustrates the fishhook maneuver used by NHTSA to evaluate dynamic roll-over vehicle stability. 


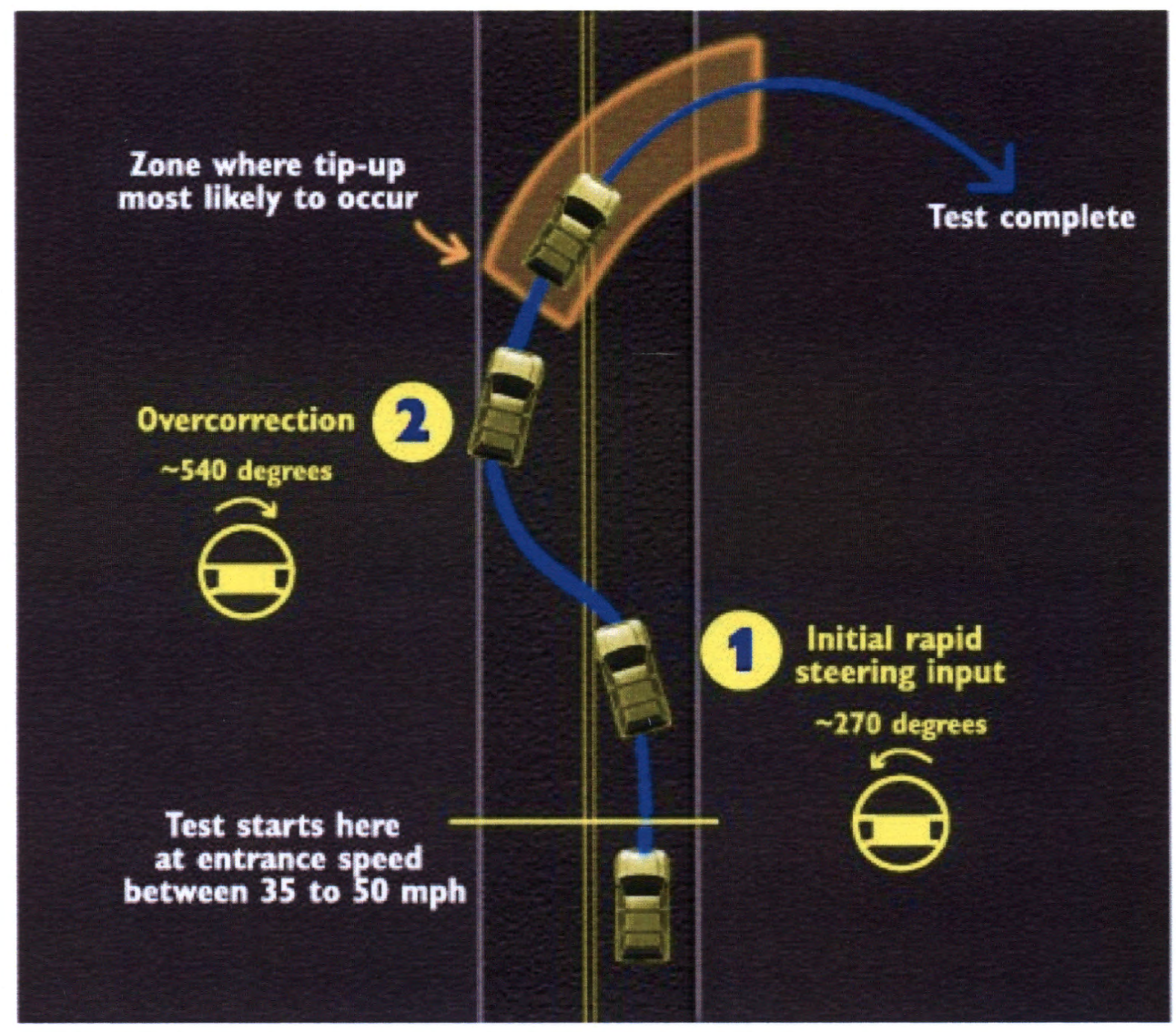

Figure 2.4 NHTSA Fishhook Maneuver (picture from NHTSA website [24])

There are several other tests like single lane change, ISO lane change, constant velocity test which are also used to measure the handling characteristics of the vehicles. 


\subsubsection{Ride Testing Procedures}

As discussed in the previous sections of this thesis, ride is a subjective perception and is normally associated with the level of comfort experienced when traveling in a vehicle. There are not many well defined metrics which are used all over the world to measure ride as it is very much subjective in nature. For one person, the ride might be excellent for a vehicle but the same vehicle may be perceived in a different way by the other person. In the automobile industry, engineers have been working for many years to come up with objective measurements of ride and to be able to comment about it with ease.

In order to be able to measure ride, RMS (Root Mean Square) acceleration is used extensively in the automotive industry $[1,5,6]$. RMS acceleration is measured in the cab for the driver seat in the vertical direction. When data is limited for the cab and seat, measuring acceleration at the total sprung mass (chassis, cab, passengers) is the only way to go and it provides a good idea about the suspension characteristics.

For ride testing, the vehicle is exposed to roads which excite the vehicle system to extreme levels of vibrations. During the test, RMS accelerations in the vertical directions are measured for the vehicle. These values can then be compared with the human tolerances studies performed to be able to comment about the ride of the vehicle. These types of test 
serve as a base or starting point for conducting the final subjective testing of any vehicle.

RMS accelerations can be calculated as described below with a simple example. Suppose, for a ride test we have measured accelerations $\left(A_{1}, A_{2}, A_{3}, A_{4}\right.$ to $\left.A_{n}\right)$ for the time instance, $t$. To find the RMS for the test, first these accelerations ( $A_{1}$ to $\left.A_{n}\right)$ are squared and added. Then mean squared value (M) is found for these added accelerations. Finally, square root of the obtained mean squared value for acceleration $(\mathrm{M})$ is found out and that corresponds to the RMS acceleration for that test. If this RMS acceleration obtained is then divided by acceleration due to gravity, $\mathrm{g}$, it corresponds to the RMS acceleration in g's which is used extensively as a measure of ride.

Equation 2.5 and 2.6 illustrates the mathematical way to find the RMS acceleration values when discrete accelerations are available for the test performed.

$$
\begin{aligned}
& M=\frac{A_{1}{ }^{2}+A_{2}{ }^{2}+A_{3}{ }^{2}+\ldots \ldots \ldots \ldots \ldots \ldots+A_{n}{ }^{2}}{n} \\
& R M S \text { Acceleration }=\sqrt{M}
\end{aligned}
$$

where;

$\mathrm{A} 1, \mathrm{~A} 2$ to An are discrete values of accelerations for the test conducted $\mathrm{n}=$ total number of accelerations measured for the test $M=$ Mean squared value of acceleration 


\subsection{About ADAMS}

ADAMS is an acronym which stands for Automatic Dynamic Analysis of Mechanical Systems. MSC.ADAMS is a powerful modeling and simulating environment that lets us build, simulate, refine, and ultimately optimize any mechanical system [18]. MSC.ADAMS suite of software helps us to simulate, understand and quantify the performance of any mechanical system before we commit to expensive hardware prototypes or conduct numerous physical tests [2]. Some of the main objectives that ADAMS can help us achieve are $[10,11$, and 18]:

- Creating fully parametric models of complex mechanical systems such as suspensions, axles etc.

- Applying force and motion to specific parts to analyze their behavior.

- Simulating full vehicle behavior to study vehicle dynamics.

- Measuring displacements, velocities, acceleration of parts in a convenient and easy to use post processing tool called ADAMS/ Post Processor.

ADAMS most fundamental modeling tools are ADAMS/view and ADAMS/solver which form the nucleus (or crux) of the software. Depending on the various industries where mechanical system modeling is required, there are number of modules that have been developed over time to help model in an easy to use GUI (Graphic User Interface) but these GUI's are just the front end to ADAMS/View.

Some of the industry specific modules are ADAMS/Car, ADAMS/Chassis, ADAMS/ Engine ADAMS/Driveline, ADAMS/Aircraft, ADAMS/Rail. Some of the 
extension products are Insight, Controls, Hydraulics, Vibration, and Durability/EDM. In this research primarily ADAMS/Insight and ADAMS/car were primarily used as the simulation tool.

\subsubsection{ADAMS/Car}

ADAMS/Car is a specialized environment for modeling vehicles. It allows you to create virtual prototypes of vehicle subsystems and to analyze the virtual prototypes much like you would analyze the physical prototypes.

ADAMS/Car is an industry specific product designed to study the behavior of full vehicle assemblies of cars etc. It provides an easy to use interface to implement complex dynamic testing maneuvers like the NHTSA (National Highway Traffic Safety Administration) Fish Hook and the ISO (International Organization for Standardization) lane change. The vehicle can be run over different kinds of roads and various measurements like chassis acceleration, tire forces and slip angles can be analyzed in the ADAMS post processor tool. 
The major components required to model in ADAMS/Car are as follows [11, 18]:

\subsubsection{Hardpoints}

Hardpoints contain information related to location and are the basic building blocks for most other components in a model. They are used to define location of parts, joints in a mechanical system, and form the basic blocks to create a parametric system model.

\subsubsection{Construction frames}

Construction frames contain both location and orientation information, and are the basic building blocks for many other components. They are based on the hardpoints and are used to specify the desired orientation for any component in the system.

\subsubsection{Parts}

Different types of parts can be built in ADAMS, some of them are explained below:

A general part is a rigid part that is defined by its location, orientation, mass, inertia, and center of gravity (CG).

$>$ Interface parts let us connect flexible bodies in the vehicle to the rest of the template. We cannot use joints (or bushings) to connect general parts and flexible bodies. We must use switch parts to achieve that connection between them.

A mount part is a massless part that acts as an alias or place holder for another part in a separate template. We can use this place holder part as the real part when creating joints, springs, contacts etc. The template-based product fixes the mount part to the part specified as the value of the corresponding output communicator 
when matching communicators of type mount are found during the assembly process. By default, a mount part is fixed to ground.

A switch part is a massless part that enables flexible topology. You can use this switch part as you would use any real part when creating joints, springs, bushings, and so on. Your template-based product has a list of real parts related to each switch part. At any time, the switch part is fixed to one and only one of the parts on the part list.

\subsubsection{Geometry}

Geometry in the template-based products allows us to easily build parametric representations of standard parts. If mass and inertia information is unavailable, we can use ADAMS to automatically calculate the mass of the general part based on the size of the geometry. We can build geometries like arm geometry, link and cylinder geometry, ellipsoid geometry and outline geometry. Geometries do not play any role in affecting the dynamics of the vehicle at the assembly level and are only used for visual representation of the components such as axles, chassis, and wheels etc.

\subsubsection{Templates}

Templates are the parameterized models in which we define the topology of the vehicle components. It includes defining all the parts, their connection with each other, and how the template communicates information to other templates and the test rig (for suspension and full vehicle analysis). At the template level we have the flexibility to not specify the mass properties or assign correct force characteristics 
as that can be done at the subsystem level. The critical concept while creating templates is to define part connectivity and the exchange of information between templates and test rigs since that cannot be modified at the subsystem level. We should always keep in mind that the template will be used in the assembly and must make sure that all the necessary communicators are defined and test them at the template building level.

\subsubsection{Subsystems}

Subsystems are based on templates created in the template building mode and allow standard users to change the parametric data of the template. We can also change the definition of some of the components at the subsystem level. The template-based product, like ADAMS/Car, organizes the basic components that make up a full assembly in to subsystems. For example, subsystems can include suspensions, wheels, chassis etc.

\subsubsection{Communicators}

Communicators are the key elements in ADAMS/ Car and they enable the different subsystems to exchange information with each other and the test rigs in the standard interface at the assembly level. To make sure that the subsystems exchanges information correctly, we must do the testing in the template builder mode. Once we are sure that all the communicators are connecting to correct components, we move to the subsystem level, and from their to the assembly level. 


\subsubsection{Assemblies}

Assemblies are constructed from different subsystems of the vehicle and these subsystems point to the template for the topology of the mechanical system. They represent the collection of subsystems, along with a test rig. Subsystems and test rig are then assembled for the required vehicle system to perform full vehicle simulations in ADAMS. Once we have the assembly ready, we then can use ADAMS/Solver to analyze the whole system. We should always make a point to check the communicators again to see that all the required communicators are passing the information correctly. If any mount part input communicator is not communicating properly, we need to make sure it is taken care of as this can lead to unusual behavior of the system. If a mount part input communicator does not find the matching communicator at the assembly level it attaches itself to the ground which is undesirable for the vehicle assembly.

\subsubsection{ADAMS/Insight}

ADAMS/Insight is a stand-alone product that also works with ADAMS/Car, ADAMS/View, ADAMS/Engine, and ADAMS/Chassis. ADAMS/Insight lets you design sophisticated design of experiments for measuring the performance of the model. It also provides a collection of statistical tools for analyzing the results of your experiments so that you can better understand how to refine and improve your model. This is used with ADAMS/car to generate multiple configurations and run the simulations to generate measures.

There are several things which are important to know while using ADAMS to 
model vehicles. Some of the important aspects of the modeling will be discussed in the next chapter on modeling and verification of the truck model.

\subsection{General Modeling Approach}

The approach is called the Crawl - Walk - Run and is explained below [10]:

- First understand the mechanism from a physical standpoint.

- Use standard building blocks of concepts that have worked in the past.

- Keep adding enhancements to the model while testing periodically.

- Always build kinematic models before building dynamic models.

- Use motions to check models before applying forces to the model.

- Use motions which start with zero velocity.

- Verify enhancements to a complex model on a simpler model first.

Following the above guidelines for modeling in ADAMS, helps us in reaching towards our goal at a rapid pace. These guidelines are very useful and important, and serve as a strong base to build the vehicle model. 


\subsection{Tire Modeling}

The Fiala tire model is the standard tire model that comes with all ADAMS/Tire modules and is used for this research [15]. The data for the tire used on truck was provided by Michelin America.

The Fiala tire model is a physical tire model, in which the carcass is modeled as a beam on an elastic foundation in the lateral direction. The contact between carcass and road is provided by the elastic brush elements. Under these assumptions, analytical expressions for the steady-state slip characteristics can be derived, which are the basis for the calculation of the longitudinal and lateral forces in ADAMS [15].

Assumptions used in the tire model are mentioned below [15]:

- The contact patch or footprint is rectangular in shape.

- The distribution of pressure is uniform across footprint or contact patch.

- Camber angle has no effect on tire forces.

- Tire relaxation effects are not considered in this tire model.

The inputs to the Fiala tire model come from two sources [15]:

1) Input parameters from the tire property file (.tir), such as tire undeflected radius, that the tire references, and

2) Tire kinematic states, such as slip angle which ADAMS/Tire calculates during a simulation.

Details of the tire property files used will be given in the next chapter on modeling and simulation of the vehicle. 


\subsection{Vehicle Design Optimization}

ADAMS/Insight is capable of generating different configurations of a base

vehicle and simulating those thorough a specified maneuver repeatedly [13]. The large design space is filtered using flexible optimization architecture according to the selected criteria for measure (or responses). The filtering technique used is based on "An Architecture for Exploring Large Design Spaces" [12]. The optimization architecture used has three primary components (listed below):

1) Design Seeker

2) Filter

3) User Interface (viewer)

The flow chart for the optimization architecture is shown in the Figure 2.5 which clearly shows the three main components of the architecture in bold text. 


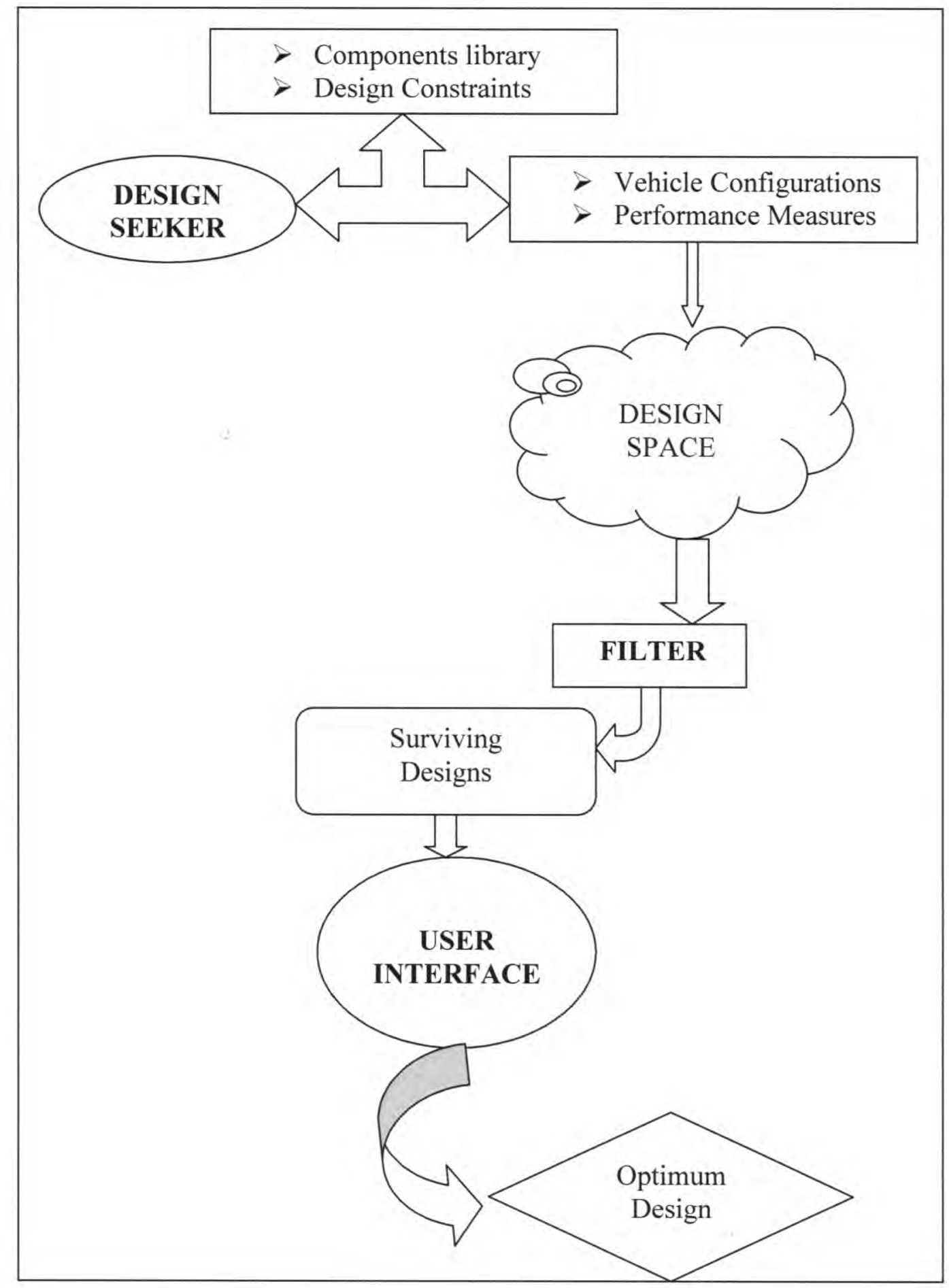

Figure 2.5: Major Components of the Optimization Architecture 
The three main components of the optimization architecture are briefly discussed below:

\subsubsection{Design Seeker}

A design seeker generates large number of different design configurations by selecting components from a large component library. These are then combined in such a way that the user desired constraints are satisfied. The complete set of different design configurations combined with the performance measures (obtained from different vehicle configurations) forms a design space [21].

\subsubsection{Filter}

Filter is used for the design space to eliminate all the dominated designs. A design candidate $\mathrm{X}$ is said to dominate another candidate $\mathrm{Y}$ if $\mathrm{X}$ is superior or equal to $\mathrm{Y}$ with respect to every criterion of evaluation and distinctly superior with respect to at least one evaluation criterion [12]. In the above example, candidate $\mathrm{Y}$ can be eliminated without any loss. It is important to note that a design candidate is removed if it is dominated by any of the other design candidates based on the defined performance criteria for the measures.

An illustration to explain the filtering technique as described by Josephson et al. [12] is shown in Figure 2.6. Consider two performance measures $M_{1}$ and $M_{2}$ and assume that larger values of them are desirable. A design candidate $\mathrm{DC}_{1}$, having a particular value of $\mathrm{M}_{1}$ and $\mathrm{M}_{2}$, is shown in Figure 2.6. Now, let us consider another design candidate $\mathrm{DC}_{2}$ that does not have the same values for performance measure $\mathrm{M}_{1}$ and $\mathrm{M}_{2}$ as $\mathrm{DC}_{1}$. Suppose that, $\mathrm{DC}_{2}$ falls in the quadrant $\mathrm{Q}_{1}$, it is clearly dominated by $\mathrm{DC}_{1}$ in all the performance measures and hence $\mathrm{DC}_{2}$ can be safely eliminated. If 
$\mathrm{DC}_{2}$ falls in quadrant $\mathrm{Q}_{3}, \mathrm{DC}_{1}$ is dominated by $\mathrm{DC}_{2}$ with respect to all the performance measures (as we desire higher values for the measures) and hence $\mathrm{DC}_{1}$ can be eliminated without any loss. On the other side, If $\mathrm{DC}_{2}$ falls in quadrant $\mathrm{Q}_{4}$ or $\mathrm{Q}_{2}$, no design dominates each other with respect to the two performance evaluation criteria's and neither $\mathrm{DC}_{1}$ nor $\mathrm{DC}_{2}$ can be eliminated.

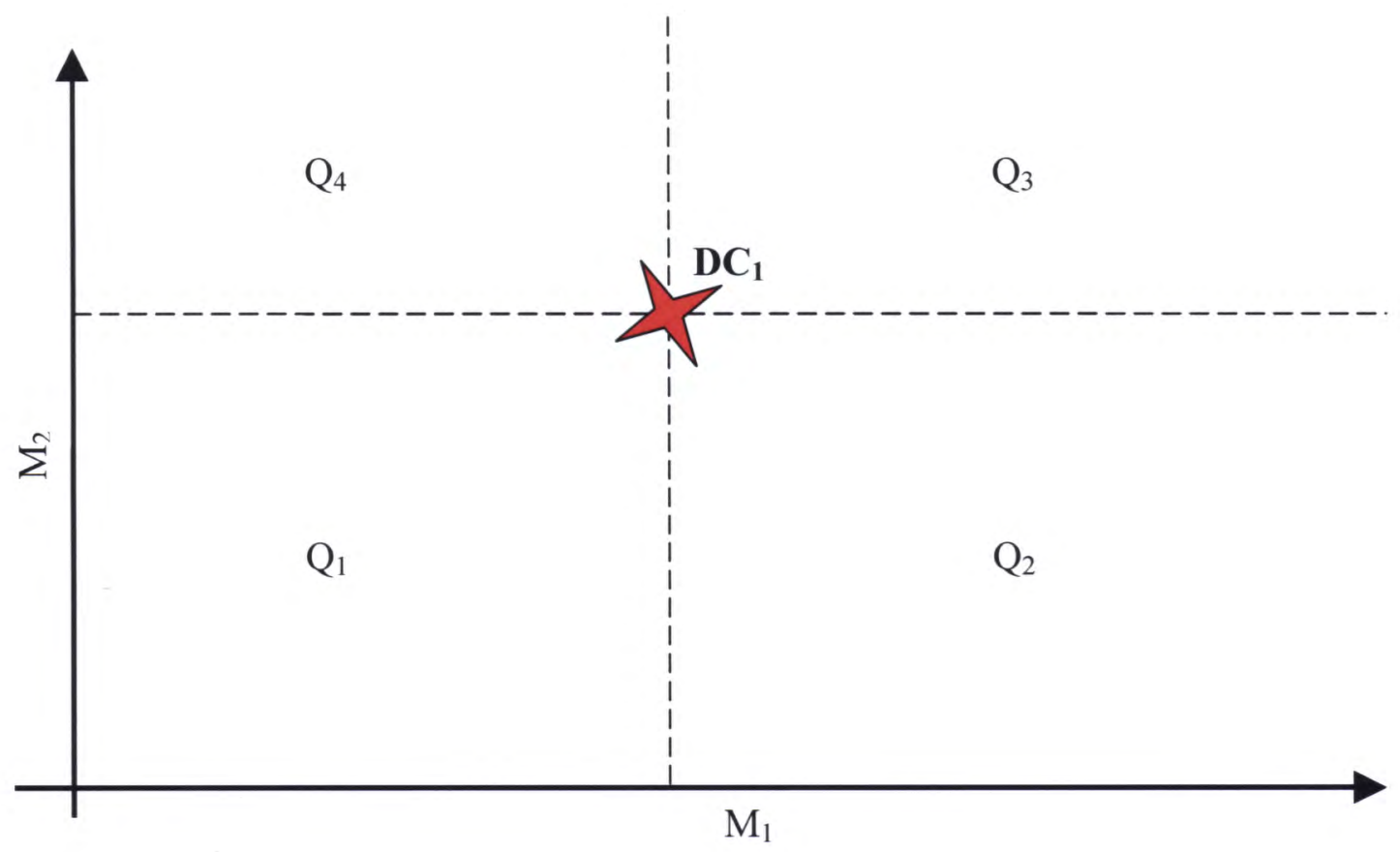

Figure 2.6: Filtering Technique Working Illustration

The above explained filtering technique can be applied to any number of design candidates and performance measures and significant number of design candidates can be eliminated without loss by the other dominant design candidates in the design space [21]. 


\subsubsection{User Interface}

The design candidates that survived after the dominance filtering are then transferred to a user interface called the Visualization Environment that presents 2D tradeoff diagrams $[19,21]$. Two dimensional (2D) scatter plot of surviving designs can be plotted for design parameters and/or performance measures as its axes. If we select, individual candidates or regions that appear to have interesting properties or trends in one diagram (or plot) will be highlighted in the other plots. This type of analysis of the design candidates in form of scatter plots helps us in finally selecting the optimized design based on the selected performance criteria's. Figure 2.7 illustrates a snapshot of the design space in the viewer.

In short, the design seeker generates different configurations, runs the simulations for the generated configuration and calculates the performance measures or metrics to evaluate the design candidates. Filter applies dominance filtering to filter out the dominated design to reduce the design space based on the selected performance criteria for the designs. Viewer helps in generating 2D scatter plots for the design parameters and/or performance measures to narrow down on the optimized vehicle with the help of linked displays in the visualization environment. Next chapter of the thesis will deal with the modeling, simulation and optimization of the MTV (Medium Tactical Vehicle) cargo truck. 


\section{CHAPTER 3}

\section{MODELING, SIMULATION AND VERIFICATION}

\subsection{Modeling}

Modeling is an important step in dynamic simulations of the vehicle. By adopting good modeling practices, we can eliminate problems in the later stages of the project. Error propagation is also a major issue and should always be avoided while modeling the vehicles. Modeling of complex vehicles can be a very tedious and time consuming process if we try to model every part and the constraints between them. The complexity of the model also depends on the type of motions we are interested in evaluating.

Modeling should be done in a way so that we can capture the dynamics we are interested in examining. Modeling of necessary parts is sufficient to be able to comment about the general behavior of the vehicle in typical maneuvers. Good modeling practices help us in making less complex models and saving significant computational power while doing large simulations. In this research, we will be conducting simulations to see the effect of suspension and tire parameter variations on ride and handling. Reducing the computational time for simulations is an important and useful step for this research. 


\subsection{Modeling in ADAMS/Car}

Templates, subsystems and assemblies were discussed in some detail in the chapter 2 of this thesis. The first step in modeling in ADAMS is to clearly understand your system physically. Once we know how the parts are connected and what parts need to be modeled, we can then begin to create templates for the vehicle.

Templates, as discussed earlier in chapter 2, define the topology of the major component of the vehicle. Templates are the parameterized models in which we define the topology of the vehicle components. It includes defining all the parts, their connection with each other, and how the template communicates information to other templates and the test rig. Once we understand the topology of the suspension, it can be created under the template builder mode of ADAMS. It is always better to start with a template from the ADAMS shared database since it can serve as a very good example for any suspension topology we want to create. In this research, the quad axle template served as an example template but it was modified to model the cargo truck front and tandem suspensions.

Templates define the topology for major components like suspension, steering, chassis and wheels. Defining the topology also includes making sure that the component will behave correctly in the whole assembly of the vehicle. For that, we need to make sure that the communicators match properly between the different components templates of the assembly. Major roles should be defined appropriately for every major component created for the vehicle. 
Once the communicators and the topology are checked, we then can move to the ADAMS/Car standard mode to create subsystems for the templates created in template builder mode. We need not worry about the correct mass and inertial values for the parts at the template builder mode as that can be specified at the subsystem level in ADAMS standard mode. Subsystems get their topology from the corresponding template and we can always change the hardpoint locations and property files at the subsystem level.

After creating subsystems for the templates and assigning them the appropriate minor roles, we then can move towards the assembly process. Assemblies are made by combining different subsystems of the vehicles and they interact with each other with the help of communicators. We should always make sure that all the communicators are appropriately defined. There are two types of standard assembly in ADAMS/car; one is the suspension assembly which consists of the suspension and the steering and the other is the full vehicle assembly which consists of all the major components of the vehicle. There is one more option called the general assembly, which allows us to make different kinds of assemblies in ADAMS/car providing a general dialogue box to assemble subsystems. This option is not available in the default setting of ADAMS/car but can be obtained by adding a code in the acarBS.cmd file. To obtain that general assembly box in ADAMS/car, the code that was added to the acarBS.cmd file is shown in the appendix. 


\subsection{Truck Modeling}

The MTV cargo truck modeled is a 5.0 ton pay load capacity truck. It has three dependent axles, power steering, chassis, cab and wheel assembly as the major components. ADAMS/car default settings allow us to only build two axle vehicles. To model a 3-axle truck, the code that was added to the acarBS.cmd file is shown in the appendix. A minor role of front was used for front axle (Axle-1), front_tractor was used for the intermediate axle (Axle-2) and rear_tractor was used for the rear most axle (Axle3). Truck modeling is a complex process and requires us to model a number of components and then assemble them to get the full vehicle assembly.

In the following sections of this thesis, modeling of required subsystems is discussed. These subsystems are then assembled to model the full vehicle assembly for the cargo truck with modified suspension.

Major components that will be discussed in following sections are:

1) Suspension (section 3.3.1)

2) Chassis (section 3.3.2)

3) Tires (section 3.3.3)

4) Steering (section 3.3.4)

5) Anti- roll bar (section 3.3.5) 


\subsubsection{Suspension}

The suspension forms the major part of the vehicle and has the following major functions in a vehicle [1]:

1) To provide vertical compliance so that the wheels can follow the rough roads and isolate the chassis from roughness in the roads.

2) To maintain the wheels in desired steer and camber with respect to road surface.

3) To resist the roll motion of the chassis or frame.

4) To keep the tires in contact with the road surface while encountering the rough roads and also to allow minimum load variations.

5) To react to the control forces produced by the tires.

The modeled truck has a dependent type of suspension, which means that both wheels of the axle steer or camber together on the front steerable axle. They are solid axle suspensions in which wheels are mounted on two sides of the rigid rod or beam. Any movement on one wheel is transmitted to the other side wheel which causes them to steer and camber together. Solid axles are used on heavy duty trucks as they are exposed to, and designed for high pay loads. They have a clear advantage in wheel camber as body roll does not affect the wheel camber for the tires [1]. 


\subsubsection{Front Steering Axle}

The front axle is the only steerable suspension in the truck. It is a solid axle suspension with parabolic tapered leaf springs, but in this research air springs are used since they are widely used on heavy duty trucks to improve ride for the trucks. As mentioned in section 3.3, the quad axle template from the ADAMS/ Car shared data base was used as a starting point but was modified to model the suspension for the cargo truck with air springs (new concept) and leaf springs (base vehicle). Figure 3.1 illustrates the front suspension assembly with the test rig.

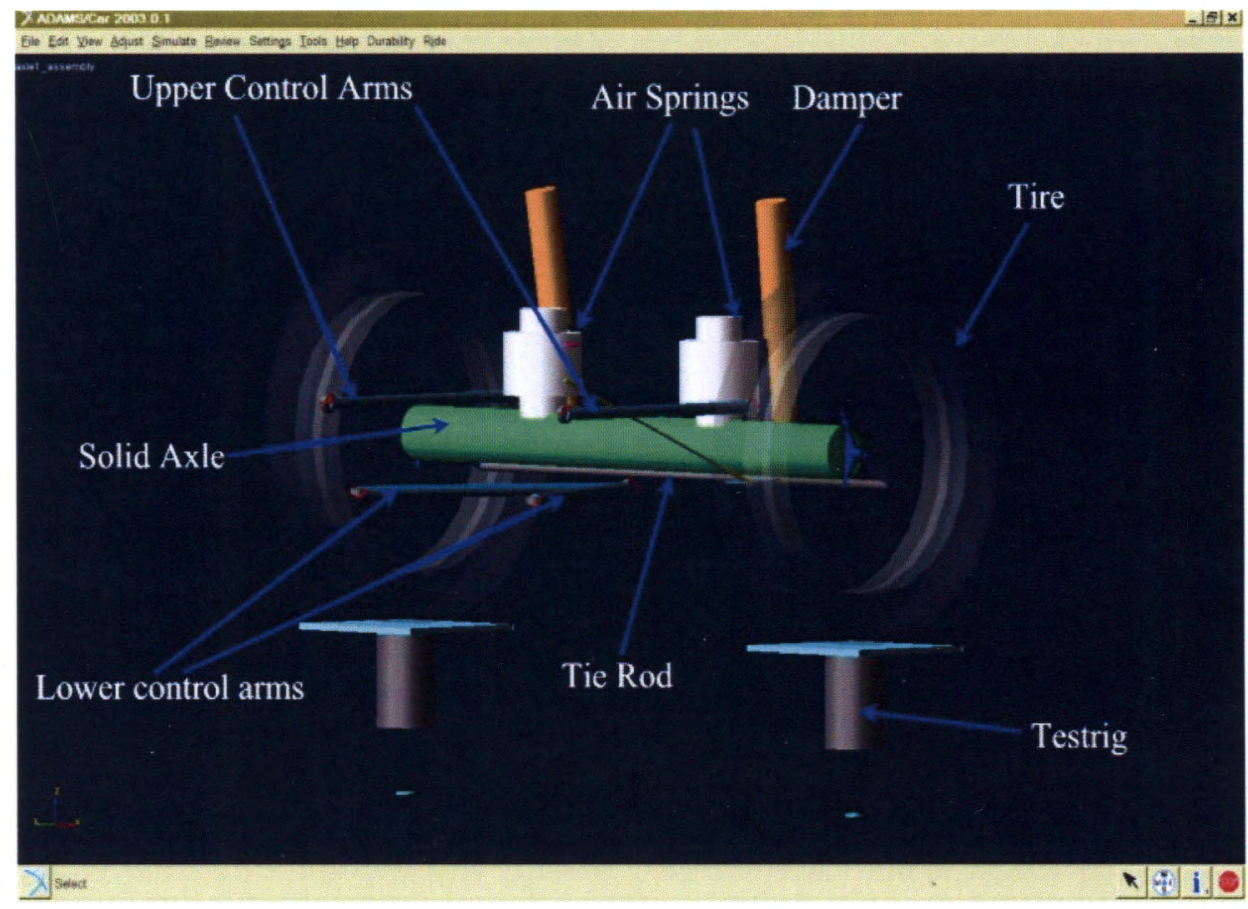

Figure 3.1: Front Axle Air Suspension Assembly for the Vehicle 
In the front suspension, the axle was modeled as a rigid body general part. Air springs are connected from the axle to the chassis using mount parts for the frame attachment. Air springs are new modeling element in ADAMS v 2003 and are modeled as a Sforce element in ADAMS which is defined using I and J parts for the suspension. The I part for the suspension is the axle and the J part is the mount part which acts as a place holder for the chassis in the suspension subsystem. The Equation 3.1 that defines the modeled Air Springs is shown in the appendix.

If we select auto trim load, an ADAMS/Solver differential equation sets the air spring's trim load based on the trim length that is defined in the air spring property file. The differential equation calculates the trim load that corresponds to the desired trim length during static equilibrium analyses. Its value is then locked to the last value calculated during static analyses for all the subsequent transient simulations. For auto trim load, the differential function is defined using the Equation 3.2 which is shown in the appendix.

The damper is modeled as a force based on a non linear spline between force and velocity. This file was created in ADAMS using curve manager and then referenced for the front dampers at the subsystem level. The tire is attached to the hub and the axle is attached to hub by revolute joints. Tierod and knuckles form the steering parts for the front suspension 
and help steer the front tires of the vehicle. Data for the front suspension hardpoints was provided by the U.S.Army.

\subsubsection{Tandem Axle Suspension}

The tandem axle suspension consists of both the intermediate and the rear axle. Solid axle suspensions without any steering linkages were modeled using quad axle template as a starting point from ADAMS/ Car shared database. Topology and hardpoints locations were changed according to the modeling data obtained from U.S. Army. The hub is directly connected to the axle part which is modeled as a general rigid body part. The wheels are attached to the hub with the help of locations and mount communicators in the assembly. Bumpstops and reboundstops are modeled to restrict the motion of the axle when it experiences high suspension travel on rough roads. Figure 3.4 illustrates the tandem suspension assembly with the tires. All major parts or components are shown in the assembly. 


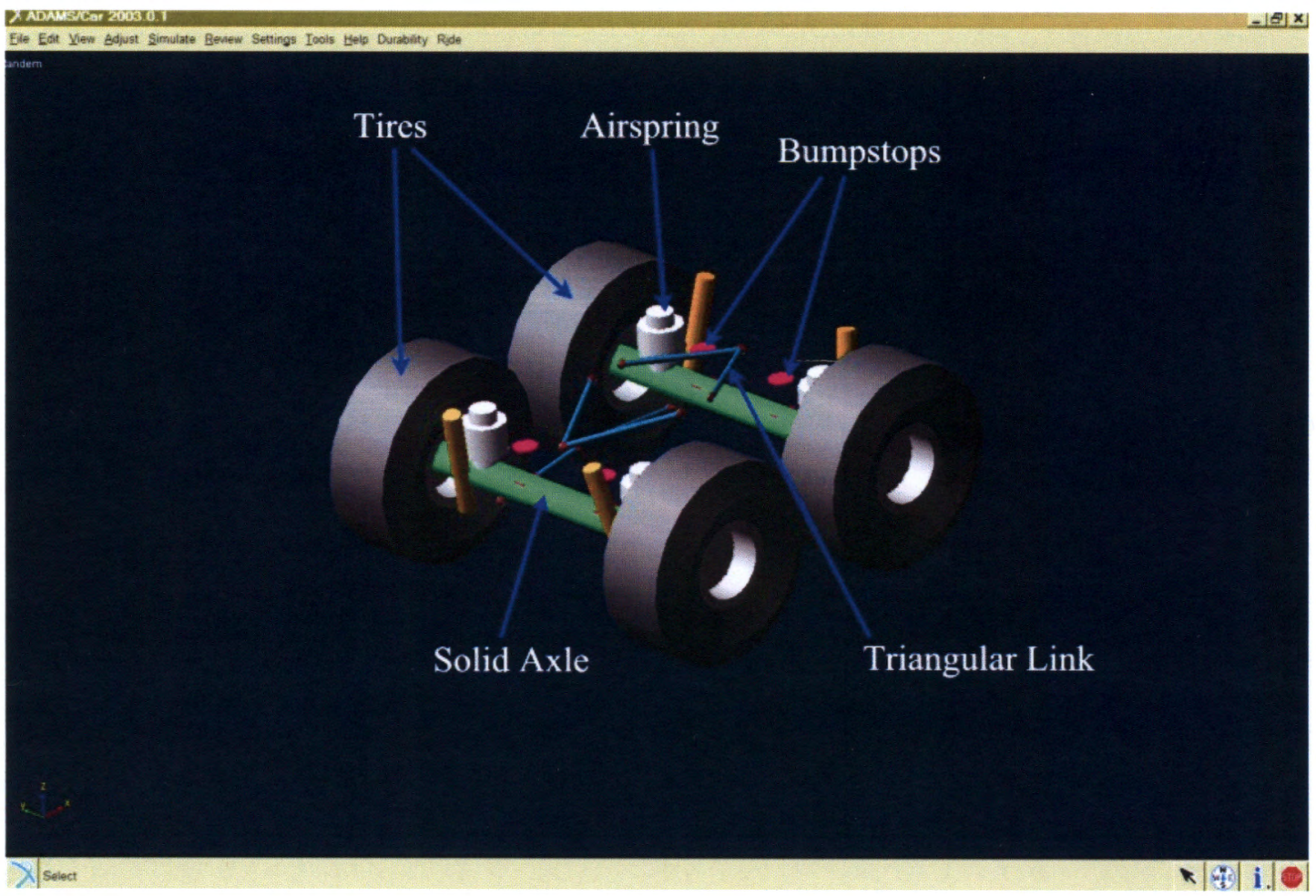

Figure 3.2: Tandem Axle Air Suspension Assembly for the Vehicle 
The air spring suspension design included the same suspension travels for the three axles as it was for the base truck with the leaf springs. Figure 3.3 illustrates the concept for the equivalence of two designs. The total vertical stiffness and roll stiffness provided by the tandem suspension leaf spring was split in the two rear axles (Axle-2 and Axle-3) with the air suspension. The data for the vertical stiffness and auxiliary roll stiffness was provided by the U.S.Army. The roll stiffness for the springs (front and tandem) obtained in the roll and vertical force analysis was verified using the Equation 3.3.
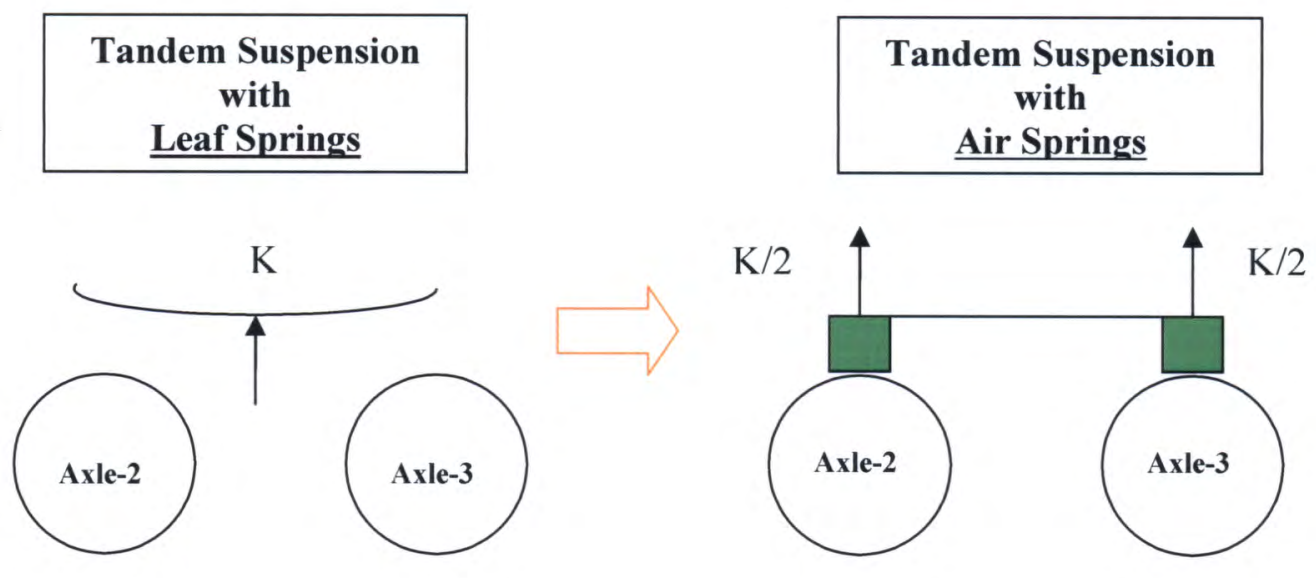

Figure 3.3: Illustration of Leaf Spring and Air Spring Suspension Design 
Roll Stiffness for the suspension is given by the following formula:

$$
\begin{aligned}
& K_{\phi}=0.5 K_{s} s^{2} \\
& K_{\phi}=\text { Roll stiffness of the suspension } \\
& K_{s}=\text { Vertical rate of each of the left and right springs } \\
& s \quad=\text { Lateral separation between the springs }
\end{aligned}
$$

The total roll stiffness for any suspension is the sum of the roll stiffness provided by the springs and the auxiliary roll stiffness of the suspension. The auxiliary roll stiffness for the suspension includes the roll stiffness due to the torsion bars, torque rods, rubber bushings, frame stiffness etc. As the frame was modeled as a rigid body and the bushings data was not available, all the auxiliary roll stiffness for each axle was provided using the anti roll bars on every axle. The base truck for the vehicle has an anti-roll bar only on the third axle because of the lack of space due to the leaf spring design. In the air suspension design, the space is not as big a constraint since there is no leaf spring connection between the axle2 and axle-3. Hence, anti-roll bars can be used to provide the auxiliary roll stiffness for each axle in the tandem suspension. This auxiliary roll stiffness is also varied using a parameter variable for torsional stiffness in the design space which will be discussed in the next chapter.

\subsubsection{Chassis}

The vehicle sprung mass (chassis) was modeled as a single rigid body and 
the shell (geometry) for the chassis was modeled in ADAMS/view which then was imported in ADAMS/Car. The mass and inertia value for the chassis includes the frame and cab which combine to make the sprung mass of the vehicle at curb and gross weight. The data for the mass and inertia, provided by the U.S.Army, was with respect to the center of gravity $(\mathrm{CG})$ of the components and the $\mathrm{CG}$ location was provided with respect to a fixed coordinate system below the front axle of the truck. The aerodynamic forces were not included for the chassis. The chassis included a number of output communicators which helped the chassis get connected to the three axles mount parts. As mentioned before, input mount parts in other subsystems are required to match with the output mount parts in the corresponding subsystems to generate a correct assembly. These output communicators were created to correctly attach the assembly to the other subsystems of the vehicle. Figure 3.4 illustrates chassis subsystem modeled for the vehicle with all the required components shown. 


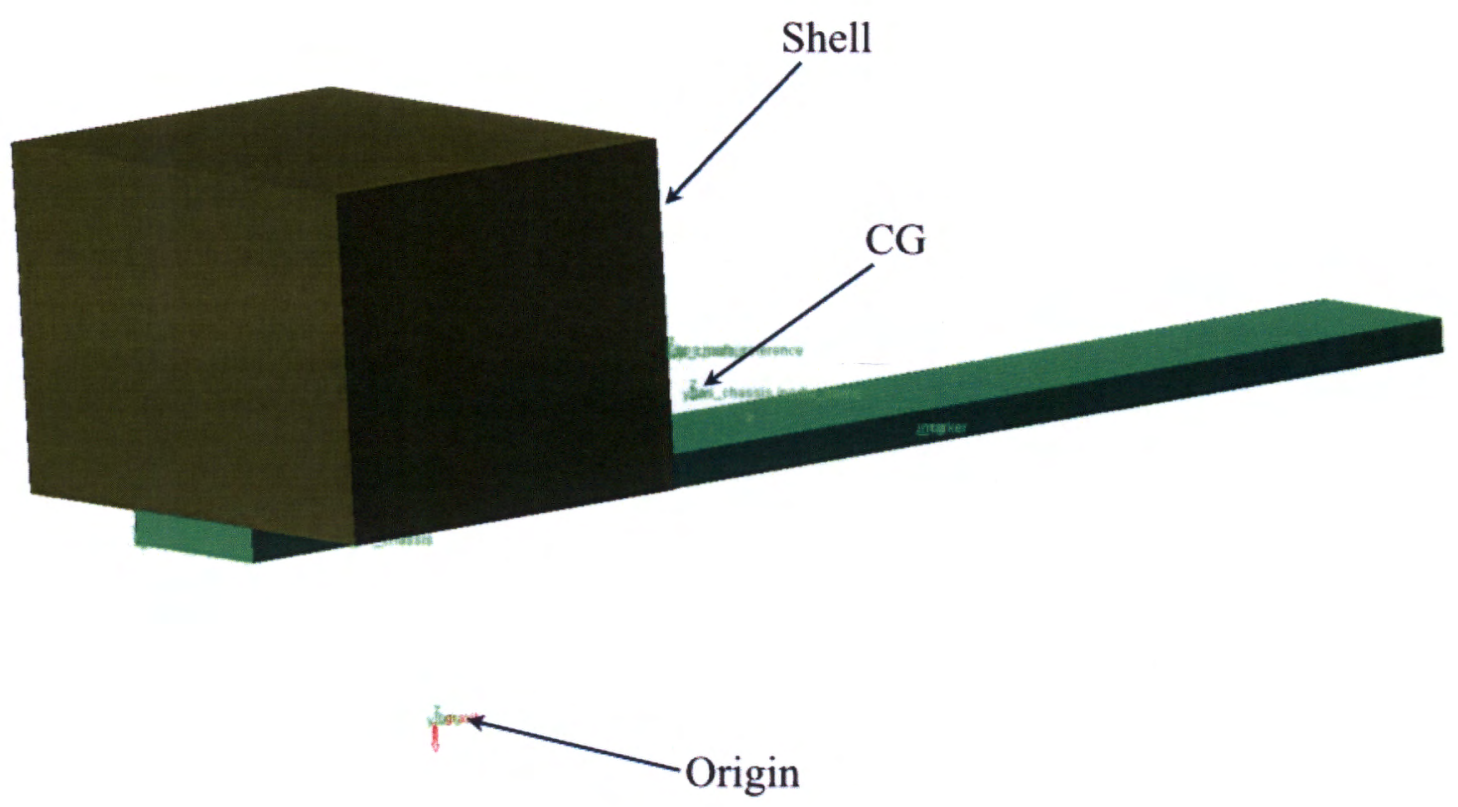

Figure 3.4: Rigid Chassis for the Truck 


\subsubsection{Tires}

Tires were modeled using the Fiala handling force model, which comes with ADAMS/Car. The inputs for the tire were calculated from the tire data provided by Michelin America and were entered in to the tire property file.

Assumptions used in the tire model are mentioned below [15]:

$>$ The contact patch is rectangular in shape.

$>$ The distribution of pressure is uniform across footprint or contact patch.

Tire forces are not affected by the change in camber angle.

$>$ Tire relaxation effects are not considered in this tire model.

$>$ Elastic brush elements are used to provide contact between road and carcass.

The inputs to the Fiala tire model come from two sources [15]:

1) Input parameters from the tire property file (.tir), such as tire undeflected radius.

2) Tire kinematic states, such as slip angle which ADAMS/Tire calculates real time during a simulation.

A sample tire property file from the ADAMS/Car shared data base for the Fiala tire model is shown in the appendix. Values were changed as this is only an example. 
The tire data was entered in the data file for the tires (Michelin 395/85R20 XML) used on the MTV cargo truck. Figure 3.5 illustrates the tires used on the truck in the vehicle. Geometry for the tire is constructed by ADAMS for the Fiala tire used which is based on the radius we specify for the tire in the tire data file.

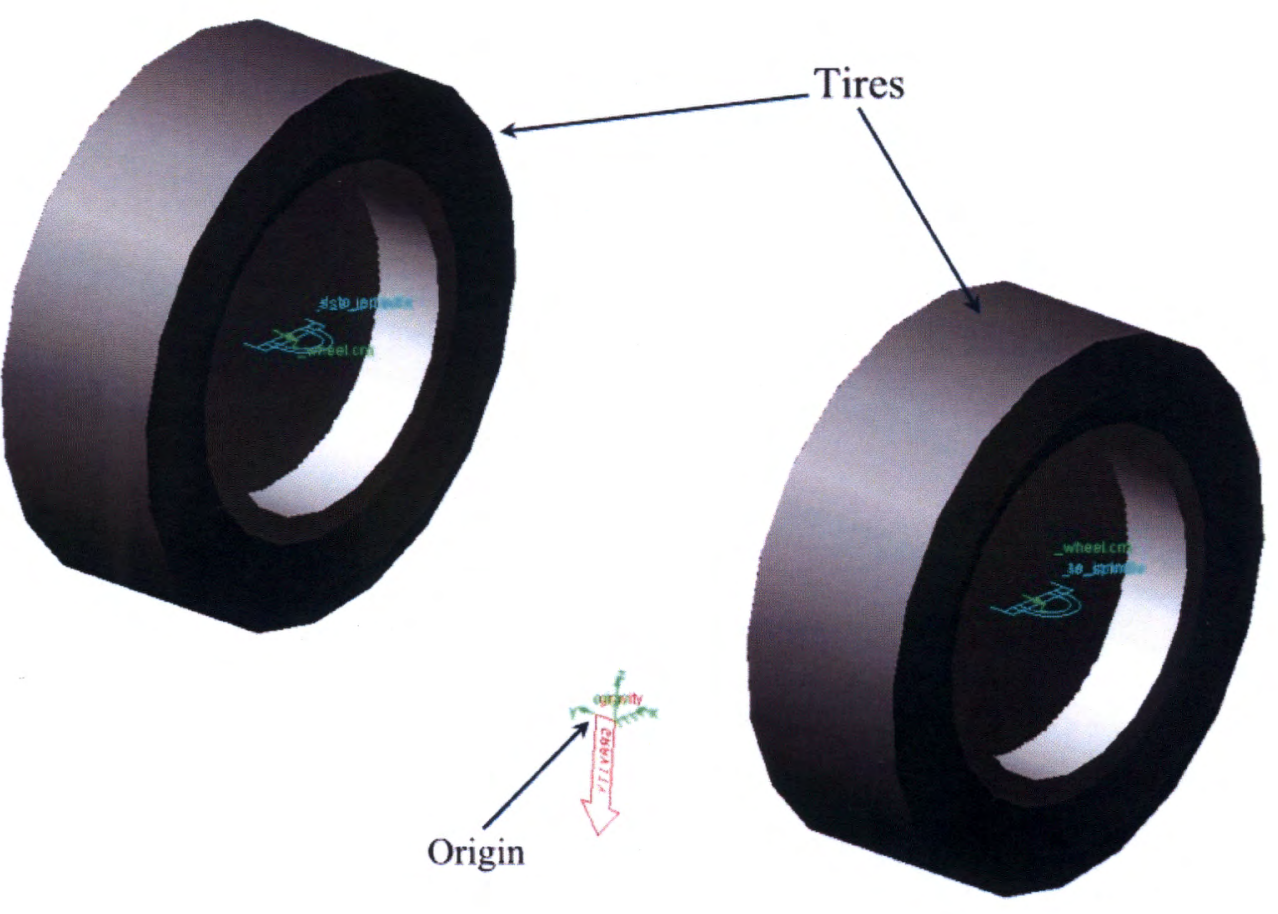

Figure 3.5: Fiala Tire Model 


\subsubsection{Steering}

Steering was modeled using the pitman arm steering template in ADAMS/ Car shared database. The topology and hardpoints location were changed to model the steering on the truck. It steers only the front suspension on the truck and the other two axles are not steered. The pitman arm pulls and pushes the draglink which then moves the tie rods to steer the vehicle. Shown below in Figure 3.6 illustrates the front suspension steering modeled in ADAMS/Car.

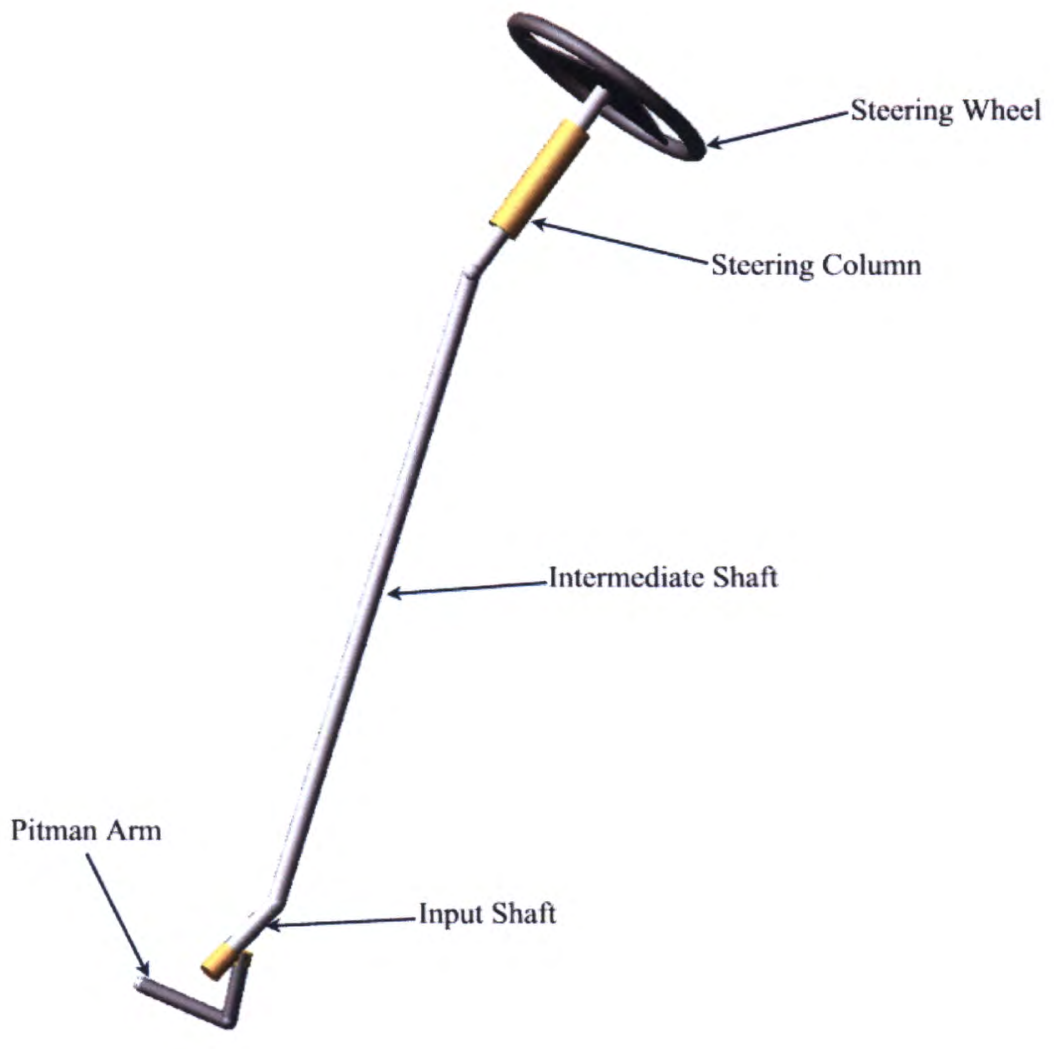

Figure 3.6: Pitman Arm Steering 


\subsubsection{Anti-Roll Bar}

Anti-roll bars (or sway bars, or stabilizers bars) were used on the front, intermediate and rear axle on the truck. They are used to reduce the roll of the body (chassis) during cornering. The simple anti-roll bar template was used as a starting point from ADAMS/Car shared database which then was modified to reflect the anti-roll bar used on the truck. The droplinks are connected to the suspension through the spherical joints. Droplinks transmit the motion of the suspension to the end of bars.

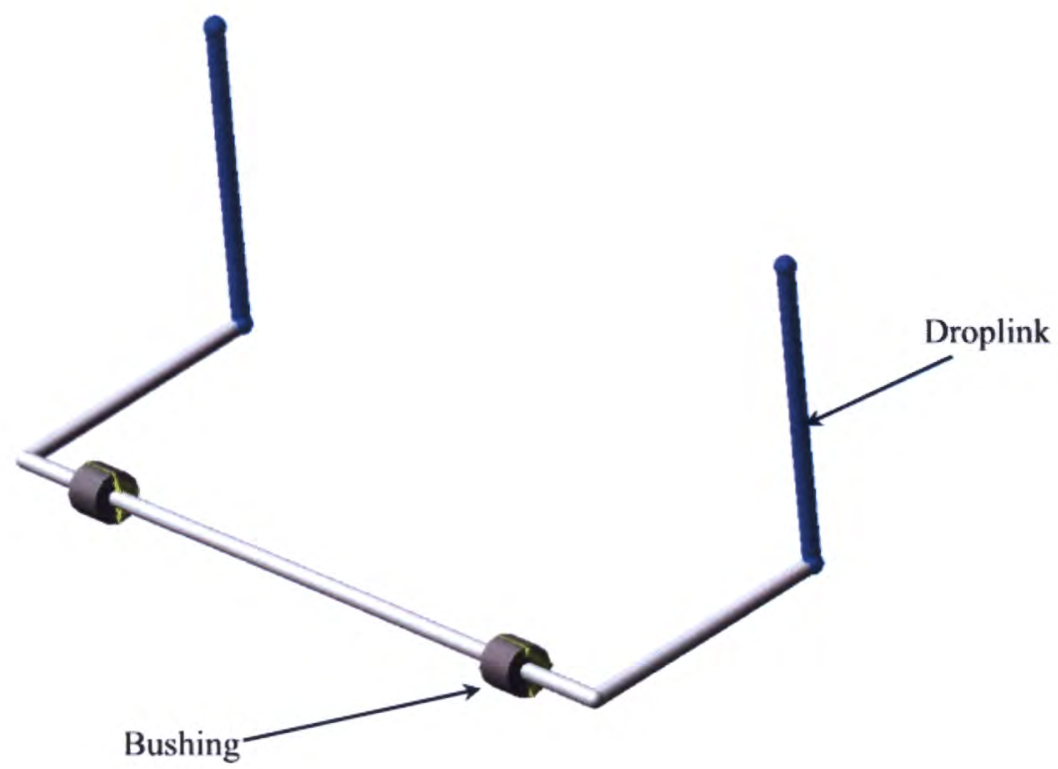

Figure 3.7: Anti-roll bar

The left and right side anti-roll bar is connected by a spring damper element that applies the action / reaction torques on the two bar halves. Mount part in the anti 
roll bar subsystem provided connectivity to the suspension. Torque applied on the I part marker is equal and opposite to the torque applied on the J part marker [23]. Figure 3.7 illustrates the anti - roll bar subsystem used in front and tandem suspension of the truck assembly. 


\subsection{Verification}

As discussed in section 3.1 , modeling should be done in a way to reduce the computation time and to capture the correct behavior of the mechanical system. The approximations used while modeling the vehicle should not affect the dynamic behavior or response of the vehicle. Simple modeling techniques should not result in deviation of the model from the actual vehicle response.

To be able to comment on the validity of the model, verification is a very critical step in the vehicle design process. In the real world, actual tests are conducted on an instrumented vehicle to capture the vehicle response. This collected data is then compared with the simulation to validate the model. If the field data does not match with the simulation data, then the model is refined to better approximate the real world test data. This process is continued until we can say that the model behaves in a desired way and its response approximates the real world test data. Once we are sure that the model data corresponds to the real world test data, we can make changes in the model to see the effect of those changes for the vehicle modeled. The variants or configurations generated from the small variations in the validated baseline truck will give us good approximations about the response of each configuration. 


\subsection{Verification of the Truck Model}

Verification is an important step in the vehicle design process. To verify the model, real tests are conducted and then are compared with the simulations results. As there was limited data available to validate the truck from U.S.Army, mathematical solutions are used to verify the model. The maneuvers selected for validation are the step steer analysis and the constant radius cornering analysis. Details of the mathematical verification will be provided in the following sections.

\subsubsection{Step Steer Analysis for Model Validation}

The step steer analysis is done at $40 \mathrm{~km} / \mathrm{h}$ with a steering angle of $60 \mathrm{deg}$ which was applied in a $3 \mathrm{sec}$ of step duration. The time for the simulation was 60 sec which was enough for the transients to die out [21].

\subsubsection{Results for Step Steer Analysis}

The path followed by the vehicle at Gross Vehicle Weight (GVW) during the step steer test is shown in Figure 3.8. It follows a circle because of the constant steering applied during the maneuver. The longitudinal velocity of the truck reduced from $40 \mathrm{~km} / \mathrm{h}$ to $35 \mathrm{~km} / \mathrm{h}$ in the step steer test as shown in Figure 3.9. The reason being the lateral forces acting on the truck during the turn. Also, as there was no powertrain modeled for this truck, there in no throttle available to keep the constant velocity of the truck during the maneuver. 


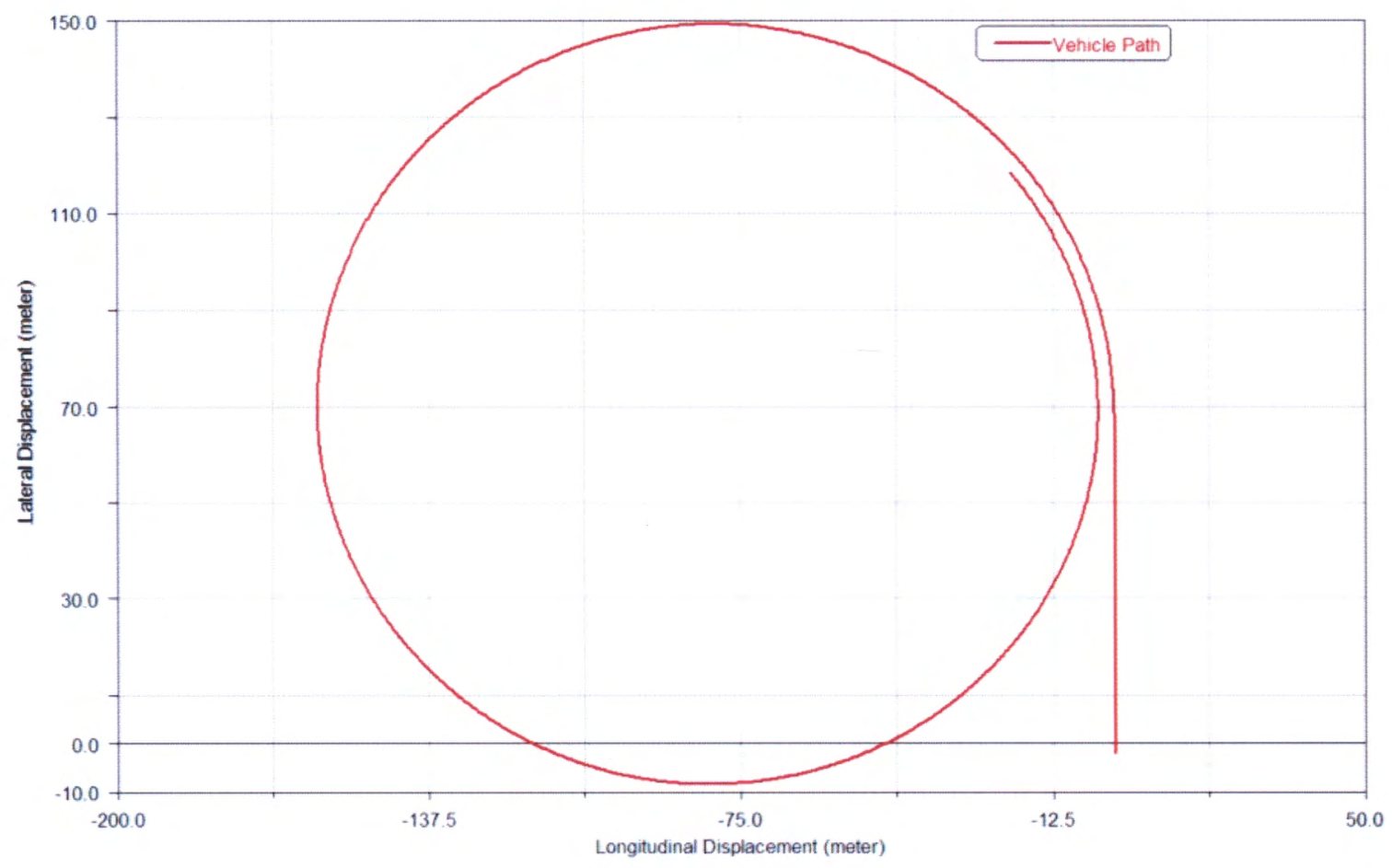

Figure 3.8: Lateral vs. Longitudinal Displacement in a Step Steer Analysis for Validation 

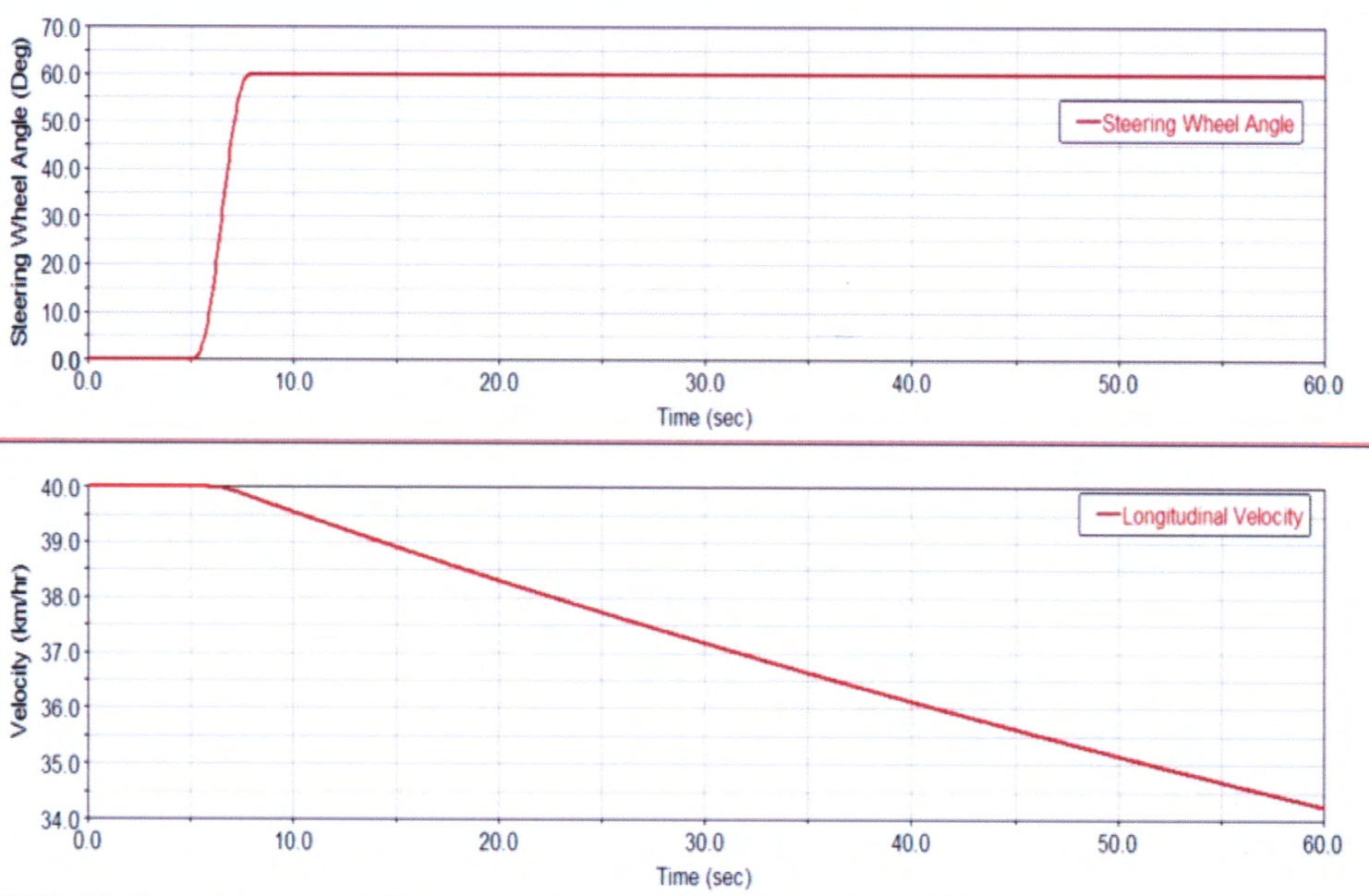

Figure 3.9: Steering Wheel Input and Longitudinal Velocity in a Step Steer Analysis for Validation

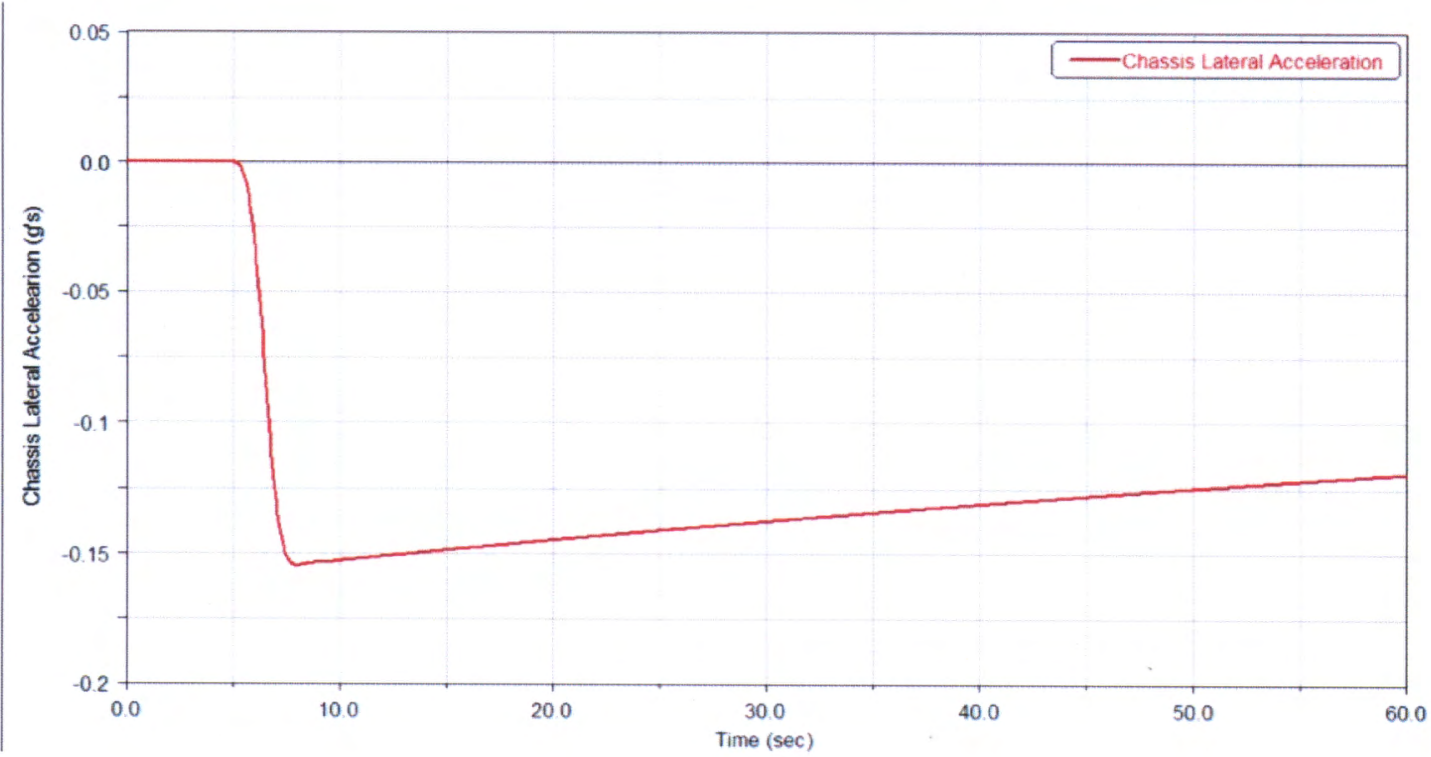

Figure 3.10: Chassis Lateral Acceleration (in g's) in a Step Steer Analysis 


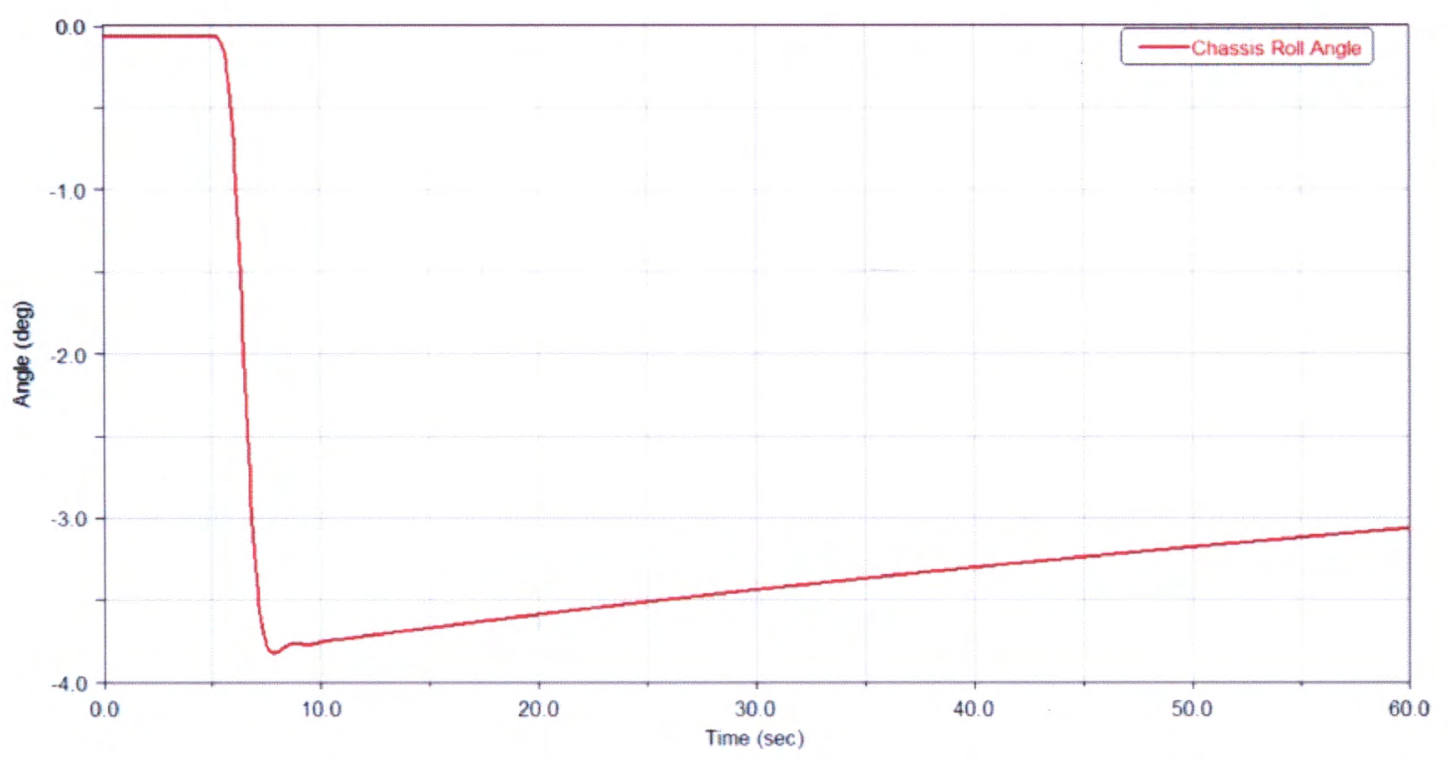

Figure 3.11: Chassis Roll Angle (in deg) in a Step Steer Analysis

The chassis lateral acceleration increases (Figure 3.10) from 0 to $0.15 \mathrm{~g}$ 's peak at the start of the steering input application, then the value decreases at a constant rate which is proportional to the decrease in velocity during the maneuver. 


\subsubsection{Validation of Lateral Acceleration}

Figure 3.9 illustrates that the average velocity during the maneuver is given as

$$
V=37.2 \mathrm{~km} / \mathrm{h}=10.34 \mathrm{~m} / \mathrm{sec}
$$

Average diameter (D) and radius (R) of the circular turn for the maneuver is

$$
\begin{gathered}
D=\frac{157.8+159.6}{2}=158.7 \mathrm{~m} \\
R=\frac{D}{2}=79.35 \mathrm{~m}
\end{gathered}
$$

The theoretical lateral acceleration of the vehicle going in a circle is given as

$$
A y=\frac{V^{2}}{R}=\frac{10.34^{2}}{79.35}=1.347 \mathrm{~m} / \mathrm{sec}^{2}
$$

Now, lateral acceleration in g's is given as;

$$
A y=\frac{1.347}{9.81} g=0.137 g
$$

From Figure 3.10, it can be shown that the average lateral acceleration during the maneuver was $0.14 \mathrm{~g}$ 's which is same as Equation 3.9. 


\subsubsection{Validation of Normal Loads on Tire}

The tire normal forces obtained during the maneuver are shown in the

Figure 3.12.

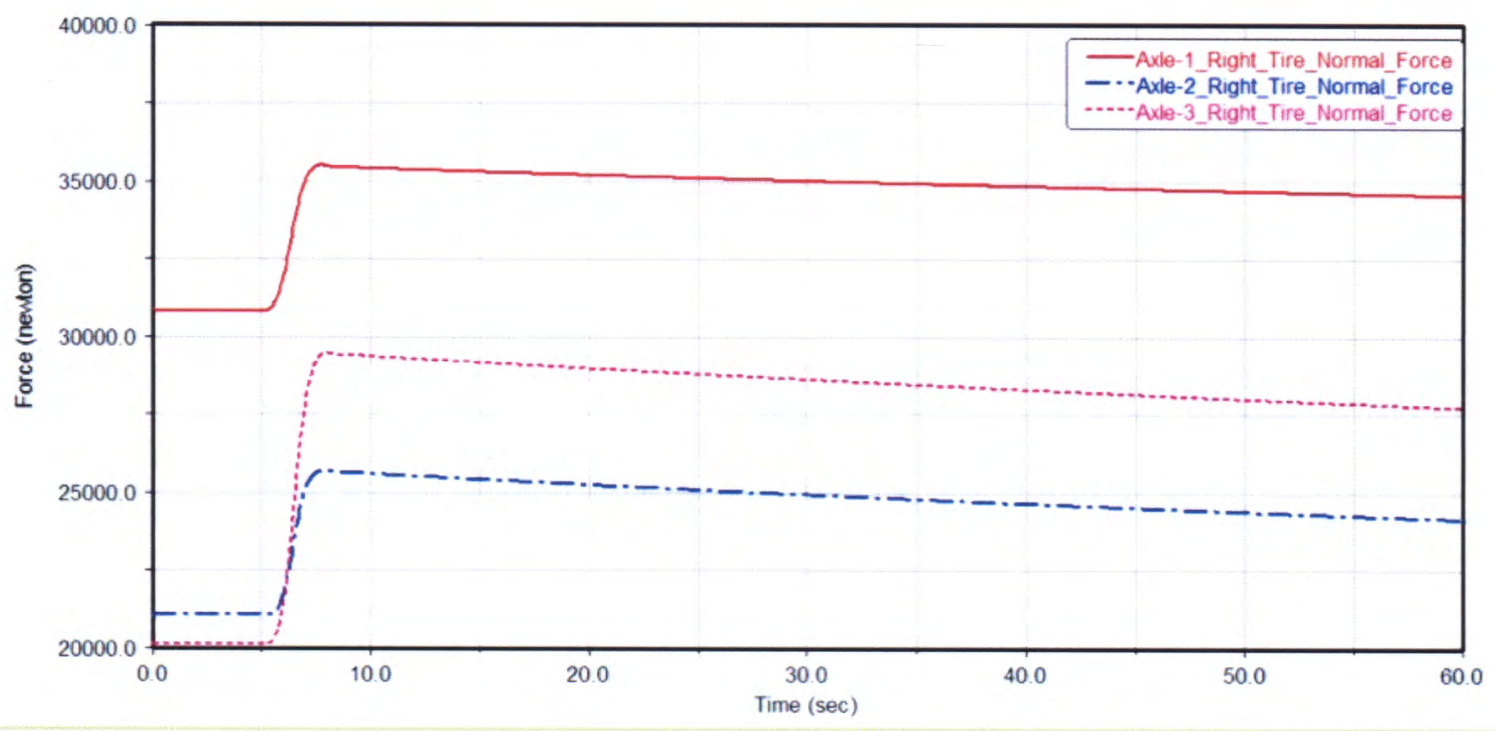

Figure 3.12: Tire Normal Forces (in N) in a Step Steer Analysis

Mass of the vehicle $(\mathrm{GVW})=14642 \mathrm{KG}$

$$
\begin{gathered}
\text { Force }=14642 * 9.81 \mathrm{~N}=143638 \mathrm{~N} \\
\text { Force } / \text { side }=99110.4 / 2=71819 \mathrm{~N}
\end{gathered}
$$

It can be shown from the Figure 3.12 that sum of tire forces at $t=0 \mathrm{sec}$ (static) is very close to this value. The front axle of the vehicle supports more force than the individual rear axles which can be clearly seen in figure 3.12 above. 


\subsubsection{Validation of Lateral Tire Forces}

The lateral right tire forces for the vehicle are shown in the figure below:

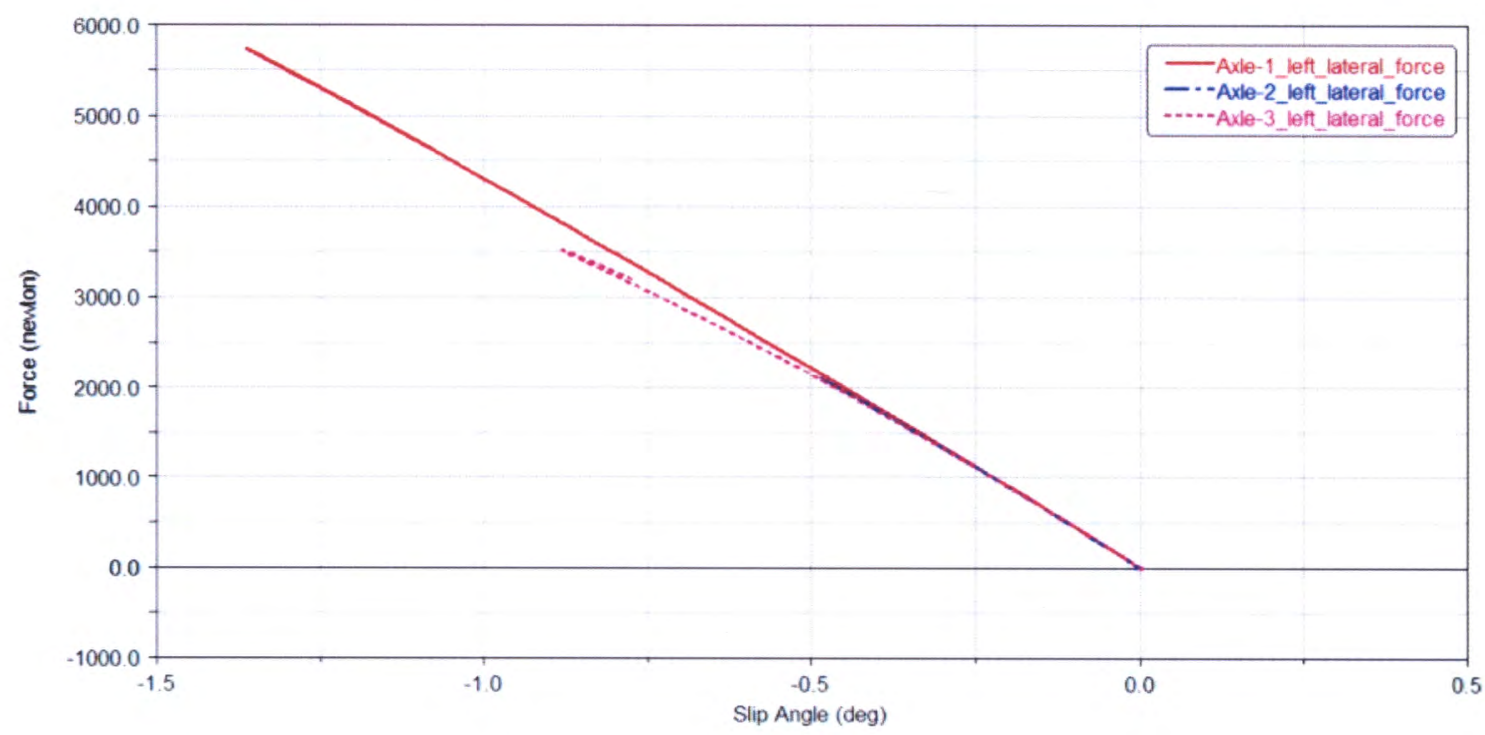

Figure 3.13: Left Tire Lateral Forces in a Step Steer Analysis

The tire for this maneuver was at a 60 psi pressure and the cornering stiffness was calculated as:

$$
C_{\alpha}=4563 \frac{N}{\operatorname{deg}}
$$

At low slip angles, lateral force developed by tires is directly proportional to the slip angle and the proportionality constant is called as the cornering stiffness for the tire. It can be compared from Figure 3.13 that ratio of lateral tire force $\left(\mathrm{F}_{\mathrm{y}}\right)$ and slip angle $(\alpha)$ (Equation 3.14) is close to the above value (Equation 3.13) which is the cornering stiffness of a tire at low slip angles. 


$$
C_{\alpha}=\frac{F_{y}}{\alpha}=\frac{1148}{0.25}=4592 \frac{N}{\operatorname{deg}}
$$

In the next section, details are given for the examination of the lateral acceleration using the constant radius cornering. 


\subsubsection{Constant Radius Cornering Analysis for Model Validation}

In this maneuver, the vehicle at Gross Vehicle Weight (GVW) is taken in a circle of constant radius for a given speed. The lateral acceleration of the vehicle can be calculated using the longitudinal velocity (V) and constant radius of the circle (R) using Equation 3.15.

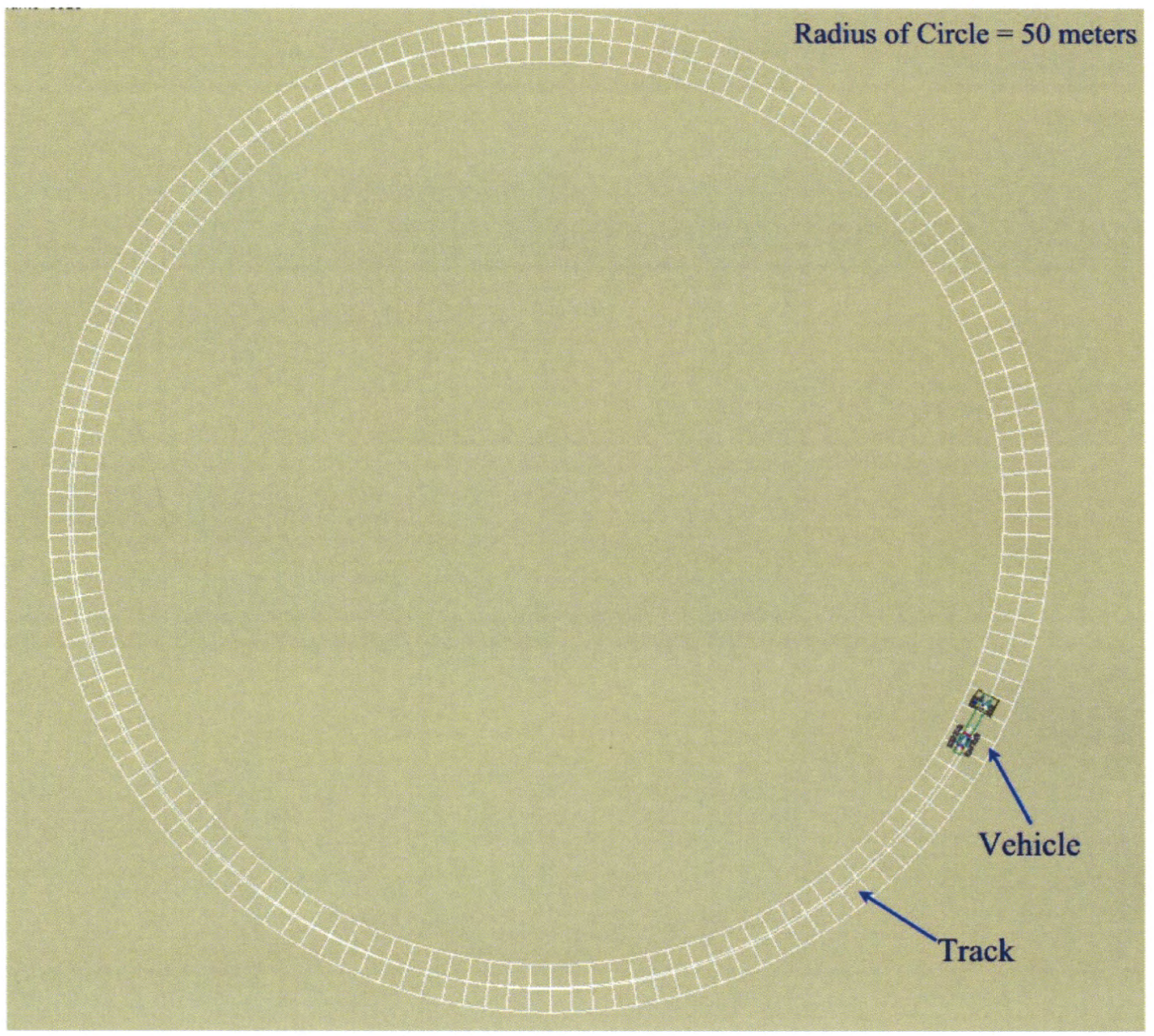

Figure 3.14: Constant Radius Cornering Track 

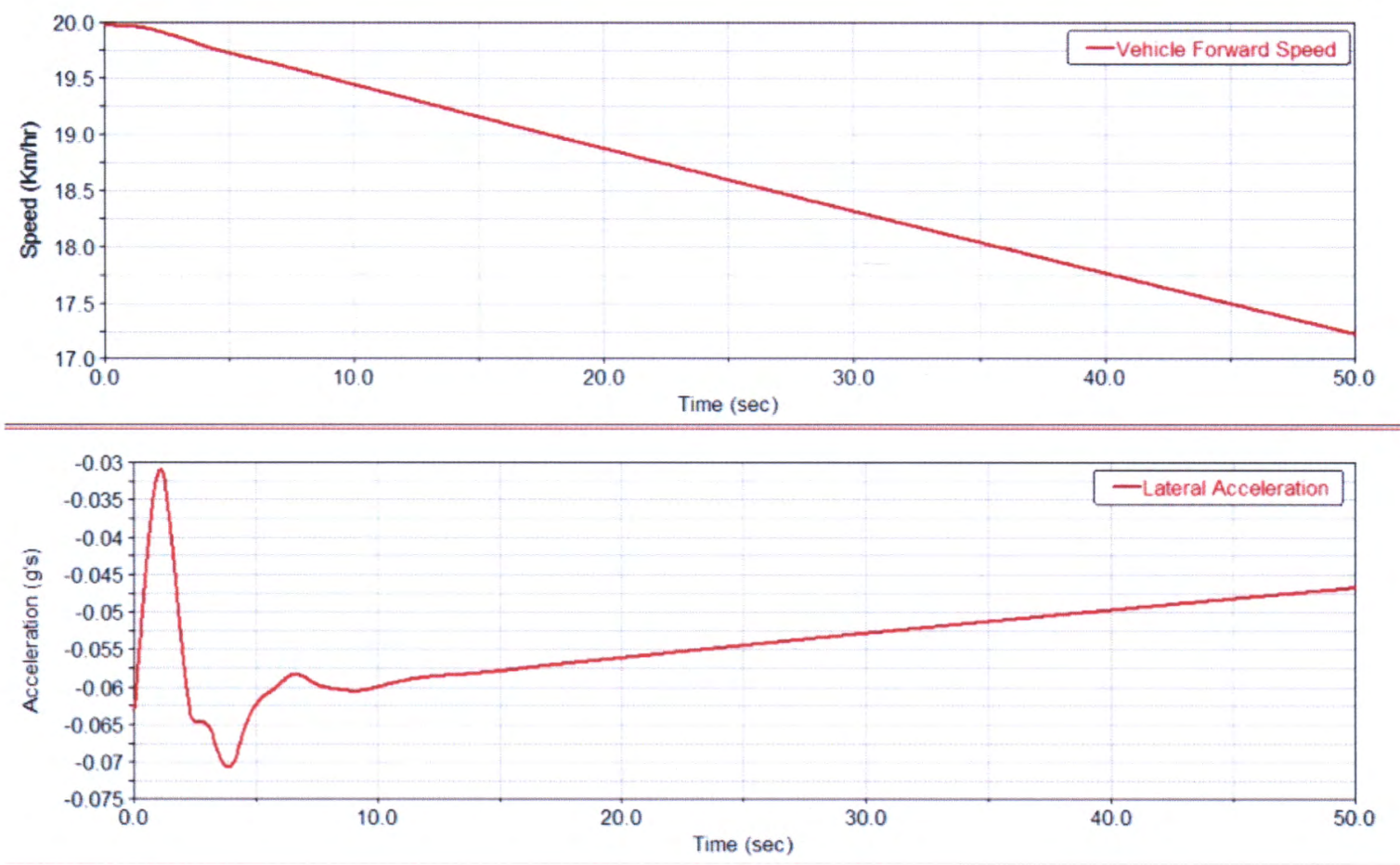

Figure 3.15: Vehicle Forward Speed and Lateral Acceleration in a Constant Radius Cornering Analysis for Validation

The vehicle was run at an average forward speed of $18.6 \mathrm{Km} / \mathrm{h}$ as seen from Figure 3.15. The constant radius for the maneuver was 50 meters. The lateral acceleration (Ay) for the maneuver is given by Equation 3.15.

$$
A y=\frac{V^{2}}{R}=\frac{5.166^{2}}{50}=0.5338 \mathrm{~m} / \mathrm{sec}^{2}
$$

Now, lateral acceleration (Ay) in g's is given as;

$$
A y=\frac{0.5338}{9.81} g=0.0544 g
$$


The average lateral acceleration for the maneuver from the simulation result (Figure 3.15) is $0.054 \mathrm{~g}$ 's which is close to what we obtained in Equation 3.16 .

The stiffness for the front, intermediate and rear suspension were examined before doing the step steer analysis (model verification). The modeling data provided by the U.S.Army was used to model the truck and the model behavior was correlated with the data for the truck. The pre-loads for the air springs were equal to the static load acting on each suspension. Parallel wheel travel analysis was used to calculate the vertical stiffness for the suspensions and the Roll and Vertical force analysis was used to compare the roll stiffness for the suspensions. These analyses are very important to make sure that the suspension travel provided is equal to that on the truck and stiffnesses are appropriate. In the next chapter analysis, results and optimization will be discussed in details. 


\section{CHAPTER 4}

\section{ANALYSIS, RESULTS AND OPTIMIZATION}

\subsection{Design Space Exploration Procedure}

After the modeling and verification of the base vehicle, the next step in this research is to do the large design space exploration of the modified vehicle with air springs. This would lead to an optimized vehicle based on the selected performance measures or metrics for the vehicle. The procedure used to optimize the modified vehicle based on the selected performance measures is achieved by the following tasks:

1. Selection of the vehicle from the Family of Medium Tactical Vehicles (FMTV).

2. Selection of the design parameters for the modified vehicle.

3. Inputs (roads and maneuvers) selection for the design study.

4. Selection of responses or measures which are used to evaluate the design candidates.

5. Generation of different configurations for the modified vehicle by varying the design parameters selected in task 2 .

6. Simulation of all the generated configurations for the selected maneuver to generate the responses or measures for all the design candidates (configurations).

7. Transfer of design space to the flexible optimization architecture. 
8. Using dominance filtering in the viewer, to filter out the designs in the design space that are completely dominated by the other better design with respect to all the selected performance measures. This is discussed in details in Chapter-2 section 2.8 .

9. Selection of the final optimized design in the visualization environment based on the desired performance measures (constraints) in the vehicle.

The above tasks of the design study are explained in detail in the following sections. In section 4.2 to 4.10 , the optimization method is discussed in detail for the gross vehicle weight and different tire pressure combination. In section 4.11 and 4.12 , the optimization method will be applied to find appropriate tire pressure for the curb vehicle weight and intermediate vehicle weight respectively.

\subsection{Selection of the vehicle from the FMTV}

The first step of the research was to select a base vehicle for the study from a large Family of Medium Tactical Vehicles (FMTV). These FMTV tractors and trailers serves the U.S.Army around the globe and are designed for durability, reliability and full mission capability. The prime criterion for selection of the base vehicle out of the large family of vehicles was the availability of modeling data for the vehicle. For our research, MTV 1083 is selected as the base vehicle since modeling data for the truck was available at the start of the project. This vehicle has 3 -axles with six tires $(6 \times 6)$ and a payload capacity of 5 tons. It is a front steerable cargo truck and used to haul equipment and 
soldiers from one point to another in the battle field. The design space exploration is done on the modified version of the truck with the air spring suspensions.

\subsection{Selection of the Design Parameters for the Modified Vehicle}

The selection of design parameters was based on critical parameters that affect the ride and handling of the cargo truck. Parameters that change in a particular maneuver for this study are anti-roll bar stiffness (to vary roll stiffness for suspension) and the damping for the dampers. A maneuver is conducted at different tire pressures and loading conditions. Three different loadings are considered, one for the curb vehicle weight $(\mathrm{CVW})$, a second corresponding to an intermediate weight, and the third corresponding to the gross vehicle weight (GVW) of the truck. The tire pressures used for this research varied from 22 psi to $72 \mathrm{psi}$. The six tire pressures selected are $22,29,37,44,60$ and 72 psi. These tire pressures cover the range of operation of the truck for different types of terrains encountered by the truck. The tire used in modeling for the truck is the Michelin 395/85 R 20 XML TL 161 G. It has the following properties:

$$
\begin{aligned}
& \text { Section width }=395 \mathrm{~mm} \\
& \text { Aspect ratio }=85 \%=(\text { height } / \text { width }) \times 100 \\
& \text { Rim Diameter }=20 \text { inches }
\end{aligned}
$$

For a particular tire pressure and loading condition, the maneuver was conducted with a suitable preload in the air spring used on the truck and then the two design parameters (ARB stiffness and damping) were changed to generate different configurations. 
Parameters that remain constant for a particular ADAMS/Insight experiment are:

1) $\underline{\text { Tire Pressure }}$
a) $\mathrm{P}_{1}=22 \mathrm{psi}$
b) $\mathrm{P}_{2}=29 \mathrm{psi}$
c) $\mathrm{P}_{3}=37 \mathrm{psi}$
d) $\mathrm{P}_{4}=44 \mathrm{psi}$
e) $\mathrm{P}_{5}=60 \mathrm{psi}$
f) $P_{6}=72 \mathrm{psi}$

2) Sprung Mass

a) Curb vehicle weight (CVW)

b) Intermediate load (INTERMEDIATE )

c) Gross vehicle weight (GVW)

3) Air Spring Preload (pl)

\begin{tabular}{|l|c|c|c|}
\hline \multicolumn{1}{|c|}{ SPRUNG MASS } & $\begin{array}{c}\text { AXLE-1 } \\
\text { Preload }\end{array}$ & $\begin{array}{c}\text { AXLE-2 } \\
\text { Preload }\end{array}$ & $\begin{array}{c}\text { AXLE-3 } \\
\text { Preload }\end{array}$ \\
\hline Curb vehicle weight $(\mathrm{CVW})$ & $\mathrm{Pl}_{1}$ & $\mathrm{Pl}_{2}$ & $\mathrm{Pl}_{3}$ \\
\hline Intermediate vehicle weight & $\mathrm{Pl}_{4}$ & $\mathrm{Pl}_{5}$ & $\mathrm{Pl}_{6}$ \\
\hline Gross vehicle weight (GVW) & $\mathrm{Pl}_{7}$ & $\mathrm{Pl}_{8}$ & $\mathrm{Pl}_{9}$ \\
\hline
\end{tabular}

Table 4.1: Air Spring Preloads 
The design parameters which vary in a particular ADAMS/Insight experiment take the following values. The design parameters that are varied are as follows:

\section{1) Scaling of Damping}

In a vehicle, the excitation of the sprung mass is provided by the motion of the unsprung mass/ tire [25]. Figure 4.1 illustrates the spring mass damper system for the sprung and unsprung mass of the vehicle. The displacement of the unsprung mass is $y$ and the displacement of the vehicle body is $\mathrm{x}$.

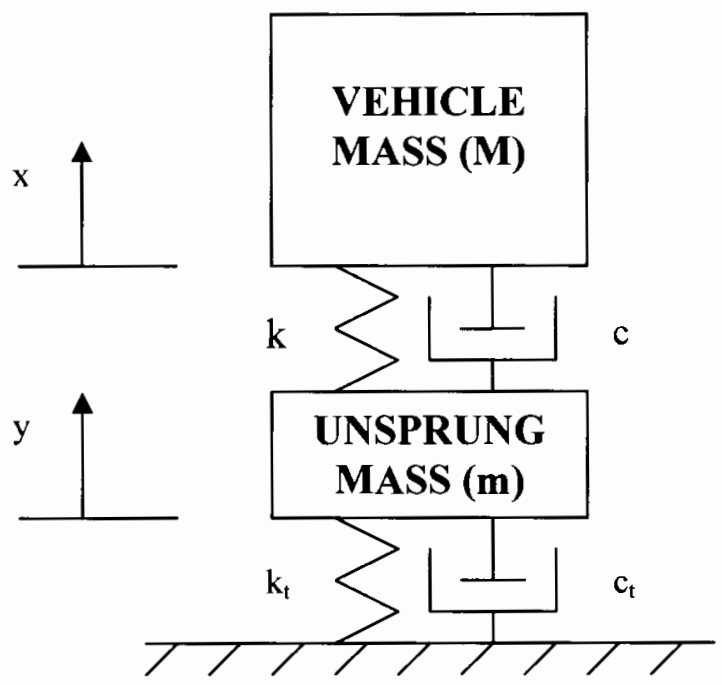

Figure 4.1: Two Degrees of Freedom Model (Quarter Car Model)

The equation of motion for the vehicle mass is given as;

$M \ddot{x}=-k(x-y)-c(\dot{x}-\dot{y})$

Now, let $\mathrm{z}=\mathrm{x}-\mathrm{y}$ 
Substituting Eq. (4.2) in Eq. (4.1), we get Eq. (4.3)

$M \ddot{z}+c \dot{z}+k z=M \ddot{y}$

Assuming the motion of the unsprung mass is harmonic in nature, the transmissibility ratio is then defined in Equation 4.4 (Thomson, 1988) [25]. It is defined as the ratio of transmitted force to the exciting force acting on the system. Figure 4.2 shows the plot of the Equation 4.4 and illustrates the effect of damping on the response of the system [25].

Transmissibility Ratio $=\frac{\text { Transmited force }}{\text { Exciting Force }}=\frac{\text { T.F }}{\text { E.F }}=\sqrt{\frac{1+\left(2 \zeta \frac{\omega}{\omega_{n}}\right)^{2}}{\left[1-\left(\frac{\omega}{\omega_{n}}\right)^{2}\right]^{2}+\left(2 \zeta \frac{\omega}{\omega_{n}}\right)^{2}}}$

Damping Factor $(\zeta)=\frac{\mathrm{c}}{2 \times \sqrt{\mathrm{m} \times \mathrm{k}}}$

Where; $\omega=$ natural frequency of the unsprung mass system

$\omega_{n}=$ natural frequency of the vehicle mass system

$\zeta=$ damping factor

$\mathrm{m}=$ mass

$\mathrm{c}=$ damping coefficient

$\mathrm{k}=$ spring stiffness 


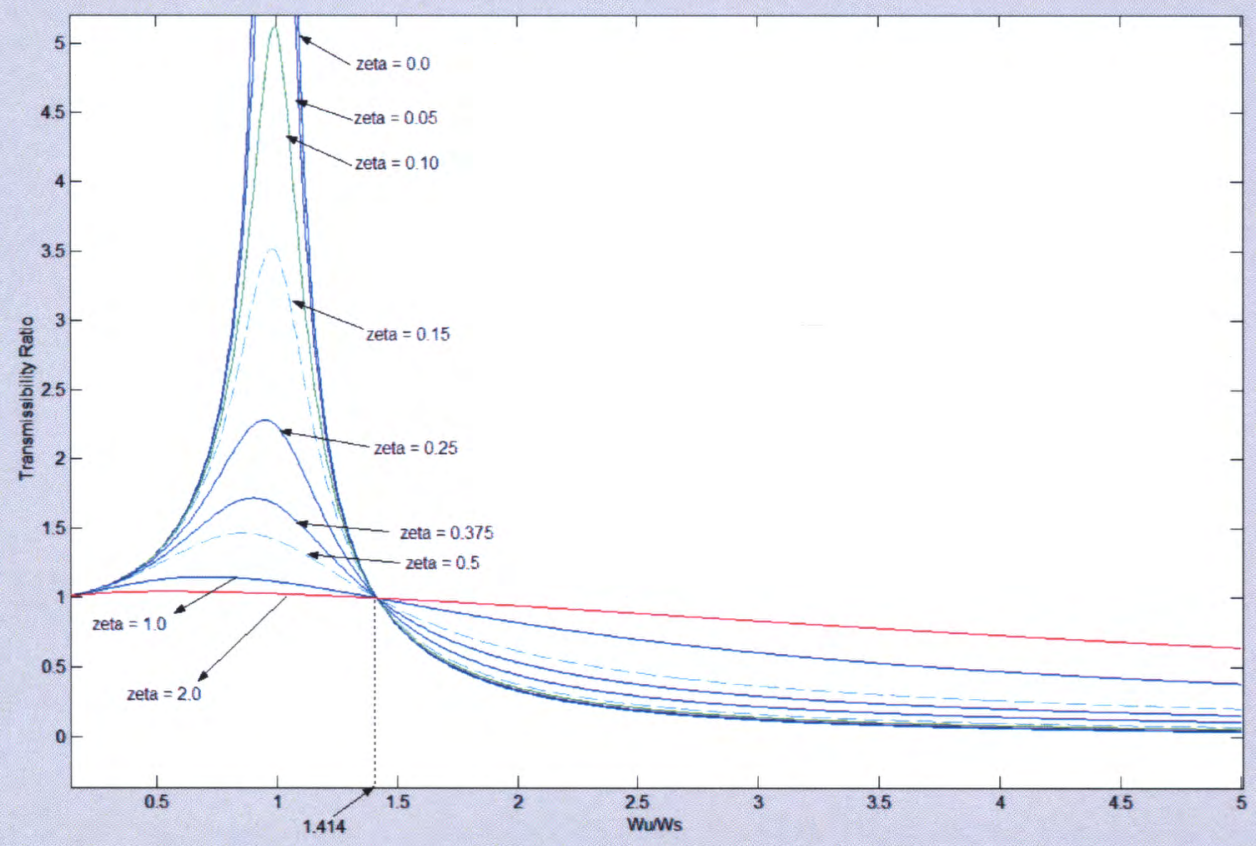

Figure 4.2: Plot of Transmissibility Ratio and ratio of $\omega / \omega_{n}$

Typically, the damping ratio $(\xi)$, for an automotive suspension varies between 0.2 to 0.4 [1]. In this research, the damping scale values were selected in such as a way so as to keep the damping ratio for the suspension to be in the range of 0.1 to 0.5 . For GVW, depending on the mass and stiffness at each axle, the damping ratio varies from 0.2-0.3 for compression and 0.4-0.5 for extension. The calculated value (using a 2 DOF model, Equation 4.5) for the damping ratio (0.25) corresponds to the linear section of the given non-linear damping spline and was approximated to vary the damping in the design space. The damping force is scaled using the damper scale values selected in Table 4.2. The new damping ratio is equal to damper scale values times the old damping ratio. 


\begin{tabular}{|c|c|c|}
\hline $\begin{array}{c}\text { OLD DAMPING RATIO } \\
\text { (calculated) }\end{array}$ & $\begin{array}{c}\text { DAMPER } \\
\text { SCALE VALUE }\end{array}$ & NEW DAMPING RATIO \\
\hline 0.25 & 0.4 & $0.10(\mathrm{~min})$ \\
\hline 0.25 & 0.6 & 0.15 \\
\hline 0.25 & 0.8 & 0.20 \\
\hline 0.25 & 1.0 & 0.25 (actual) \\
\hline 0.25 & 1.2 & 0.30 \\
\hline 0.25 & 1.4 & 0.35 \\
\hline 0.25 & 1.6 & 0.40 \\
\hline 0.25 & 1.8 & 0.45 \\
\hline 0.25 & 2.0 & 0.50 (max) \\
\hline
\end{tabular}

Table 4.2: Scale Values for Damping Variations

where, a scale value of less than 1 reduces the value and a scale value of greater than 1 increases the damping for the suspension. In total, we have 9 values for the damping for the truck.

\section{2) Scaling of Auxiliary Roll Stiffness}

Torsional stiffness for the anti-roll bar is changed using the parameter variable for torsional stiffness of the spring damper element modeled in MSC- ADAMS. The roll stiffnesses due to anti- roll bars on three suspensions are kept in the range of $+/-30$ percent as illustrated in Table 4.3. This range was selected so as to see the effect of change of roll stiffness $\left(\mathrm{RS}_{\mathrm{n}}\right)$ on the vehicle dynamics from the base values given in the modeling data for the vehicle. 


\begin{tabular}{|c|c|c|c|c|}
\hline \multicolumn{3}{|l|}{ Auxiliary Roll Stiffness } & & \\
\hline Percentage change & Axle-1 & Axle-2 & Axle-3 & \\
\hline$-30 \%$ & $-30 \% \mathbf{R . S} \mathbf{S}_{1}$ & $-30 \% \mathbf{R} . \mathbf{S}_{2}$ & $-30 \% \mathbf{R} . \mathbf{S}_{1}$ & \\
\hline$-20 \%$ & $-20 \%$ R.S & $-20 \%$ R.S & $-20 \%$ R.S.S & \\
\hline$-10 \%$ & $-10 \%$ R.S & $-10 \% \mathbf{R} . S_{1}$ & $-10 \%$ R.S.S & \\
\hline$\%$ & R.S $\mathbf{S}_{1}$ & $\mathbf{R} . \mathbf{S}_{\mathbf{2}}$ & $\mathbf{R}_{\mathbf{S}} \mathbf{S}_{\mathbf{3}}$ & $\begin{array}{l}\text { Base } \\
\text { Value }\end{array}$ \\
\hline$+10 \%$ & $+10 \% \mathbf{R} . \mathbf{S}_{1}$ & $+10 \%$ R.S.S & $+10 \% \mathbf{R} . S_{1}$ & \\
\hline$+20 \%$ & $+20 \% \overline{\text { R.S }} \mathbf{1}$ & $+20 \%$ R.S $\mathbf{S}_{2}$ & $+20 \%$ R.S & \\
\hline$+30 \%$ & $+30 \%$ R.S 1 & $+30 \%$ R.S 2 & $+30 \%$ R.S & \\
\hline
\end{tabular}

Table 4.3: Parametric Values for Auxiliary Roll Stiffness for Suspension

The total roll stiffness for a suspension is the sum of roll stiffness due to springs and the auxiliary roll stiffness. The total roll stiffness for the suspension was varied by changing the auxiliary roll stiffness $(+/-30 \%)$ of the suspension from the base value given in the modeling data. In total, we have seven (7) values for the auxiliary roll stiffness of the suspension. The change in auxiliary roll stiffness along with the damping for the vehicle resulted in a total of 63 configurations for a given spring mass and tire pressure combination.

Figure 4.3 illustrates the flow chart for the total simulations conducted for the design space exploration. Only one single connected path is shown in the flow chart corresponding to tire pressures (P) and one load (L3) combination. 


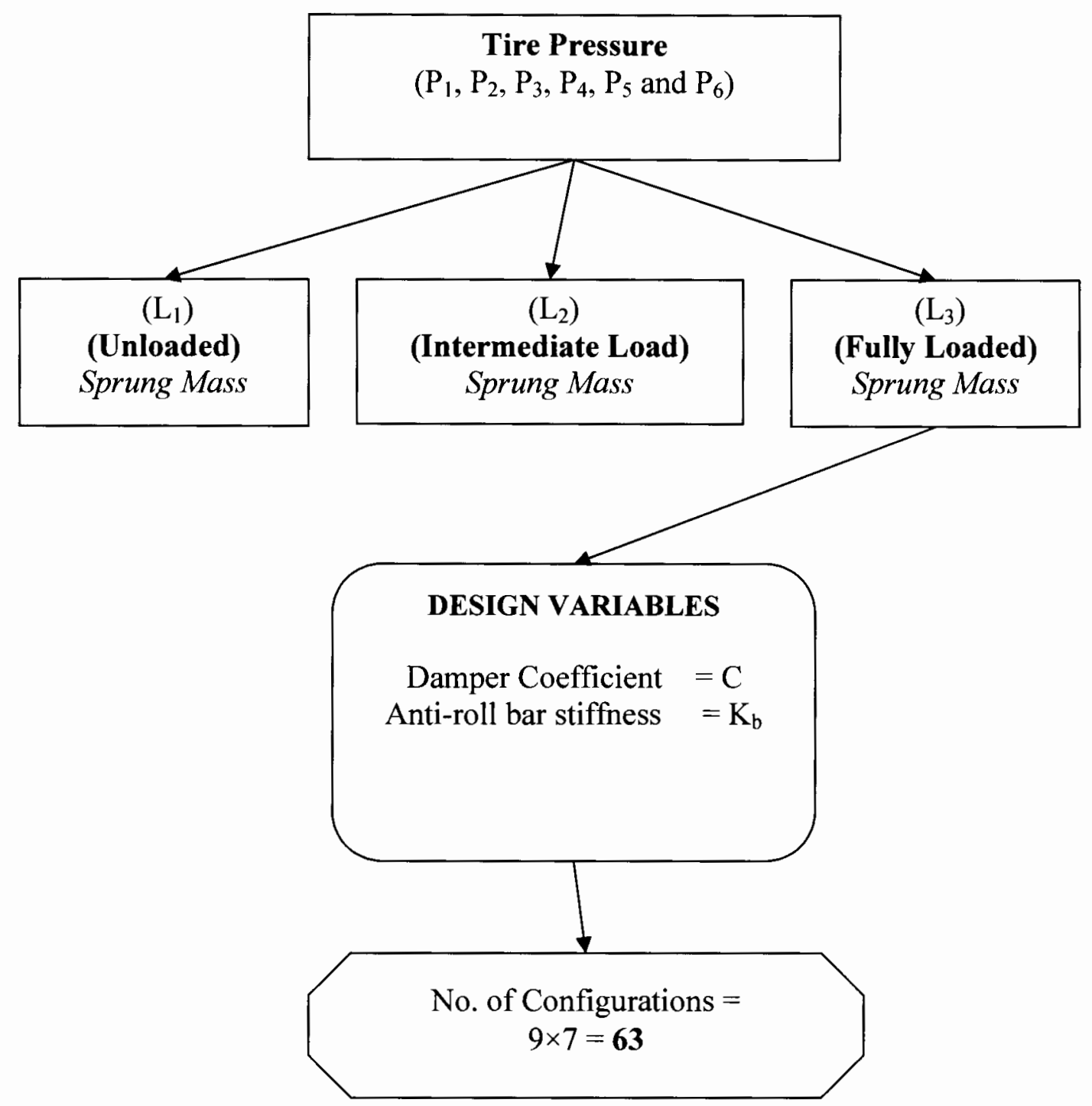

Figure 4.3: Flow Chart for an Experiment in ADAMS/Insight 
As we can see in Figure 4.3, for each pressure and load we have 63 configurations per maneuver. The flow chart of Figure 4.3 applies to each combination of sprung mass and tire pressure as shown below:
1) for $\mathrm{P}_{1}=22 \mathrm{psi} ;\left(\mathrm{P}_{1}, \mathrm{~L}_{1}\right) ;\left(\mathrm{P}_{1}, \mathrm{~L}_{2}\right) ;\left(\mathrm{P} 1, \mathrm{~L}_{3}\right)$
2) for $\mathrm{P}_{2}=29 \mathrm{psi} ;\left(\mathrm{P}_{2}, \mathrm{~L}_{1}\right) ;\left(\mathrm{P}_{2}, \mathrm{~L}_{2}\right) ;\left(\mathrm{P}_{2}, \mathrm{~L}_{3}\right)$
3) for $\mathrm{P}_{3}=37 \mathrm{psi} ;\left(\mathrm{P}_{3}, \mathrm{~L}_{1}\right) ;\left(\mathrm{P}_{3}, \mathrm{~L}_{2}\right) ;\left(\mathrm{P}_{3}, \mathrm{~L}_{3}\right)$
4) for $\mathrm{P}_{4}=44 \mathrm{psi} ;\left(\mathrm{P}_{4}, \mathrm{~L}_{1}\right) ;\left(\mathrm{P}_{4}, \mathrm{~L}_{2}\right) ;\left(\mathrm{P}_{4}, \mathrm{~L}_{3}\right)$
5) for $\mathrm{P}_{5}=60 \mathrm{psi} ;\left(\mathrm{P}_{5}, \mathrm{~L}_{1}\right) ;\left(\mathrm{P}_{5}, \mathrm{~L}_{2}\right) ;\left(\mathrm{P}_{5}, \mathrm{~L}_{3}\right)$
6) for $\mathrm{P}_{6}=72 \mathrm{psi} ;\left(\mathrm{P}_{6}, \mathrm{~L}_{1}\right) ;\left(\mathrm{P}_{6}, \mathrm{~L}_{2}\right) ;\left(\mathrm{P}_{6}, \mathrm{~L}_{3}\right)$

For every P, L combination we have 63 configurations which depend on the two design variables and the values we have chosen for them (Table 4.2 and 4.3). This will result in 1134 simulations per maneuver. As we conducted two maneuvers in this research, one for ride and the other for handling, we need to perform a total of 2268 simulations for the vehicle.

\subsection{Selection of Inputs for the Design Study}

Inputs for the simulation are the selected roads and maneuvers along with the specified initial conditions for the maneuvers. For ride and handling maneuvers, different inputs were selected which are explained as follows.

For ride evaluation, we use the data provided by the U.S.Army TACOM for secondary and cross country roads. This data is in the form of $\mathrm{X}$ (longitudinal) vs. $\mathrm{Z}$ (vertical) for the left and right side of the vehicle. The track width of the profilometer used was 4 feet. Road sections were taken from different types of terrains and then 
combined to form a single road file for ride evaluation. Figure 4.4 illustrates the distribution of the road sections used to make the road profile used for ride analysis.

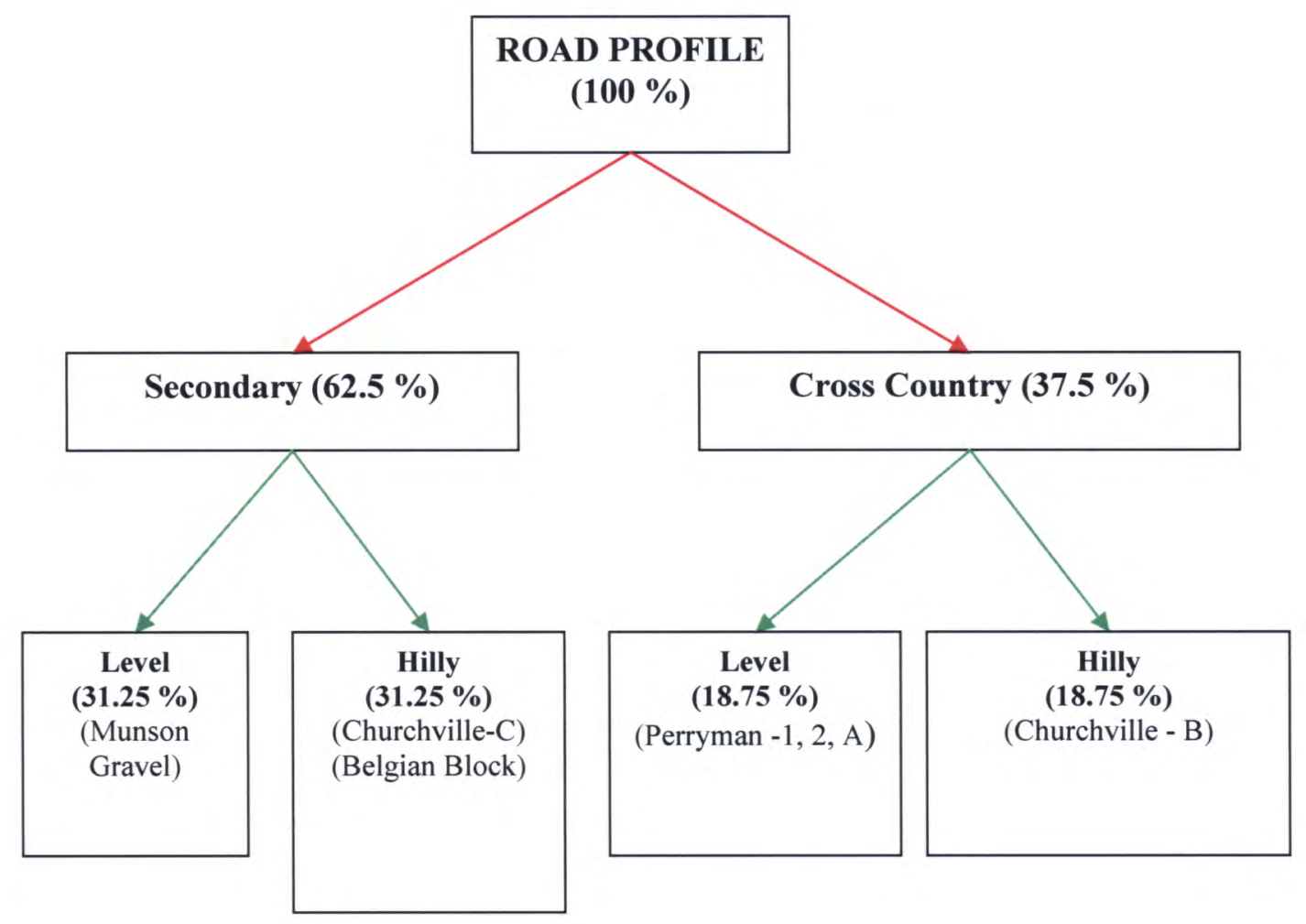

Figure 4.4: Road Profile for Ride Analysis

Figure 4.5 illustrates the vertical vs. longitudinal displacement of the road in feet. A total length of 1000 feet was used for ride analysis of the truck. The grade was taken out from the road sections by subtracting the average value of the vertical displacement from the actual displacement for the selected road sections from different terrains. 


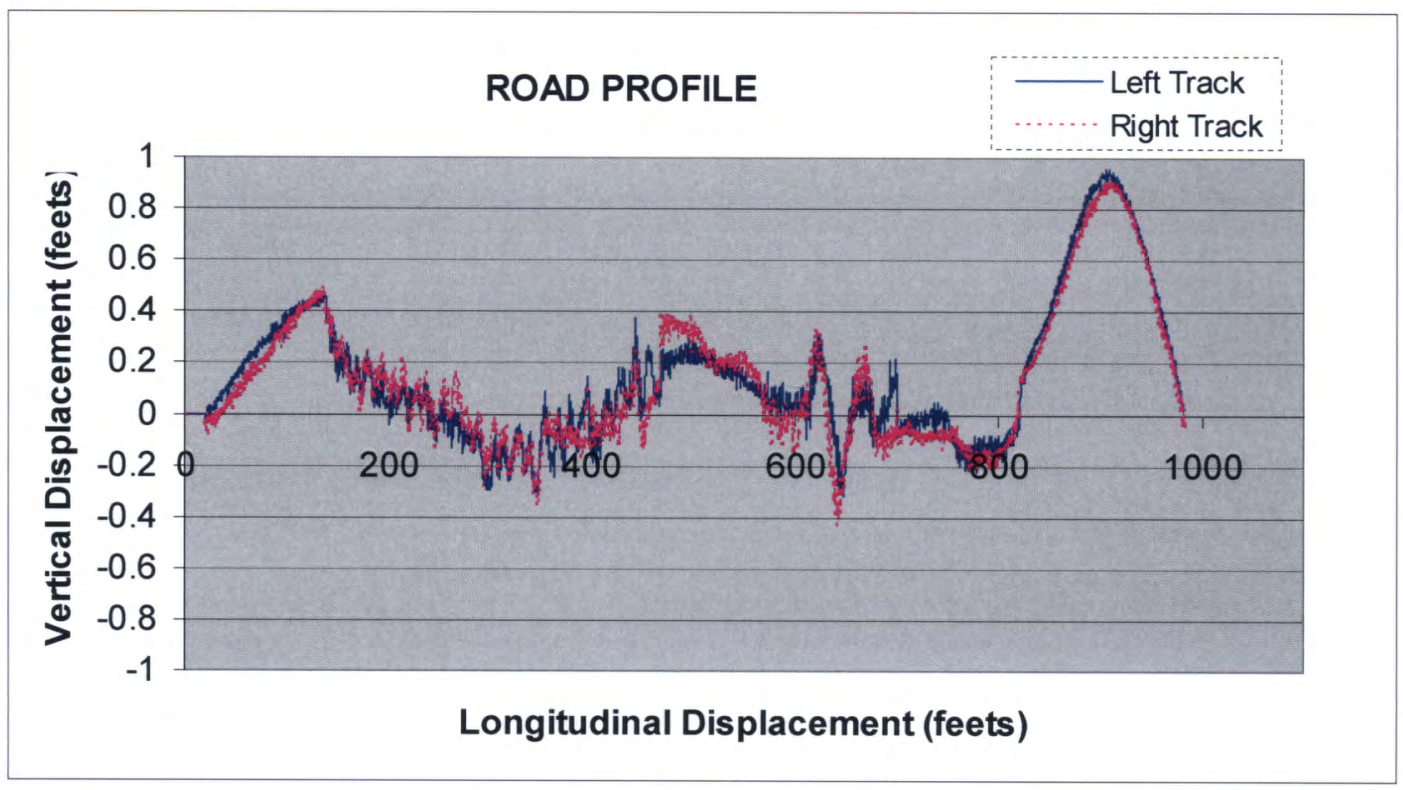

Figure 4.5: Road Profile for Left and Right Track

For handling evaluation, we use the $2 \mathrm{D}$ flat road provided in the ADAMS database to do the ISO lane change maneuver. The speed for the ISO lane change is $50 \mathrm{~km} / \mathrm{h}$ and for the ride analysis the speed is $40.3 \mathrm{~km} / \mathrm{h}$.

\subsection{Selection of Responses used to evaluate the Design Candidates}

The selection of measures or responses involves selecting important metrics that are used to evaluate design candidates in the large design space. In this study, design metrics are divided in two categories to evaluate the performance of the vehicle. One category includes measures related to the ride of the vehicle and the other category includes handling measures of the cargo truck. Responses or metrics for both of the categories are discussed below with example simulations. 


\section{(A) RIDE}

To evaluate the ride quality, we use the following measures:

R1) RMS Chassis Vertical Acceleration

R2) Peak Chassis Vertical Acceleration (maximum absolute value)

R3) Peak Chassis Pitch Acceleration (maximum absolute value)

R4) Peak Chassis Roll Angle (maximum absolute value)

\section{R1) RMS Chassis Vertical Acceleration (Sprung Mass)}

Equation 4.6 illustrates the mathematical way to find the RMS acceleration $(\tilde{a})$ values when discrete accelerations values are available for the test performed.

$$
\text { RMS Acceleration }=\widetilde{a}=\sqrt{\left\langle x^{2}\right\rangle}=\sqrt{\frac{\sum_{i=1}^{n} x_{i}^{2}}{n}}
$$

where;

$x_{1}, x_{2}$ to $x_{\mathrm{n}}$ are discrete values of accelerations for the test conducted

$\mathrm{n}=$ total number of accelerations measured for the test

$\left\langle x^{2}\right\rangle=$ Mean squared value for acceleration 
This RMS acceleration (Eq. 4.6, Figure 4.6) obtained is then divided by acceleration due to gravity, g, to the obtain RMS acceleration in g's which is used extensively as a measure of ride. Minimum RMS chassis vertical accelerations are preferred for better comfort.

\section{R2) Peak Chassis Vertical Acceleration (maximum absolute value)}

The peak chassis vertical acceleration $\left(\ddot{z}_{\text {peak }}\right)$ corresponds to the maximum absolute value obtained for the linear acceleration in the vertical (z) direction for the chassis. Figure 4.6 illustrates this value in a sample simulation. Minimum peak chassis vertical accelerations are preferred for better comfort.

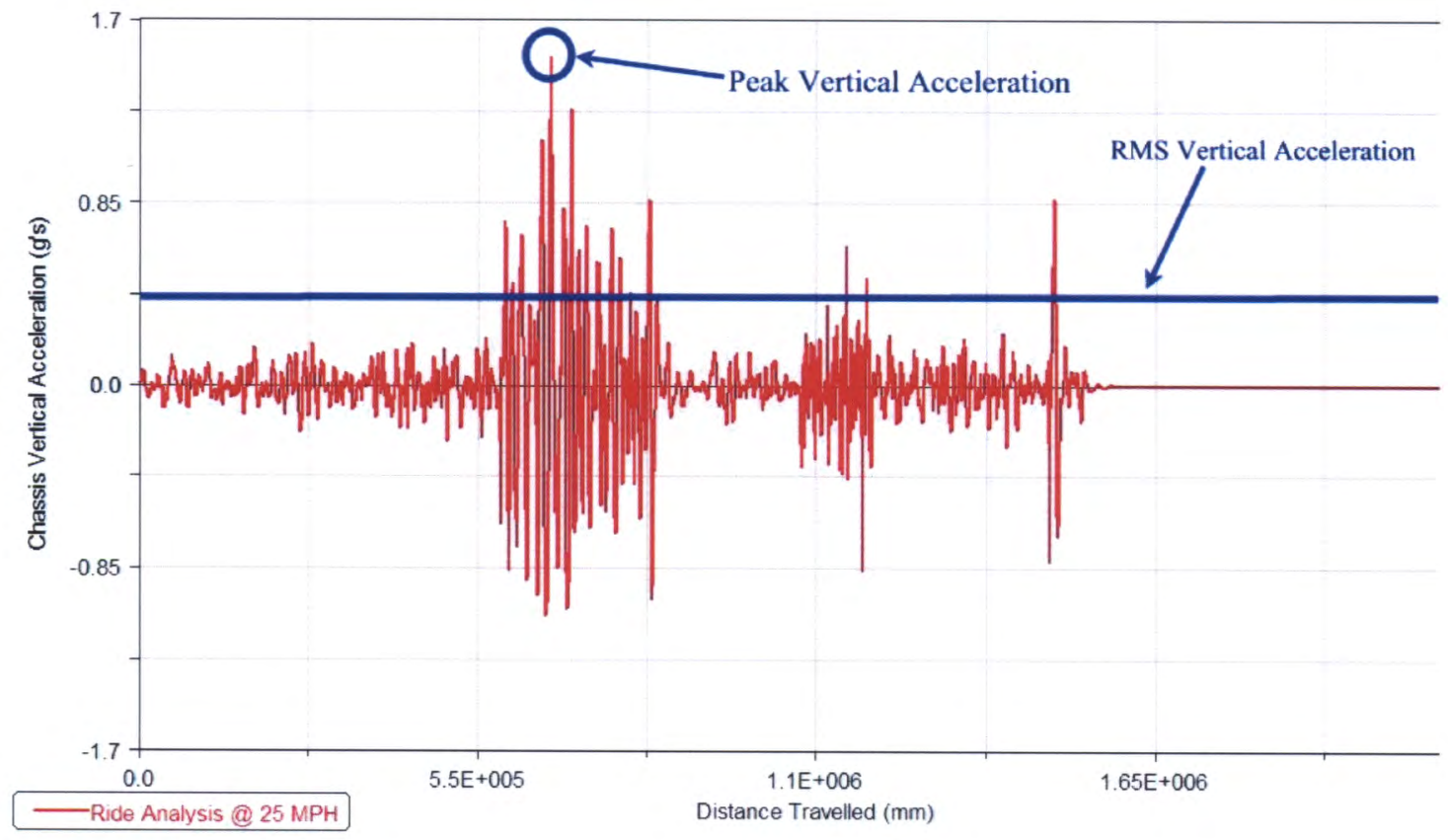

Figure 4.6: Chassis Vertical Acceleration (in g's) for illustration purpose 
Since the whole sprung mass was represented by a single rigid body, the accelerations were measured at the CG of the chassis (total sprung mass). It will be most appropriate to measure the accelerations at the driver's seat if the modeling data was available for seat and cab separately.

\section{R3) Peak Chassis Pitch Acceleration (maximum absolute value)}

The peak chassis pitch acceleration $\left(\dot{q}_{\text {peak }}\right)$ is the maximum absolute value of angular acceleration of the sprung mass about the lateral axis of the vehicle. This gives an indication of the extreme pitching the vehicle is exposed to on a rough road. Minimum chassis pitch accelerations are preferred.

\section{R4) Peak Chassis Roll Angle (maximum absolute value)}

The peak chassis pitch roll angle $\left(\phi_{\text {peak }}\right)$ is the maximum absolute value of the angular displacement of the sprung mass about the longitudinal axis of the vehicle. This gives an indication of the extreme roll experienced by the vehicle when it is exposed to rough roads. Minimum chassis roll angles are preferred.

Peak values for the measures are chosen since they correspond to the worst scenario in a maneuver. Our goal is to minimize these values for a vehicle so as to optimize the ride and handling for the truck. 


\section{(B) HANDLING}

To evaluate the handling, the following metrics are used in the design space exploration of the cargo truck.

H1) Chassis Peak Lateral Acceleration

H2) Chassis Peak Yaw Rates

H3) Chassis Peak Roll Acceleration

H4) Peak Percentage Lateral Load Transfer (PLLT)

H5) Understeer Measure - difference between first and third axle slip angles (If positive - Understeer and If negative - oversteer)

\section{H1) Peak Chassis Lateral Acceleration}

Lateral acceleration is the component of the vector acceleration of a point in the vehicle perpendicular to the vehicle $\mathrm{x}$-axis and parallel to the road plane. Peak chassis lateral acceleration $\left(\ddot{y}_{\text {peak }}\right)$ gives a good concept about the stability of the vehicle during cornering. Smaller values of chassis lateral accelerations are preferred.

\section{H2) Peak Chassis Yaw Rates}

Yaw velocity (r) of the vehicle is the angular velocity of the vehicle about the vertical axis. Peak chassis yaw rates $\left(r_{\text {peak }}\right)$ gives a good idea about the yaw response of the vehicle during a turn. Smaller values are preferred to improve yaw stability for the vehicle. 


\section{H3) Peak Chassis Roll Acceleration}

Roll acceleration $\left(\ddot{\phi}_{\text {peak }}\right)$ is the angular acceleration of the vehicle about its longitudinal axis. This is primarily a measure of driver's comfort during a turn. Low roll acceleration are preferred for the vehicle.

\section{H4) Total Percentage Lateral Load Transfer (TPLLT)}

The lateral load transfer occurs in a vehicle during a cornering. The load transfer occurs due to two mechanisms as discussed below [1].

a) Lateral Load transfer due to cornering forces. This arises from the lateral force imposed on the axle, and is thus an instantaneous effect. It is independent of the roll angle of the body and the roll moment distribution.

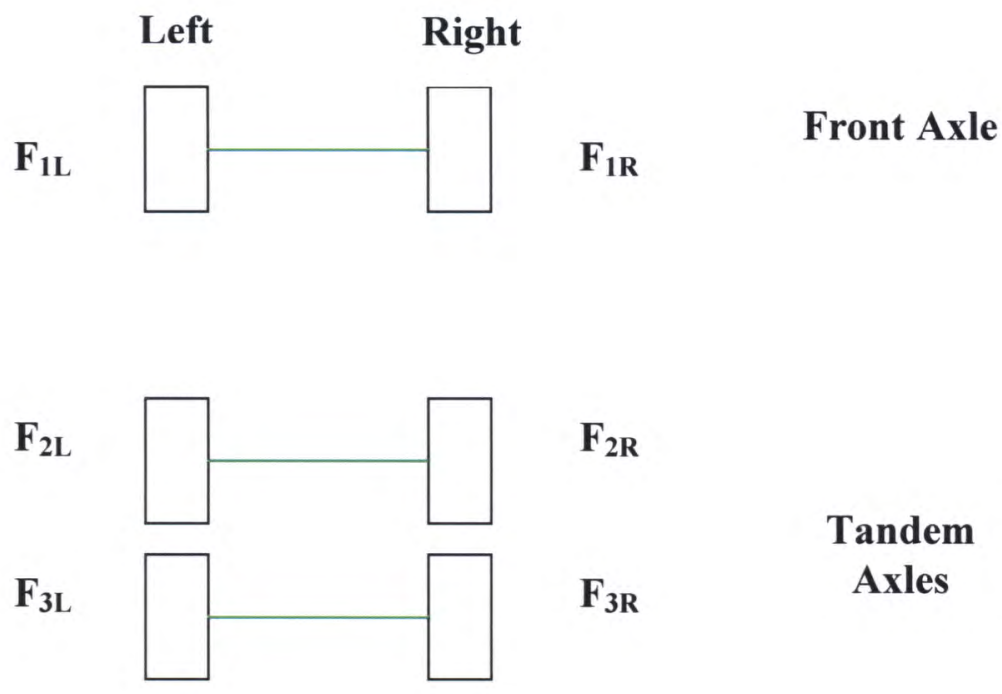

Figure 4.7: Vehicle Layout 
The peak percentage lateral load transfer at the front and the tandem suspension during the ISO lane change maneuver is given as;

$\underline{\text { Peak Percentage Front Lateral Load Transfer (PPFLLT) }}$

PPFLLT $=\left\langle\frac{\mathrm{F}_{1 L \max }-\mathrm{F}_{1 \mathrm{Rmin}}}{\mathrm{F}}\right\rangle * 100$

Peak Percentage Rear Lateral Load Transfer (PPRLLT)

$P P R L L T=\left\langle\frac{\mathrm{F}_{2 \mathrm{Lmax}}+\mathrm{F}_{3 \mathrm{Lmax}}-\mathrm{F}_{2 \mathrm{R} \min }-\mathrm{F}_{3 \mathrm{R} \min }}{\mathrm{F}}\right\rangle * 100$

where;

Total vehicle load $=F=F_{1 L}+F_{2 L}+F_{3 L}+F_{1 R}+F_{2 R}+F_{3 R}$ $F_{i L / R}=$ Normal force acting on tires $(i=1$ to 6$)$

If we calculate the instantaneous variations for normal load on tires during the maneuver, the maximum load transfer corresponds to the value calculated in Equation 4.7 and 4.8 for the ISO lane change maneuver. The sum of Equation 4.7 and 4.8 gives the Total Lateral Load Transfer (TLLT) which occurs in the handling maneuver. This total load transfer was used as a metric for which minimum values are preferred. Figure 4.8 illustrates the tire normal forces acting on the left and right side of the vehicle during an ISO Lane change maneuver for vehicle at GVW with a speed of $50 \mathrm{~km} / \mathrm{h}$.

The difference between maximum value of tire normal forces for the left tire and the minimum value of tire normal forces for the right tire gives the value corresponding 
to the maximum load transfer that occurs during the ISO lane change maneuver. This value when divided by the total vehicle weight gives us the maximum percentage lateral load transfer that occurs on the front and the tandem suspension for the vehicle. Minimum lateral load transfer is preferred for better stability of the vehicle during cornering. Usually, the maximum cornering force per unit load occurs at the lightest loads [1]. This lateral load transfer, especially for the heavy duty vehicle (higher vehicle CG's), if not controlled during a cornering, can ultimately result in rollover for the vehicle.

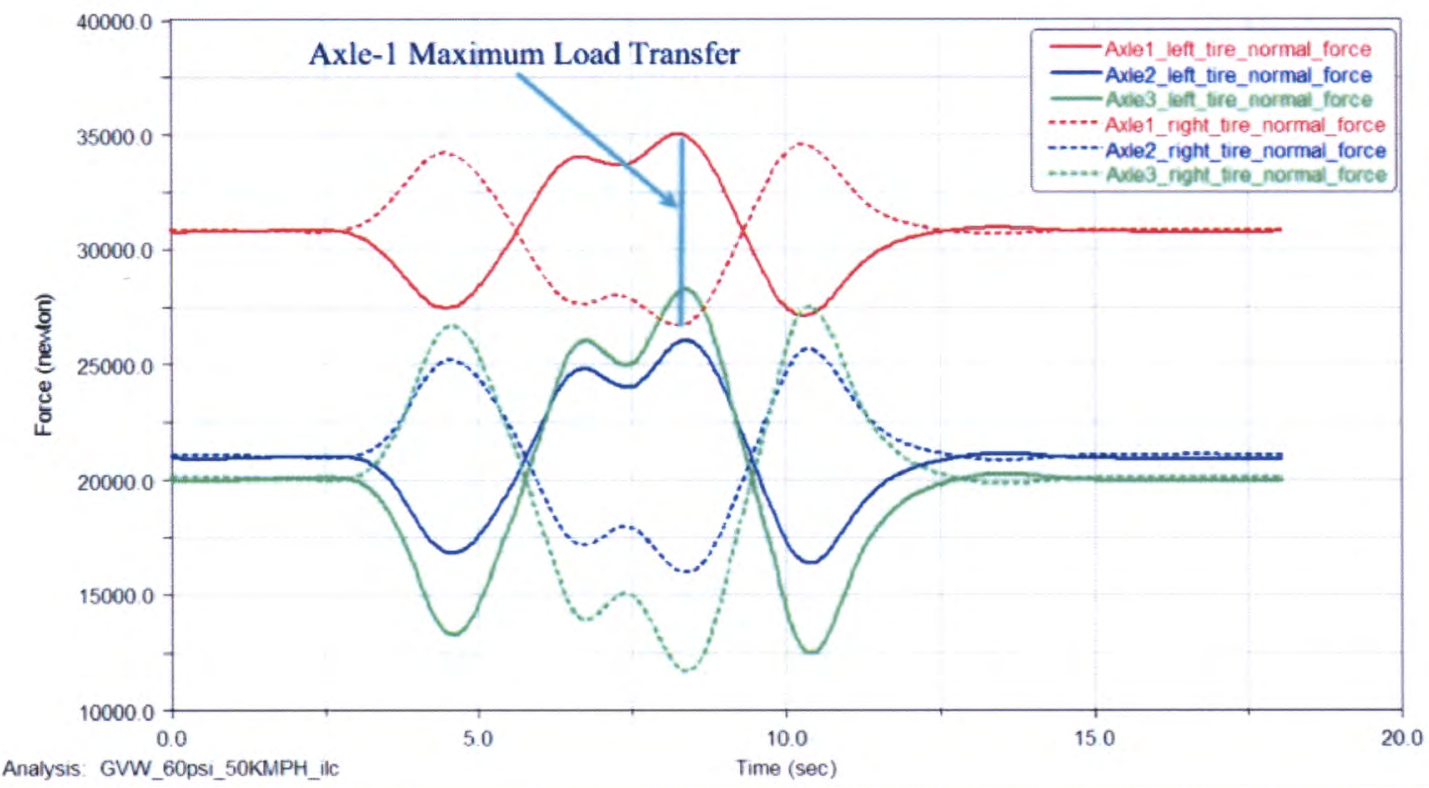

Figure 4.8: Tire Normal Forces in ISO Lane Change for GVW - for illustration purpose

\section{H5) Understeer Measure (UM)}

The angle between the vehicle's direction of heading and its direction of travel is called tire lateral slip. In the steady state cornering, for this vehicle, if the difference 
between the first and third tire lateral slip is positive, the vehicle understeers and if it is negative, the vehicle oversteers. The magnitude of the difference is a measure of extent of understeer or oversteers. Generally for safety purposes an understeer vehicle is preferred. Figure 4.9 illustrates the lateral tire slips obtained for the right side of the vehicle for axle-1 and axle-3. As we can see, in this case the difference between first and third tire lateral slip is negative, thus the vehicle oversteers. This measure is not used in the design space exploration since the variation in the value for the understeer measure is negligible and the vehicle always oversteers for the chosen design parameters.

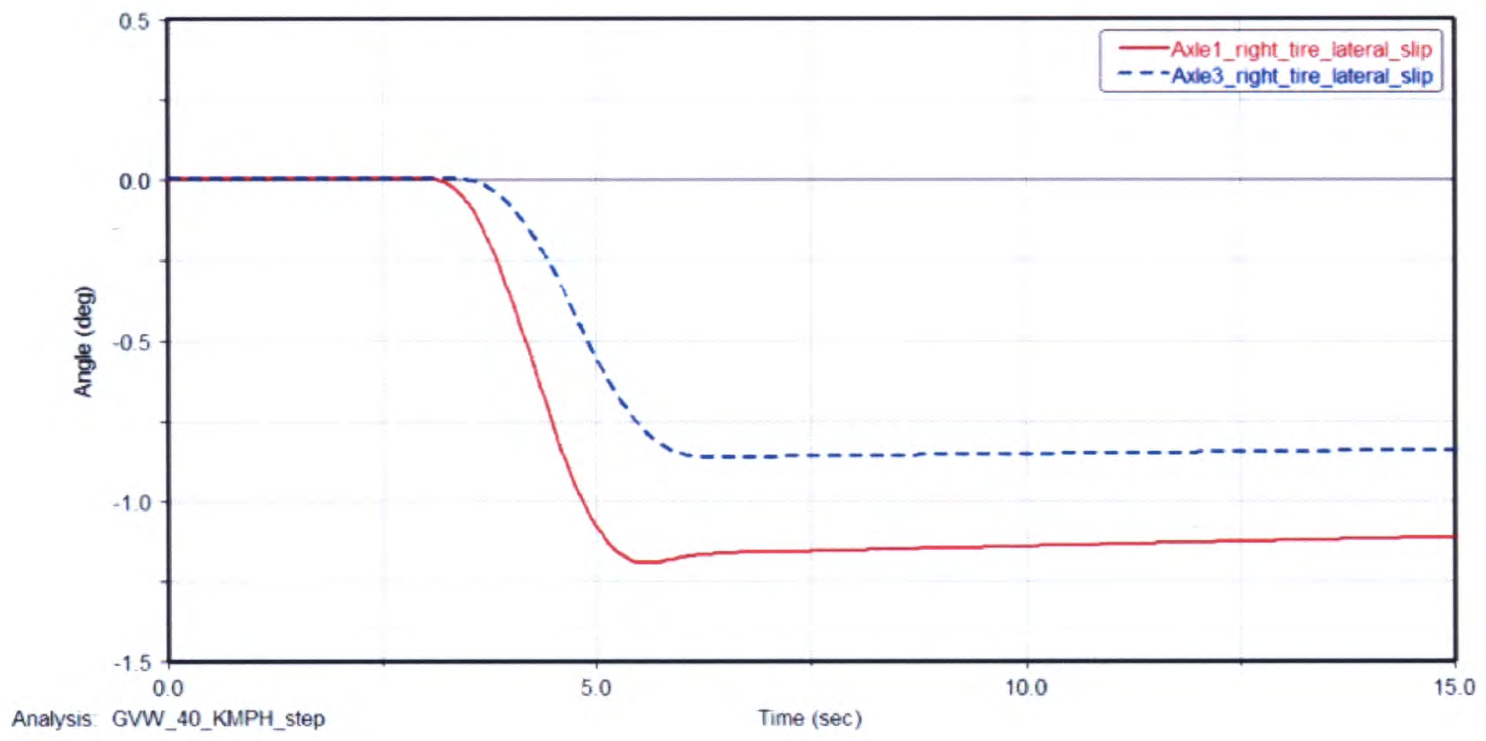

Figure 4.9: Tire Lateral Slip in Step Steer Analysis for GVW - for illustration purpose 


\begin{tabular}{|c|l|c|c|}
\hline S.No. & \multicolumn{1}{|c|}{ Ride Metric } & Value & Units \\
\hline R1 & RMS Chassis Vertical Acceleration & (RMS) & (g's) \\
\hline R2 & Peak Chassis Vertical Acceleration & $\begin{array}{c}\text { (Maximum } \\
\text { absolute value) }\end{array}$ & (g's) \\
\hline R4 & Peak Chassis Pitch Acceleration & $\begin{array}{c}\text { (Maximum } \\
\text { absolute value) }\end{array}$ & $\left(\mathrm{rad} / \mathrm{sec}^{2}\right)$ \\
\hline R23 & Peak Chassis Roll Angle & $\begin{array}{c}\text { (Maximum } \\
\text { absolute value) }\end{array}$ & $(\mathrm{deg})$ \\
\hline
\end{tabular}

Table 4.4: Ride Metrics to evaluate Design Candidates

\begin{tabular}{|c|l|c|c|}
\hline S.No & \multicolumn{1}{|c|}{ Handling Metric } & Value & Units \\
\hline H1 & Peak Chassis Lateral acceleration & $\begin{array}{c}\text { (Maximum } \\
\text { absolute value) }\end{array}$ & $(\mathrm{g}$ 's $)$ \\
\hline H2 & Peak Chassis Yaw rate & $\begin{array}{c}\text { (Maximum } \\
\text { absolute value) }\end{array}$ & $(\mathrm{deg} / \mathrm{sec})$ \\
\hline H3 & Peak Chassis Roll Acceleration & $\begin{array}{c}\text { (Maximum } \\
\text { absolute value) }\end{array}$ & $\left(\mathrm{deg} / \mathrm{sec}^{2}\right)$ \\
\hline H4 & Peak Percentage Lateral Load Transfer & $\begin{array}{c}\text { (Maximum } \\
\text { absolute value) }\end{array}$ & $(\%)$ \\
\hline
\end{tabular}

Table 4.5: Handling Metrics to evaluate Design Candidates 


\subsection{Generation of Different Configurations for the Modified Vehicle}

The parameters used are of two types, one which changes during the simulations and the others which remain constant. They were discussed in detail in section 4.3 . The design parameters which change during a set of simulations include damping scale values and the scale values for torsional stiffness of the Anti-roll bars. For every combination of tire pressure and sprung mass, there are 63 different configurations. For six different tire pressures $(22,29,37,44,60,72$ psi) and 3 sprung masses (CVW, Intermediate, GVW), we have 1134 different simulations for the truck. Tests were done for ride and handling evaluation for these parametric variations, which resulted in a total of 2268 different simulations for the study. ADAMS generates the script for a particular maneuver with a fixed sprung mass and tire pressure for the vehicle. After the script is generated, it is exported to ADAMS/Insight after defining the design objectives in ADAMS/Car environment. In ADAMS/ Insight, design values for the parameters (or factors) are set. ADAMS/Insight then run the simulations for every combination of the parameters in the design matrix and calculates the desired responses or measures for all the simulations. The entire process will be discussed below in details.

\subsubsection{Defining Factors}

A factor represents the variable or parameter in the experiment. They act as input to the system. They are used to generate different configurations of the 
vehicle. Factors can be defined individually or as a tie. Factors defined as a tie do not vary with respect to each other during the simulations. On the other side, factors in different ties change with each other to generate different configurations. Two factor ties were considered for this study. Figure 4.10 illustrates the ties used for the design study conducted for the MTV cargo truck. They take the values so as to obtain the parametric values illustrated in Table 4.3 and 4.4. Roll and vertical force analysis is used to obtain the desired changes (Table 4.3) for the roll stiffness of the front and rear suspension for the truck.

\begin{tabular}{|c|}
\hline Tie_ARB \\
Axle1 Anti-roll bar torsional stiffness \\
Axle2 Anti-roll bar torsional stiffness \\
Axle3 Anti-roll bar torsional stiffness \\
\hline
\end{tabular}

\begin{tabular}{|c|}
\hline Tie_Damper \\
Axle1 Left Damper \\
Axle1 Right Damper \\
Axle2 Left Damper \\
Axle2 Right Damper \\
Axle2 Left Damper \\
Axle2 Right Damper \\
\hline
\end{tabular}

Figure 4.10: Ties and Factors for the Work Space 


\subsubsection{Specifying Responses for the Simulations}

Responses are defined to evaluate the ride and handling of the design candidates in the design space. Measures used for evaluating ride and handling of the truck are discussed in details in section 4.5. Table 4.4 and 4.5 illustrates the ride and handling metrics used for this research.

\subsubsection{Specification of the Design Space}

A response surface method (RSM) was used as the investigating strategy for this research. A cubic model along with a full-factorial design type was

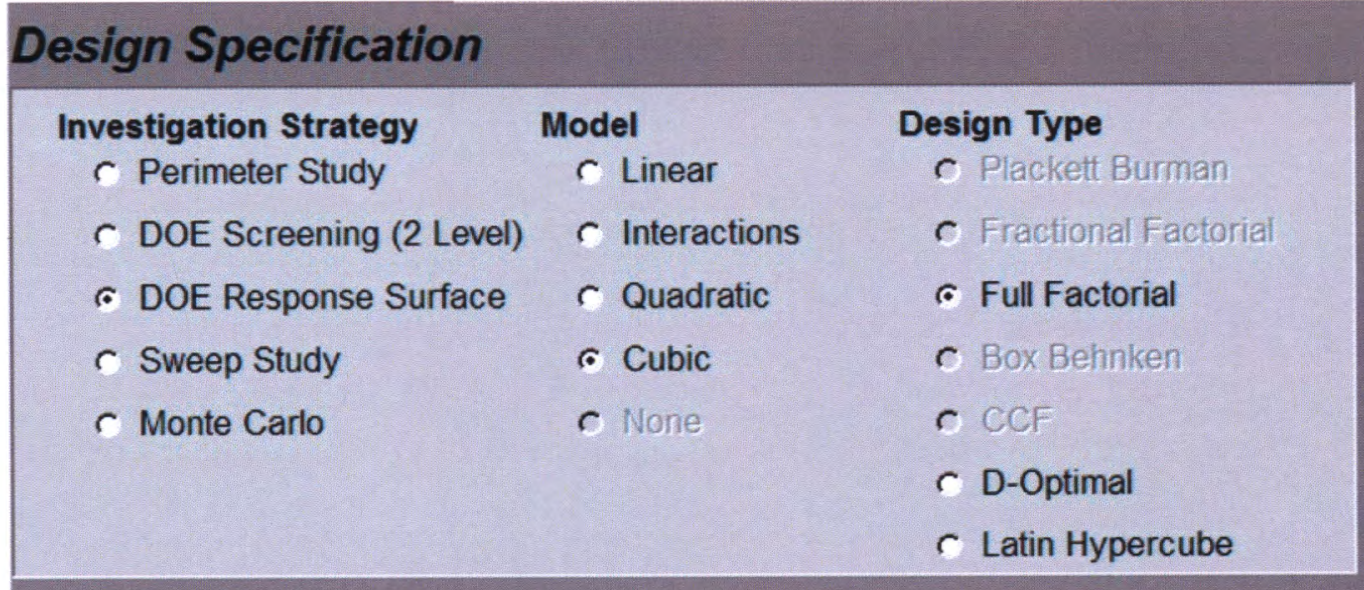

\section{Candidate Runs}

6 All

c Random

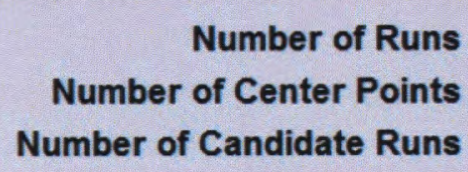

100 100

\section{Run Order}

6. Standard

c Random

c Ease of Adjustment

Figure 4.11: Design Specification 
chosen to do the number of runs for the defined parameters range. The design specification for the study is illustrated in Figure 4.11.

\subsubsection{Generating Workspace}

After the design specification, the next step was to create a workspace.

Workspace is a matrix with the columns representing the factors and responses, and the row indicating the runs or trials. In this study, two design workspaces were constructed, one for ride analysis and one for the handling. Figure 4.12 illustrates the workspace for ride analysis. Trial number in the first column represents the total runs for the experiment. Tie_ARB and Tie_Damper are the factors which are explained in section 4.6.1 and represent the design parameters for the experiment. The columns selected by a rectangle illustrate the responses used for the ride evaluation for the truck. The 63 configurations in the matrix are for a single sprung mass and tire pressure combination. This matrix repeats for every sprung mass and tire pressure combination. 
Elle Edt Define 0 sal Tools Help

\begin{tabular}{|c|c|c|c|c|c|c|c|c|}
\hline \multirow{3}{*}{ 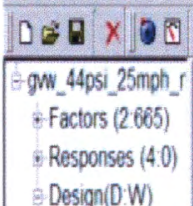 } & \multicolumn{8}{|c|}{ Work Space } \\
\hline & & Trial & Tie damper & Tie arb & Peak Chassis Pitch Acceleration & Peak Chassis Rol Acceleration & Peak Chassis Roll Angle & Peak Chassis Vertical Accel \\
\hline & 1 & Trial 1 & 04 & 06557 & 266912 & 142235 & 00633243 & 0338112 \\
\hline Soecification & 2 & Trial 2 & 04 & 0.7705 & 265714 & 1.50859 & 00659161 & 0339298 \\
\hline - Inclusions & 3 & Thal 3 & 0.4 & 0.8952 & 266535 & 157720 & 0.0683577 & 0336001 \\
\hline - incusionts & 4 & Trial 4 & 04 & 1 & 264315 & 1.61561 & 0,0679318 & 0.339289 \\
\hline - Design Space & 5 & Trial 5 & 0.4 & 1.1147 & 2.63715 & 1.6481 & 0.0685372 & 0.339347 \\
\hline Work Space & 6 & Trial 6 & 0.4 & 1.2295 & 2.63347 & 167415 & 0.0704206 & 0.339476 \\
\hline Work Space R & $\frac{1}{7}$ & Trial $?$ & 04 & $1.3442 \pi$ & 2.62903 & 168674 & 00703559 & 0339631 \\
\hline - Simulation & 8 & Trial 8 & 0.6 & 0.6557 & 239609 & 120547 & 00582949 & 0339429 \\
\hline Analysis & 9 & Thal ? & 0.6 & 0.7706 & 23982 & 127115 & 00606298 & 0.339304 \\
\hline & 10 & Trial 10 & 06 & 0.8852 & 239858 & 1.32338 & 00624408 & 0.339252 \\
\hline & 荘 & $\begin{array}{l}T=1 \\
T=10\end{array}$ & $A A$ & $\therefore$ ing & 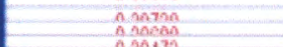 & 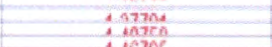 & $\begin{array}{l}\text { A somertan } \\
\text { Anerts }\end{array}$ & $\begin{array}{l}\text { Amanom } \\
\text { Anapses }\end{array}$ \\
\hline & $\frac{1+2}{4}$ & 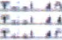 & $\frac{A A}{A A}$ & 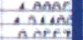 & 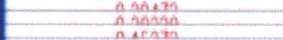 & $\begin{array}{l}1 \text { nimase } \\
i \text { thate }\end{array}$ & 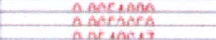 & 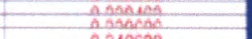 \\
\hline & 要 & $\begin{array}{l}x+1 \\
T=10 \\
T=17\end{array}$ & $\begin{array}{l}\hat{n} \\
\hat{n} \hat{n}\end{array}$ & 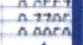 & 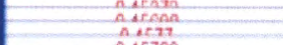 & 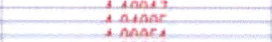 & 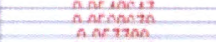 & 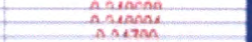 \\
\hline & $\frac{10}{10}$ & $\begin{array}{ll}T=1 \\
T=1\end{array}$ & $\hat{n}$ & $\therefore A 7$ & nicron & 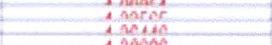 & 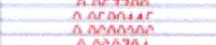 & 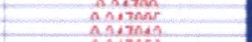 \\
\hline & in & 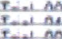 & $\begin{array}{l}A B \\
A A\end{array}$ & 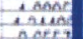 & 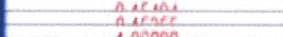 & $\begin{array}{l}\text { a sation } \\
\text { I tangas }\end{array}$ & 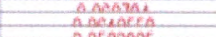 & 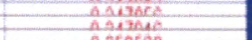 \\
\hline & 要 & 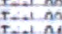 & $i$ & nathen & 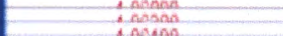 & 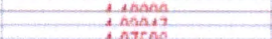 & 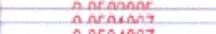 & 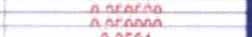 \\
\hline & $\frac{a}{m}$ & 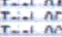 & $i$ & $\therefore$ & 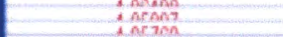 & $\begin{array}{l}\text { invano } \\
\text { inmos. }\end{array}$ & 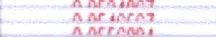 & $\begin{array}{l}\text { Anren: } \\
\text { A narman }\end{array}$ \\
\hline & in & 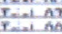 & $\because$ & $\begin{array}{l}\text { inand } \\
\text { itiug }\end{array}$ & 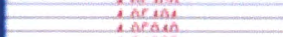 & I I Inan & 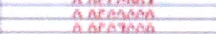 & 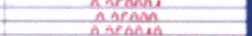 \\
\hline & 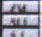 & 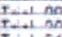 & in & 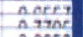 & $\begin{array}{l}\text { Inetar } \\
\text { insesi. }\end{array}$ & 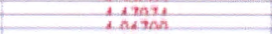 & Onectons & A nopons \\
\hline & 音 & 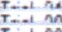 & in & Anand & $\begin{array}{l}\text { A.nowin } \\
\text { insin }\end{array}$ & 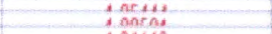 & 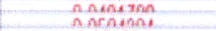 & 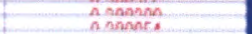 \\
\hline & $\frac{14}{x}$ & $\begin{array}{l}\text { Trial } 32 \\
\text { Trial }\end{array}$ & 12 & $\begin{array}{l}11417 \\
\text { inang }\end{array}$ & $\begin{array}{r}185170 \\
\text { i } 156600\end{array}$ & $\frac{131110}{13260}$ & 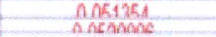 & $\frac{A 392192}{\text { A.רAA4 }}$ \\
\hline & sin & $\begin{array}{ll}x=1 \\
T=1\end{array}$ & $\ddot{i}$ & anding & $\begin{array}{l}\text { A ararz } \\
\text { ismonos }\end{array}$ & 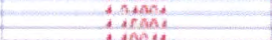 & $\begin{array}{l}\text { AnCAuACA } \\
\text { a ainamai }\end{array}$ & $\begin{array}{l}\operatorname{Anmama} \\
\operatorname{sinimpo}\end{array}$ \\
\hline & = & 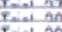 & $\because 1$ & $\begin{array}{l}A \text { nand } \\
\text { A nard }\end{array}$ & 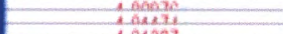 & 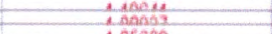 & 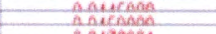 & 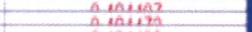 \\
\hline & 前 & $t=1$ in & $\because:$ & $\therefore$ ind & 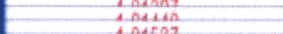 & 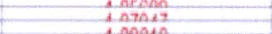 & 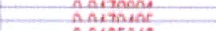 & $\begin{array}{l}\text { nimuss } \\
\text { nutasat }\end{array}$ \\
\hline & $\frac{\mu}{\mu}$ & 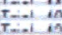 & $\because 1$ & 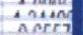 & 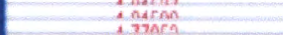 & Ansin & 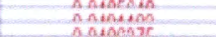 & 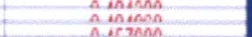 \\
\hline & min & 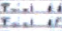 & $\therefore A$ & A mond & 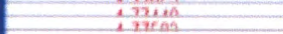 & $\begin{array}{l}\text { Then } \\
\text { ingen }\end{array}$ & Showhons & himpos \\
\hline & $\frac{m}{4}$ & 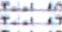 & $\therefore A$ & $\therefore$ Ant & 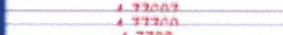 & 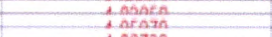 & 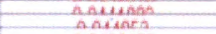 & 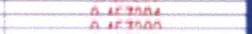 \\
\hline & $\frac{10}{24}$ & 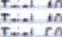 & in & 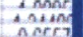 & $\begin{array}{l}\text { A. } 7 \mathrm{man} \\
\text { A } 7 \mathrm{nar} \\
\end{array}$ & $\begin{array}{l}\text { insona } \\
\text { inomar }\end{array}$ & $\begin{array}{l}\text { Anirains } \\
\text { Anisora }\end{array}$ & 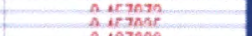 \\
\hline & 51 & Irial 51 & 18 & 0.7705 & 174931 & 1.16791 & 004045 & 0487855 \\
\hline & 52 & Trial 52 & 18 & 0.8852 & $174896^{\circ}$ & 1.19344 & 0.0409844 & 0.487879 \\
\hline & 53 & Trial 53 & 18 & 1 & 1.75015 & 1.21521 & 0.0416332 & 0.487886 \\
\hline & 54 & Trial 54 & 18 & 1.1147 & 1.75107 & 123353 & 0.0422711 & 0.487878 \\
\hline & 55 & Trial 55 & 18 & 1.2295 & 17518 & 124898 & 00428189 & 0.48780 \\
\hline & 56 & Trial 56 & 18 & 134426 & 175241 & 126191 & 0,0434759 & 0487835 \\
\hline & 57 & Irial 57 & 2 & 0.6557 & 173421 & 1.13744 & 00388764 & 0516052 \\
\hline & 58 & Trial 58 & 2 & 0.7705 & 17357 & 1.16315 & 00395027 & 0516103 \\
\hline & 59 & Trial 59 & 2 & 0.8852 & 173695 & 1.18569 & 00401204 & 0.516132 \\
\hline & 60 & Trial 60 & 2 & 1 & 1.73802 & 1.20529 & 00406975 & 0516125 \\
\hline & 61 & Trial 61 & 2 & 1.1147 & 17389 & 1.22213 & 00412148 & 0.51614 \\
\hline & 62 & Trial 62 & 2 & 1.2295 & 173964 & 1.23648 & 0.0416042 & 0516127 \\
\hline 1 & 63 & Inial 63 & 2 & 134426 & 174018 & 124874 & 00420515 & 0516104 \\
\hline
\end{tabular}

Figure 4.12: Work Space for Ride Analysis 


\subsection{Simulation of the Generated Configurations}

The simulations were run for 63 different configurations for ride and handling analysis for a single tire pressure and sprung mass combination. In total, we selected six tire pressures and three sprung masses which results in 18 different combinations for the vehicle. For these 18 different combinations, roll stiffnesses and damping values were changed in the suspension to generate 63 different configurations. In total we have 1134 different combinations for the vehicle and $1134 * 2=2268$ simulations for ride and handling analysis. The process is illustrated in Figure 4.3. ADAMS/ Insight runs the simulations for different configurations specified in work space and generates the specified responses for the maneuver. A total of 4 ride measures and 4 handling measures were chosen and combined later for every sprung mass and tire pressure combination. The work space including the factors and responses was exported as a CSV (comma separated value) file for the dynamic maneuvers. The final combined design space for ride and handling metrics is illustrated in Table 4.6. R1 to $\mathrm{R} 4$ corresponds to the four selected responses for the ride evaluation and, $\mathrm{H} 1$ to $\mathrm{H} 4$ represent the final four responses selected for the handling maneuver. As mentioned before, this design space repeats for every tire pressure and sprung mass for the vehicle. Thus, we had a total of 18 design matrices to be exported to the viewer for further analysis. 


\begin{tabular}{|c|c|c|c|c|c|c|c|c|c|c|}
\hline \multirow[t]{2}{*}{$\begin{array}{l}\text { Trial } \\
\text { No. }\end{array}$} & \multirow[t]{2}{*}{$\begin{array}{c}\text { Damping } \\
\text { Ratio }\end{array}$} & \multirow{2}{*}{$\begin{array}{c}\text { Percentage } \\
\text { Auxiliary } \\
\text { Roll } \\
\text { Stiffness- }\end{array}$} & \multicolumn{4}{|c|}{ RIDE METRICS } & \multicolumn{4}{|c|}{$\begin{array}{c}\text { HANDLING } \\
\text { METRICS }\end{array}$} \\
\hline & & & R1 & $\mathbf{R} 2$ & $\mathbf{R 3}$ & R4 & H1 & H2 & H3 & H4 \\
\hline 1 & 0.1 & $-30 \%$ & & & & & & & & \\
\hline 2 & 0.1 & $-20 \%$ & & & & & & & & \\
\hline 3 & 0.1 & $-10 \%$ & & & & & & & & \\
\hline 4 & 0.1 & $0 \%$ & & & & & & & & \\
\hline 5 & 0.1 & $+10 \%$ & & & & & & & & \\
\hline 6 & 0.1 & $+20 \%$ & & & & & & & & \\
\hline 7 & 0.1 & $+30 \%$ & & & & & & & & \\
\hline 8 & 0.15 & $-30 \%$ & & & & & & & & \\
\hline 9 & 0.15 & $-20 \%$ & & & & & & & & \\
\hline 10 & 0.15 & $-10 \%$ & & & & & & & & \\
\hline 11 & 0.15 & $0 \%$ & & & & & & & & \\
\hline 12 & 0.15 & $+10 \%$ & & & & & & & & \\
\hline 13 & 0.15 & $+20 \%$ & & & & & & & & \\
\hline 14 & 0.15 & $+30 \%$ & & & & & & & & \\
\hline 15 & 0.2 & $-30 \%$ & & & & & & & & \\
\hline 16 & 0.2 & $-20 \%$ & & & & & & & & \\
\hline 17 & 0.2 & $-10 \%$ & & & & & & & & \\
\hline 18 & 0.2 & $0 \%$ & & & & & & & & \\
\hline 18 & 0.2 & $+10 \%$ & & & & & & & & \\
\hline 20 & 0.2 & $+20 \%$ & & & & & & & & \\
\hline 21 & 0.2 & $+30 \%$ & & & & & & & & \\
\hline 22 & 0.25 & $-30 \%$ & & & & & & & & \\
\hline 23 & 0.25 & $-20 \%$ & & & & & & & & \\
\hline $24 .$. & 0.25 & $-10 \%$ & & & & & & & & \\
\hline 63 & $\ldots \ldots \ldots$ & .............. & $\ldots \ldots$ & & & & & & & \\
\hline
\end{tabular}

Table 4.6: Combined Design Matrix for Ride and Handling Maneuvers 


\subsection{Design Space Transfer to the Flexible Optimization Architecture}

The combined design matrix for the different sprung masses is then exported to the optimization architecture for further analysis. Figure 4.13 illustrates the imported design space for gross vehicle weight (GVW) in the optimization architecture. The design matrix in CSV format is exported to the flexible optimization architecture after converting it to a vdz format which is recognized by the architecture.

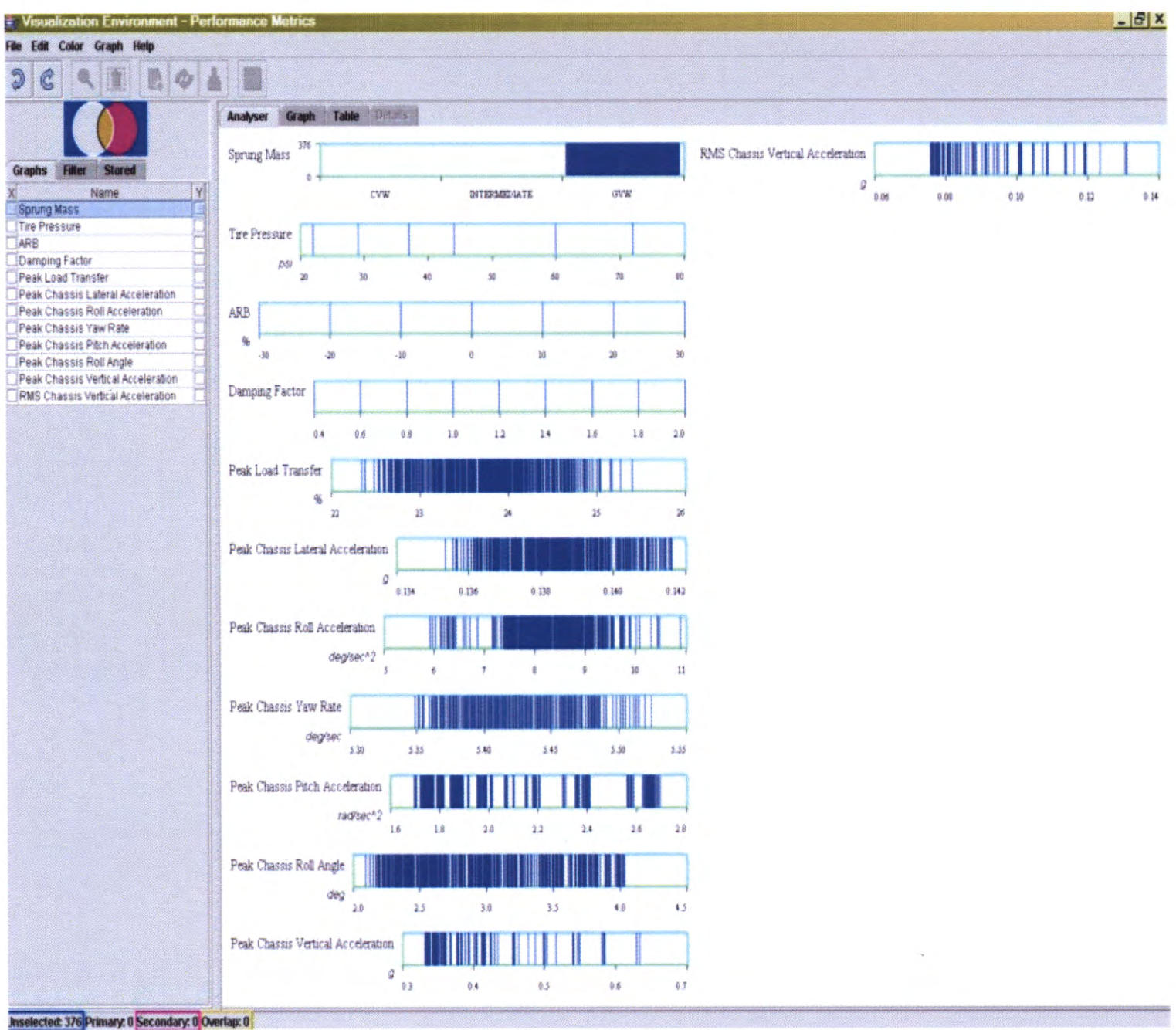

Figure 4.13: Design Space for GVW in Visualization Environment 
Figure 4.13 illustrates the analyzer which contains the design space of the vehicle for all the tire pressures and gross vehicle weight combination. The design space consists of the factors and responses as shown in the Figure 4.13. The values in the $\mathrm{x}$-axis represent the magnitude for the responses obtained during the simulations. These plots show every different configuration with a line and we can easily see the range of values obtained for different performance measures. In the left pane, we can see the list of responses for the study which can be used to plot the two dimensional scatter plots for the design parameters and/or performance measures. The Venn diagram in the top left can be used to select configurations with different characteristics and to filter the design space for the required performance characteristics in the vehicle.

\subsection{Dominance Filtering for the Design Space}

Filtering methodology is discussed in detail in Chapter 2 Section 2.8. Filtering for the design space was based on the criteria's illustrated for performance measures in Table 4.6. The downward arrow ( $\downarrow$ ) in the table corresponds to the goodness in value for the performance measure. For the selected performance measures in Table 4.6, we are interested in the lower values for them and thus the goodness for the measures was kept to be low in the filtering process. 


\begin{tabular}{|l|c|}
\hline \multicolumn{1}{|c|}{ Performance Measures } & Goodness \\
\hline Ride Measures & \\
\hline RMS Chassis Vertical Acceleration & $\downarrow$ \\
\hline Peak Chassis Vertical Acceleration & $\downarrow$ \\
\hline Peak Chassis Pitch Acceleration & $\downarrow$ \\
\hline Peak Chassis Roll Angle & $\downarrow$ \\
\hline Handling Measures & \\
\hline Peak Chassis Lateral Acceleration & $\downarrow$ \\
\hline Peak Chassis Yaw Rate & $\downarrow$ \\
\hline Peak Chassis Roll Acceleration & $\downarrow$ \\
\hline Peak Percentage Load Transfer & $\downarrow$ \\
\hline
\end{tabular}

Table 4.7: Performance Measures selected for Filtering of the Design Space

As explained before in Chapter 2 Section 2.8, only the configurations which have lower values (goodness) for all the selected performance measures are kept in the design space and other dominated candidates are filtered out. In the Figure 4.14, the gray lines correspond to the configurations which have the desired characteristics in them. Other configurations are filtered out from the design space. The total number of configurations dominated out is 42 out of the total design space. 


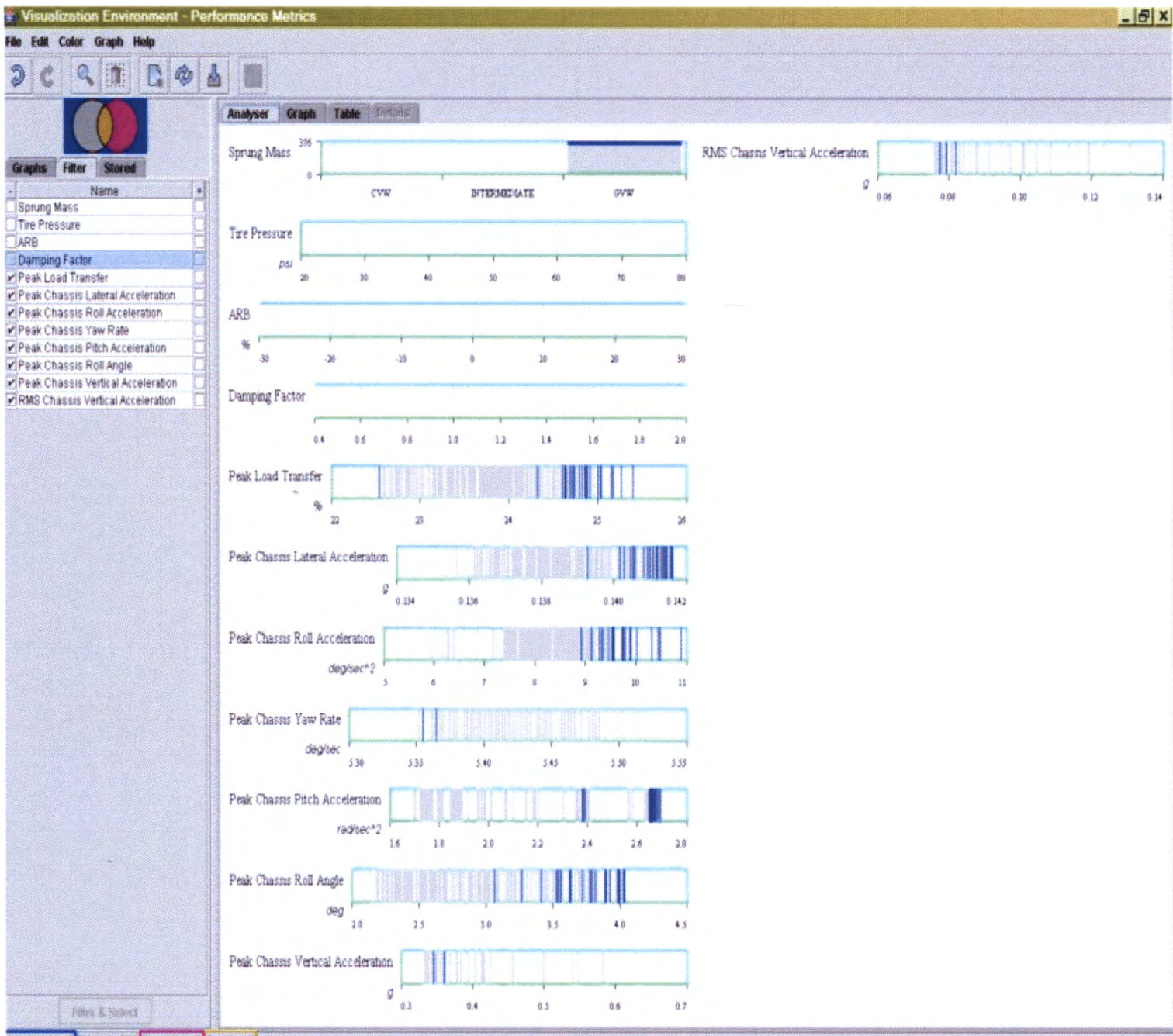

Inselected 12 Primary: 334 Secondary 0 overlar: 0

Figure 4.14: Filtered Design Space for the Gross Vehicle Weight in the Viewer 


\subsection{Selection of the Final Optimized Design based on the desired performance of the vehicle in the Viewer}

\section{Tire Inflation Pressures and Vehicle Dynamics}

It is the air pressure that creates tension in the carcass allowing the tire to function as a load-carrying device. That's why inflation is very important. The air pressure for tire of the cargo truck on highways is $60 \mathrm{psi}$ (4.14 bars). The tire does not support the load for a vehicle, the air pressure does. The maximum load and inflations pressure are critical tire design elements. They directly affect the ride and handling of the vehicle. Under inflated tires can result in improper cornering and reduce the ability of the truck to support the load. It may also cause severe tire wear at the edge of the contact patch and splitting in the sidewall. Correct tire pressures are very important for increasing tire life, good ride quality and vehicle safety. Low tire pressures allow the tire sidewalls to flex more which results in a smoother ride. On the other side, it can cause sidewalls to flex excessively which results in excessive heat build up in the tires, which can cause tire failures resulting in a total loss of control of the vehicle. Reduced tire pressures may also cause unstable handling when the vehicle is maneuvered quickly. This instability can result in rollovers for the heavy duty vehicles as they generally have a higher center of gravity while carrying heavier loads. Having the correct tire pressure is as important to off road performance as the rest of the vehicle itself. At very high pressures, the contact patch (foot print) size reduces which results in a low traction performance. On the other hand, very low tire pressures, result in the possible risk of damaging the rim or tires. To find the right tire pressure for a given loading condition is very important to fine tune the balance 
between ride and handling for the vehicle. With the right tire pressure, the flexibility of the tire and the correct foot print (contact patch) will allow the vehicle to securely grab and hold on to the terrain and as well as float on the irregular surfaces.

Central Tire Inflation Systems (CTIS) is used to control the tire pressures for the vehicle based on the terrain and loading conditions. Depending on the terrain such as snow, mud, sand and rocks, the tire inflations can be adjusted to provide the appropriate contact patch for the tires and good ride on a given terrain. Correct tire pressures for a given terrain and loading condition results in improved mobility, increased tractive effort and greater safety for the off-road vehicles. The tire pressures used for this study varied from $22 \mathrm{psi}$ to $72 \mathrm{psi}$. The selected range for tire pressures was mainly dependent on the recommended tire pressures for the different kind of terrains for the truck.

The filtered design space for the gross vehicle weight (GVW) is further analyzed in the viewer based on the selected performance measures for optimizing ride and handling of the truck. Since the change in peak lateral accelerations ( 0.13 to $0.14 \mathrm{~g}$ 's) and peak yaw rate ( 5.4 to $5.5 \mathrm{deg} / \mathrm{sec}$ ) obtained for the chassis were not significant, only peak chassis roll accelerations and peak lateral load transfers were used to do further analysis to optimize the ride and handling of the vehicle. Figure 4.15 plot-1 illustrates a tradeoff between ride and handling for the vehicle. Vehicle designers have to make a number of tradeoffs during the process of vehicle design parameter optimization. As the peak percentage total lateral load transfer (handling measure) increases, the RMS chassis vertical acceleration (ride measure) decreases and vice-versa. Since, we want to optimize 
the ride and handling for the truck, design configurations with less than $23.5 \%$ peak lateral load transfer and a RMS chassis vertical acceleration of 0.09 g's were selected for further analysis. This selection resulted in reducing the design space from 334 to 21 configurations.
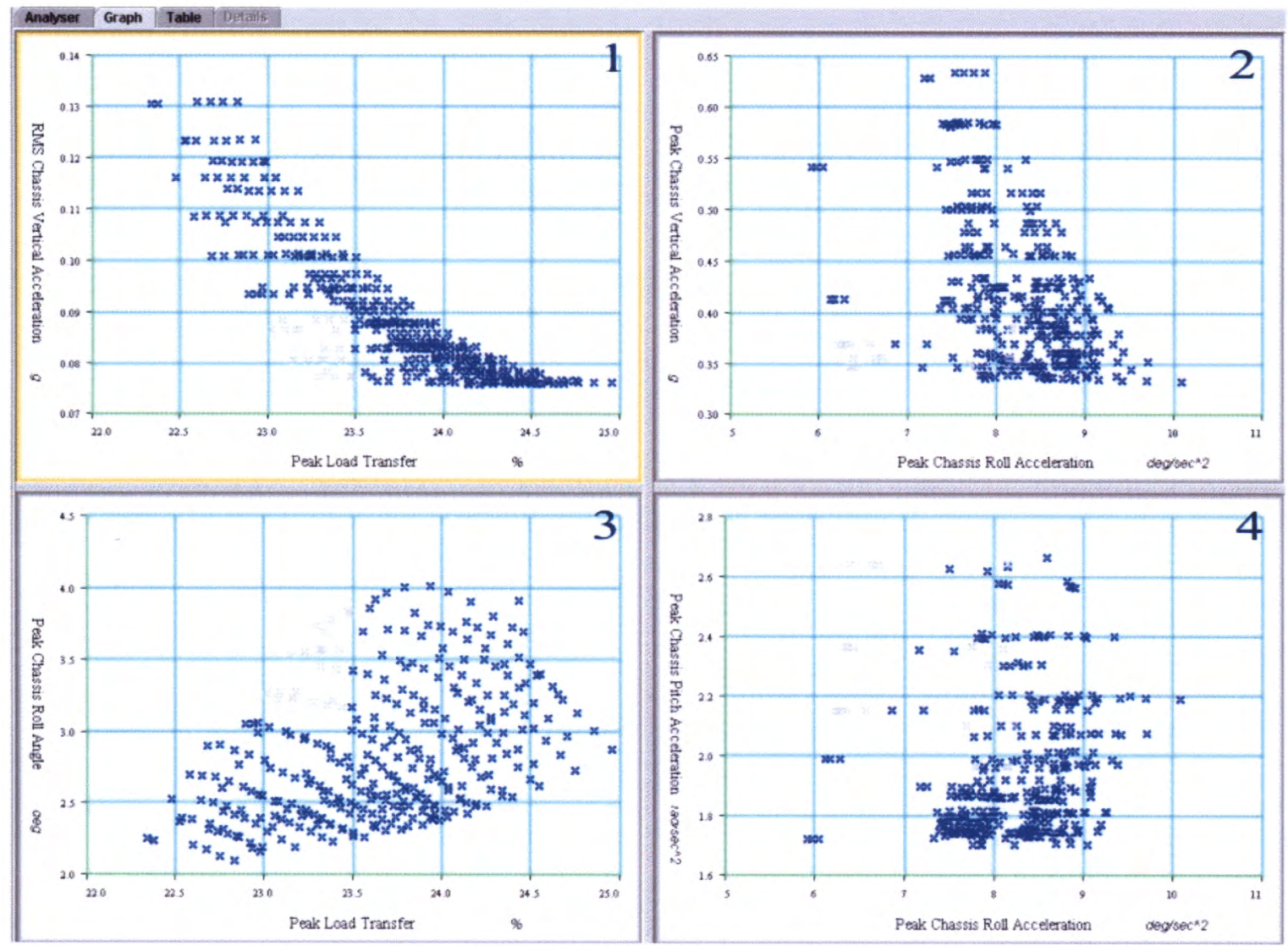

Figure 4.15: Viewer: User Selection based on RMS Chassis Vertical Acceleration and Peak Lateral Load Transfer for Gross Vehicle Weight 
Figure 4.16 illustrates a selection made in the plot-3 to minimize the peak chassis roll
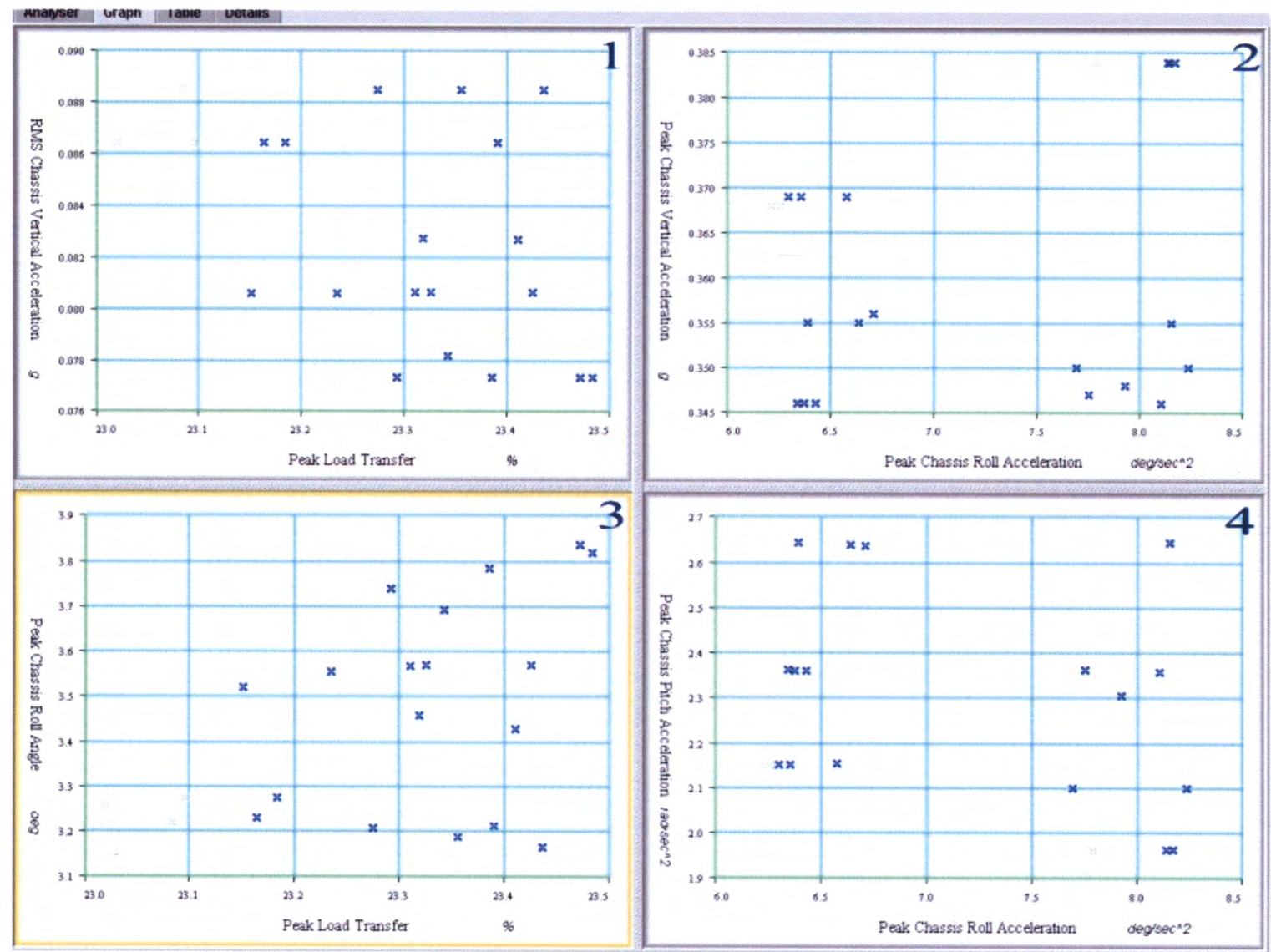

Figure 4.16: Viewer: User Selection based on Chassis Roll Angle and Lateral Load Transfer for Gross Vehicle Weight

angle obtained in the ride maneuver and the peak lateral load transfer in the handling maneuver. The selection was made so as to keep the peak roll angles less than $3.3 \mathrm{deg}$ and to obtain the peak total lateral load transfer less than $23.1 \%$. This resulted in reducing the design space from 21 to 3 configurations. Finally out of these remaining 3 design configurations, the design configuration with the minimum chassis roll acceleration is selected. This configuration corresponds to a tire pressure of 72 psi. The 
final configuration for the modified truck requires higher auxiliary roll stiffness of $30 \%$ more than the base value to optimize the ride and handling of the vehicle. The final configuration based on the selected constraints has the following design parameters and measures or responses:

\begin{tabular}{|c|c|}
\hline Parameters & Gross Vehicle Weight (GVW) \\
\hline Tire Pressure & 72 psi \\
\hline Auxiliary Roll Stiffness & $+30 \%$ \\
\hline Damping Ratio & 0.20 \\
\hline \multicolumn{2}{|l|}{ Measures } \\
\hline RMS Chassis Vertical Acceleration & 0.086 g's \\
\hline Peak Chassis Vertical Acceleration & $0.368 \mathrm{~g}$ 's \\
\hline Peak Chassis Pitch Acceleration & $2.149 \mathrm{rad} / \mathrm{sec}^{2}$ \\
\hline Peak Chassis Roll Angle & $3.259 \mathrm{deg}$ \\
\hline Peak Chassis Lateral Acceleration & 0.139 g's \\
\hline Peak Chassis Yaw Rate & $5.508 \mathrm{deg} / \mathrm{sec}$ \\
\hline Peak Chassis Roll Accelerations & $6.218 \mathrm{deg} / \mathrm{sec}^{2}$ \\
\hline Peak Percentage Load Transfer & $23.02 \%$ \\
\hline
\end{tabular}

Table 4.8: Optimized Configuration for Gross Vehicle Weight (GVW) 


\subsection{Selection of the final optimized design for the Curb Vehicle Weight in the Viewer}

The selection of tire pressures depends on the sprung mass and the terrain conditions for the cargo truck. After exporting the data in to the viewer, the first step is to use dominance filtering as discussed in section 4.9 for the selected performance measures illustrated in Table 4.7.

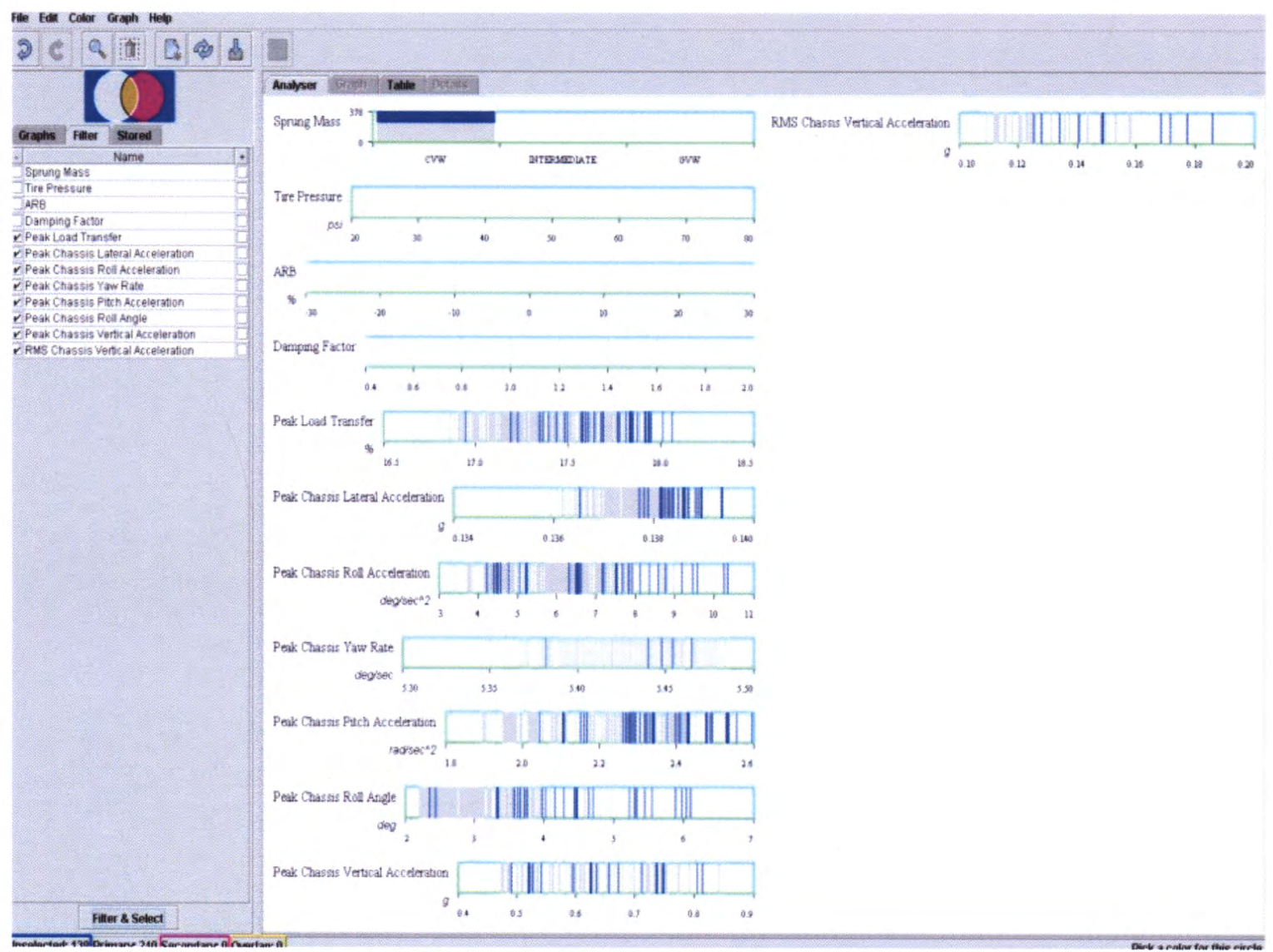

Figure 4.17: Filtered Design Space for the Curb Vehicle Weight (CVW) in the Viewer

The gray lines in the Figure 4.17 correspond to the configurations which are retained in the design space and the remaining are filtered out. In the bottom left of the Figure 4.17, 
we can see that out of a total of 378 configurations, 138 will be filtered out and the remaining 240 will be retained in the design space for further analysis. Figure 4.18 illustrates the selection done in the plot-1 which results in highlighting of the configurations in plot-2, 3 and 4 . The criterion for selection is to minimize the RMS chassis vertical acceleration and the peak load transfers experienced by the truck at curb vehicle weight. The selection was made so as to keep the RMS chassis vertical acceleration less than $0.14 \mathrm{~g}$ 's and to keep the peak load transfers less than $17 \%$.

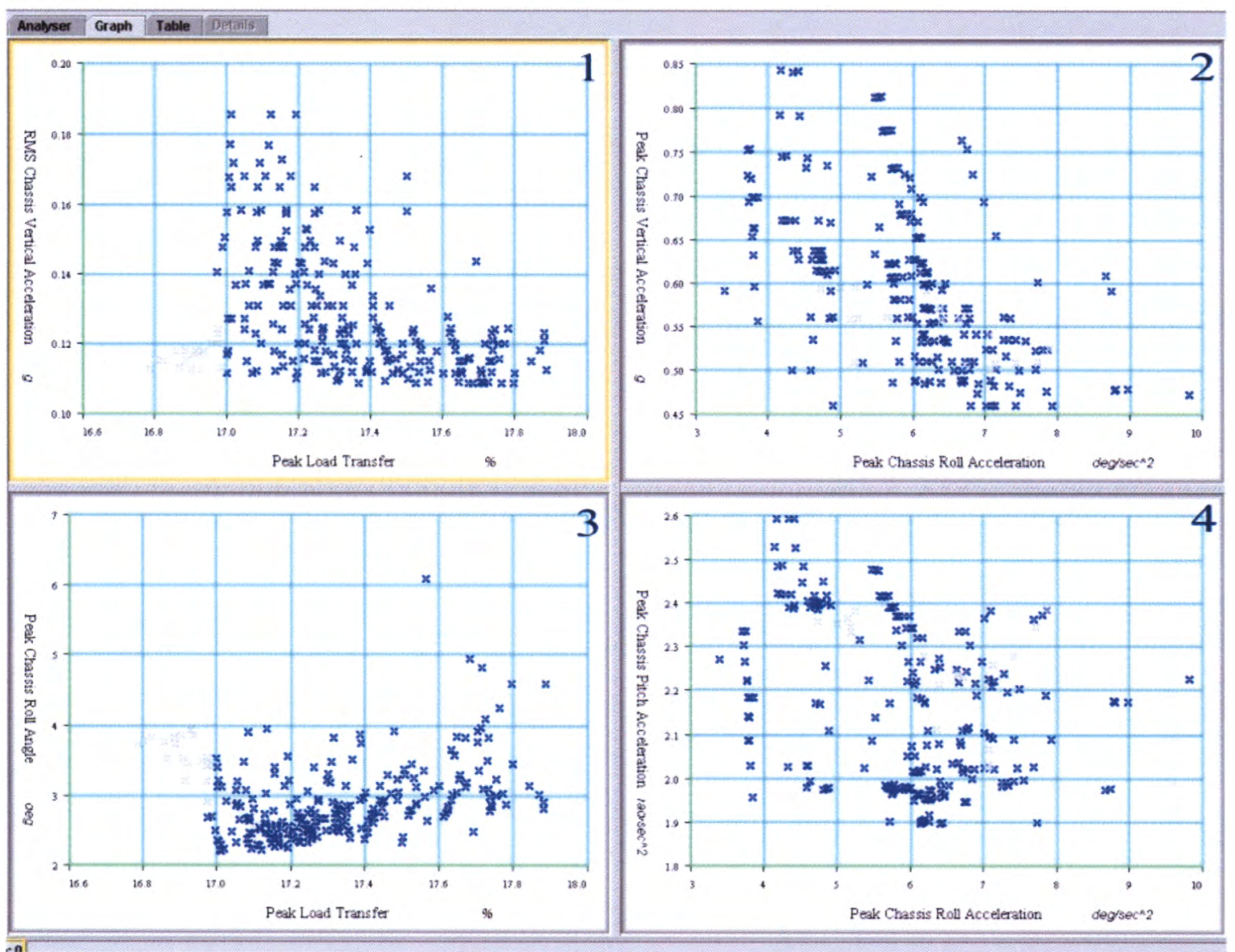

Figure 4.18: Viewer: User Selection based on RMS Chassis Vertical Acceleration and Peak Lateral Load Transfer for Curb Vehicle Weight 
This selection resulted in reducing the design space from 221 configurations to 19 configurations of the truck. Since the RMS chassis vertical acceleration are optimized for the remaining configurations, the next selection is made in the Figure 4.19 plot- 3 where the peak chassis roll angles experienced by the vehicle is kept under $3.2 \mathrm{deg}$. This selection resulted in reducing the design space from 19 configurations to 3 design configurations.
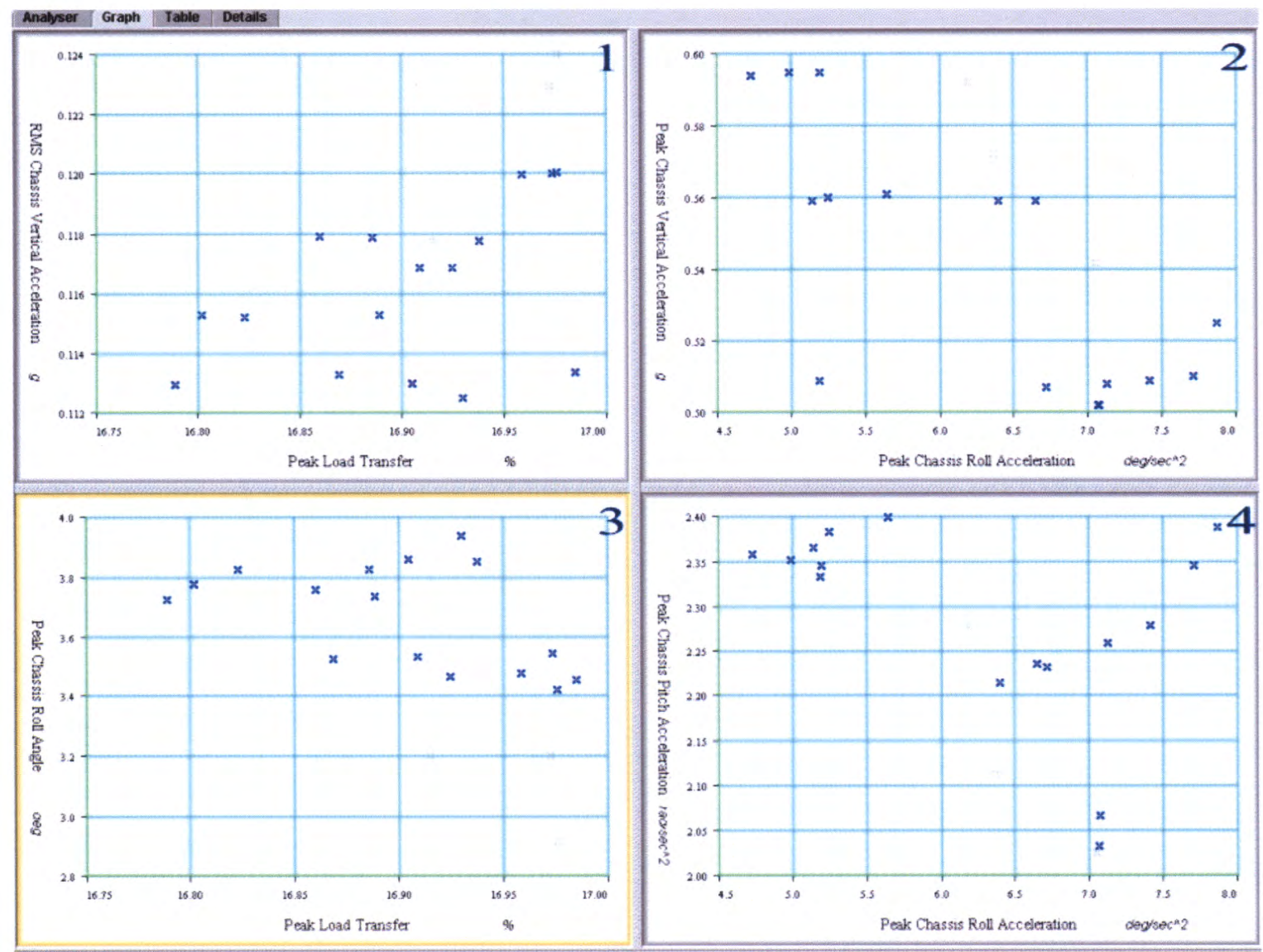

Figure 4.19: Viewer: User Selection based on Chassis Roll Angle and Lateral Load Transfer for Curb Vehicle Weight 
Figure 4.20 illustrates the final selection made to reduce the peak chassis pitch acceleration and the chassis roll accelerations experienced by the truck at curb vehicle weight. This configuration corresponds to a tire pressure of $44 \mathrm{psi}$. The final
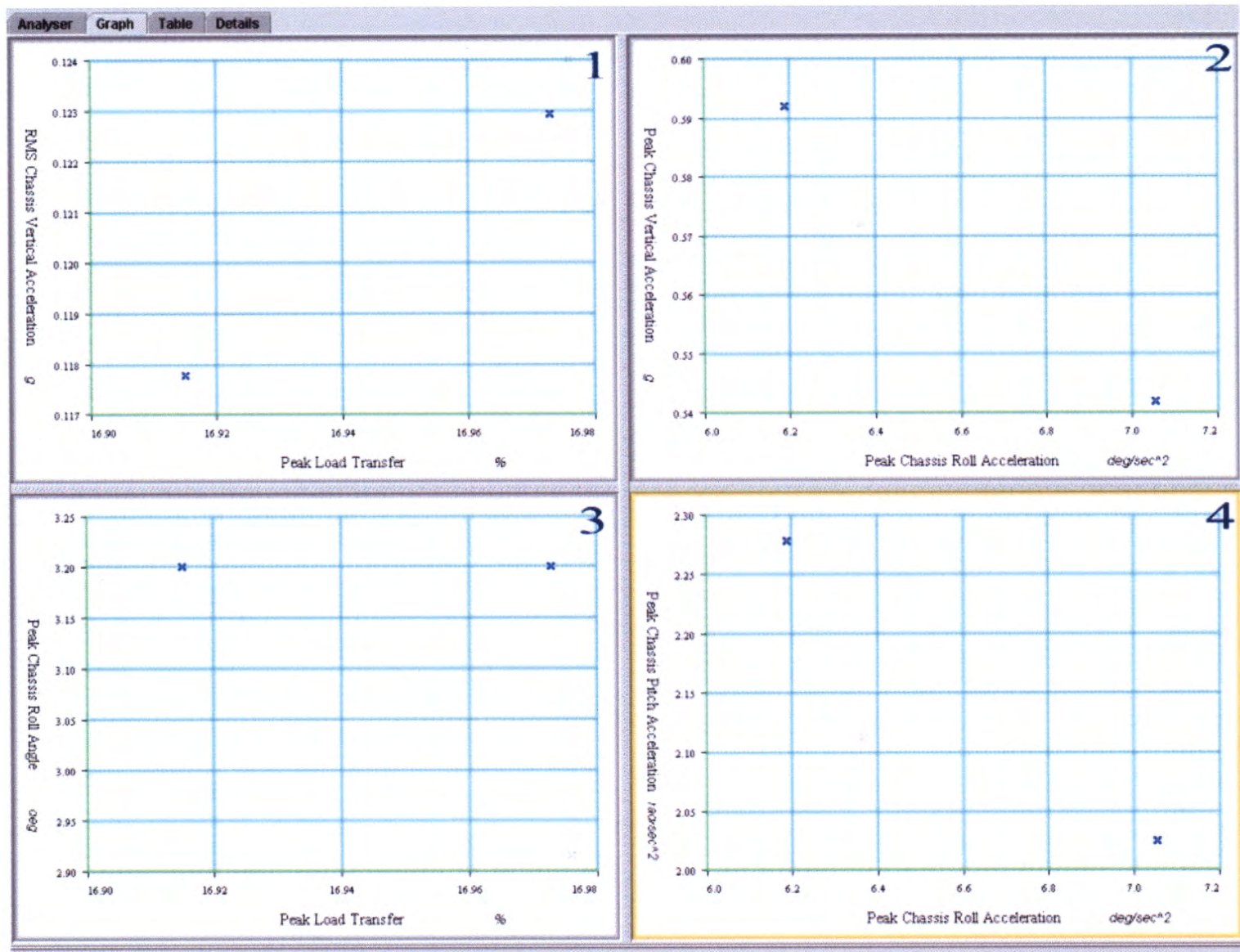

Figure 4.20: Viewer: User Selection based on Chassis Pitch Acceleration and Chassis Roll Acceleration for Curb Vehicle Weight

configuration for the curb vehicle weight for the modified truck requires higher auxiliary roll stiffness of $30 \%$ more than the base value to optimize the ride and handling of the 
vehicle. The final configuration for the curb vehicle weight based on the selected constraints has the following design parameters and measures:

\begin{tabular}{|l|c|}
\hline \multicolumn{1}{|c|}{ Parameters } & Curb Vehicle Weight (CVW) \\
\hline \multicolumn{1}{|c|}{ Tire Pressure } & $44 \mathrm{psi}$ \\
\hline Auxiliary Roll Stiffness & $+30 \%$ \\
\hline Damping Ratio & 0.25 \\
\hline \multicolumn{1}{|c|}{ Measures } & \\
\hline & \\
\hline RMS Chassis Vertical Acceleration & $0.124 \mathrm{~g}$ 's \\
\hline Peak Chassis Vertical Acceleration & $0.572 \mathrm{~g}$ 's \\
\hline Peak Chassis Pitch Acceleration & $2.113 \mathrm{rad} / \mathrm{sec}^{2}$ \\
\hline Peak Chassis Roll Angle & $2.92 \mathrm{deg}$ \\
\hline & $0.136 \mathrm{~g}$ 's \\
\hline Peak Chassis Lateral Acceleration & $5.427 \mathrm{deg} / \mathrm{sec}^{2}$ \\
\hline Peak Chassis Yaw Rate & $6.367 \mathrm{deg} / \mathrm{sec}^{2}$ \\
\hline Peak Chassis Roll Accelerations & $16.976 \%$ \\
\hline Peak Percentage Load Transfer & \\
\hline
\end{tabular}

Table 4.9: Optimized Configuration for Curb Vehicle Weight (CVW)

\subsection{Selection of the final optimized design for the Intermediate Vehicle Weight in the Viewer}

After exporting the data for the intermediate vehicle weight in to the viewer, the first step is to use dominance filtering as discussed in Section 4.9 for the selected performance measures illustrated in Table 4.7. The gray lines in the Figure 4.21 correspond to the configurations which are retained in the design space and the remaining are filtered out. In the bottom left of the Figure 4.21, we can see that out of a total number 
of configurations, 175 will be filtered out and the remaining 200 will be retained in the design space for further analysis.

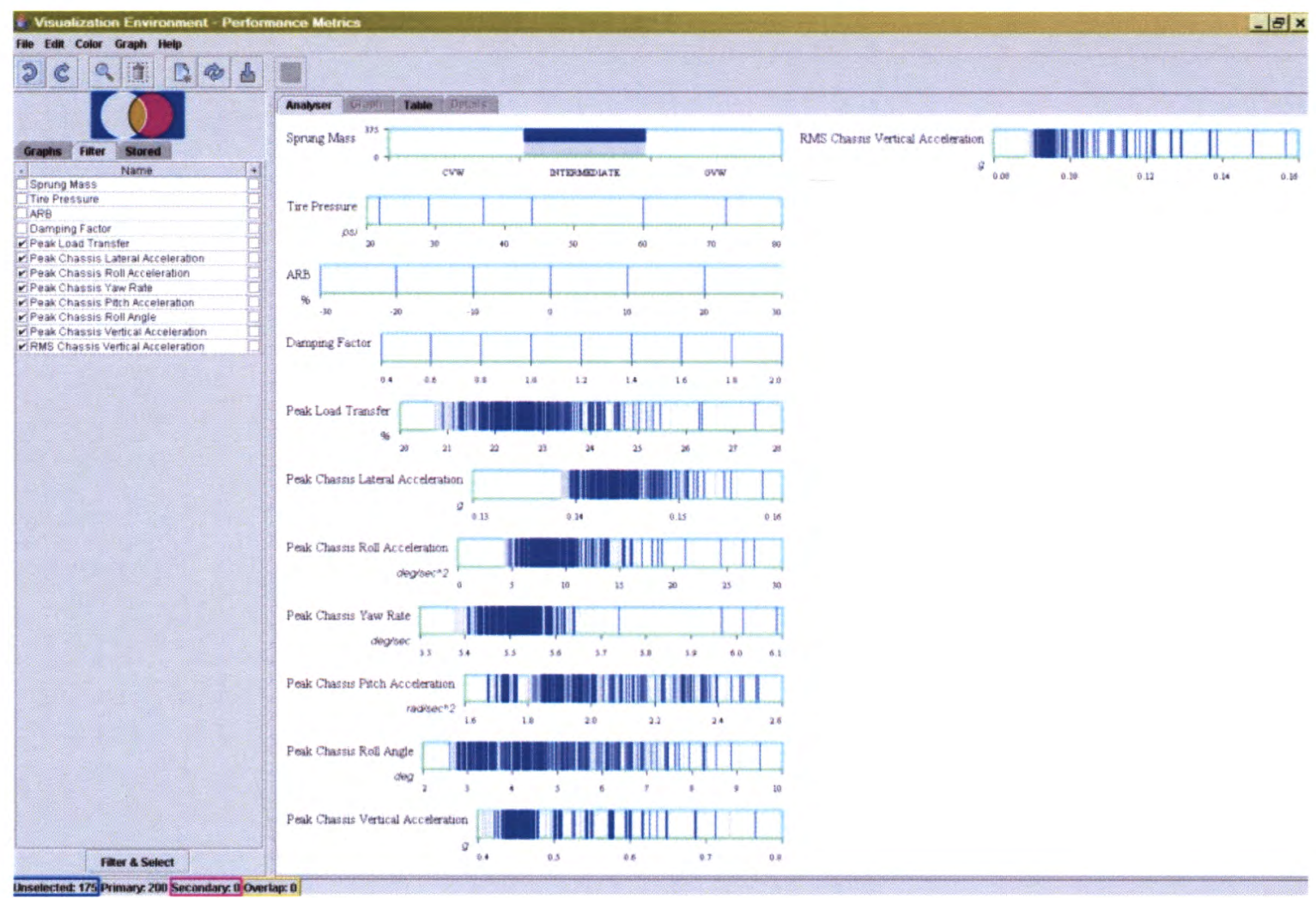

Figure 4.21: Filtered Design Space for the Intermediate Vehicle Weight in the Viewer

Figure 4.22 illustrates the selection done in the plot-1 which results in highlighting of the same configurations in plot-2,3 and 4 . The criterion for selection is to minimize the RMS chassis vertical acceleration and the peak load transfers experienced by the truck at intermediate vehicle weight. The selection was made so as to keep the RMS chassis vertical acceleration less than $0.11 \mathrm{~g}$ 's and to keep the peak load transfers less than $22 \%$. This selection resulted in reducing the design space from 200 configurations to 57 configurations of the truck. 

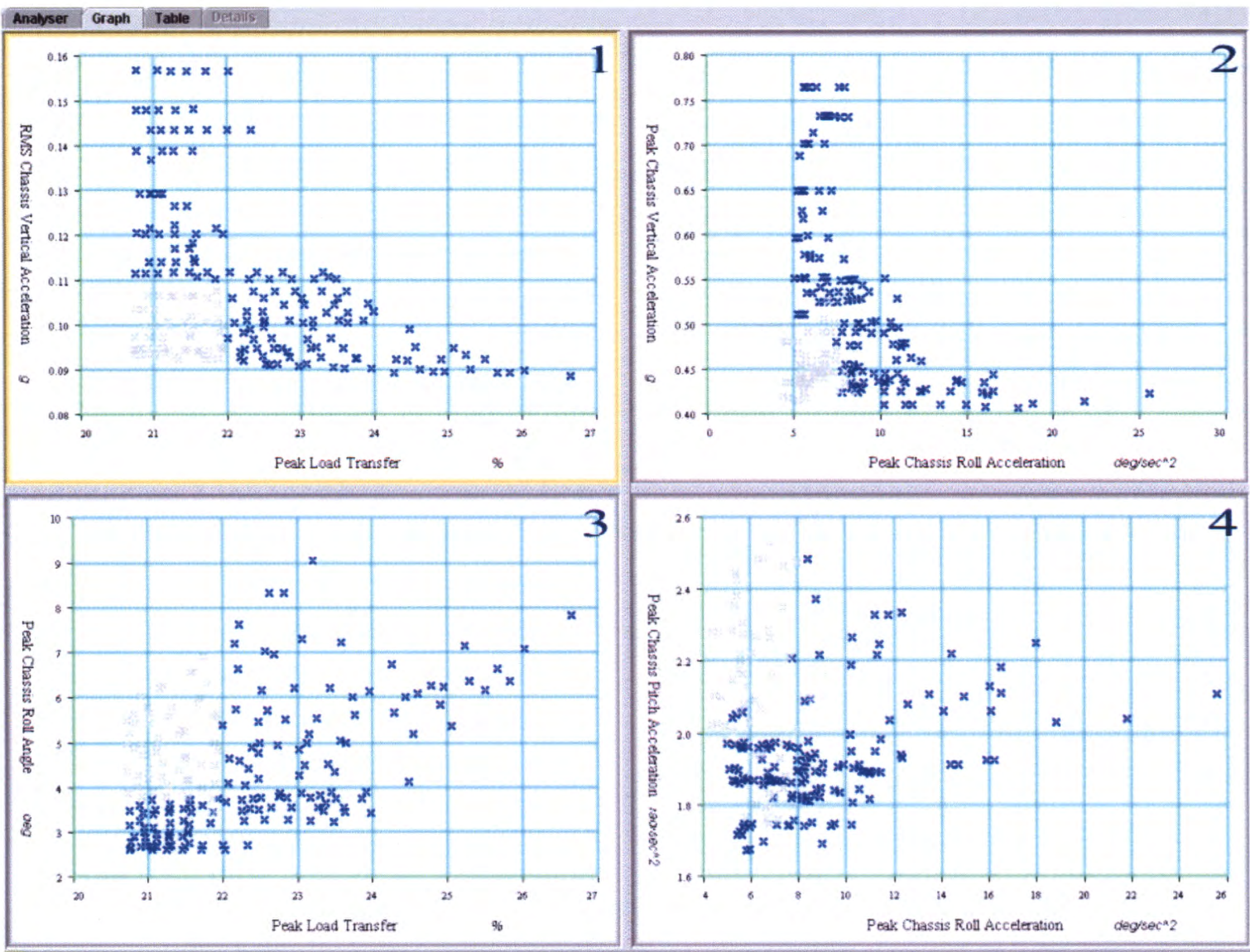

Figure 4.22: Viewer: User Selection based on RMS Chassis Vertical Acceleration and Peak Lateral Load Transfer for Intermediate Vehicle Weight

Since the chassis vertical acceleration and peak lateral load transfers are optimized for the remaining configurations, the next selection is made in the Figure 4.23 plot- 2 where the peak roll acceleration experienced by the vehicle chassis is kept under $5 \mathrm{deg} / \mathrm{sec}^{2}$. This selection resulted in reducing the design space from 57 configurations to 7 design 
configurations. Figure 4.23 illustrates the remaining 7 configurations in gray color.

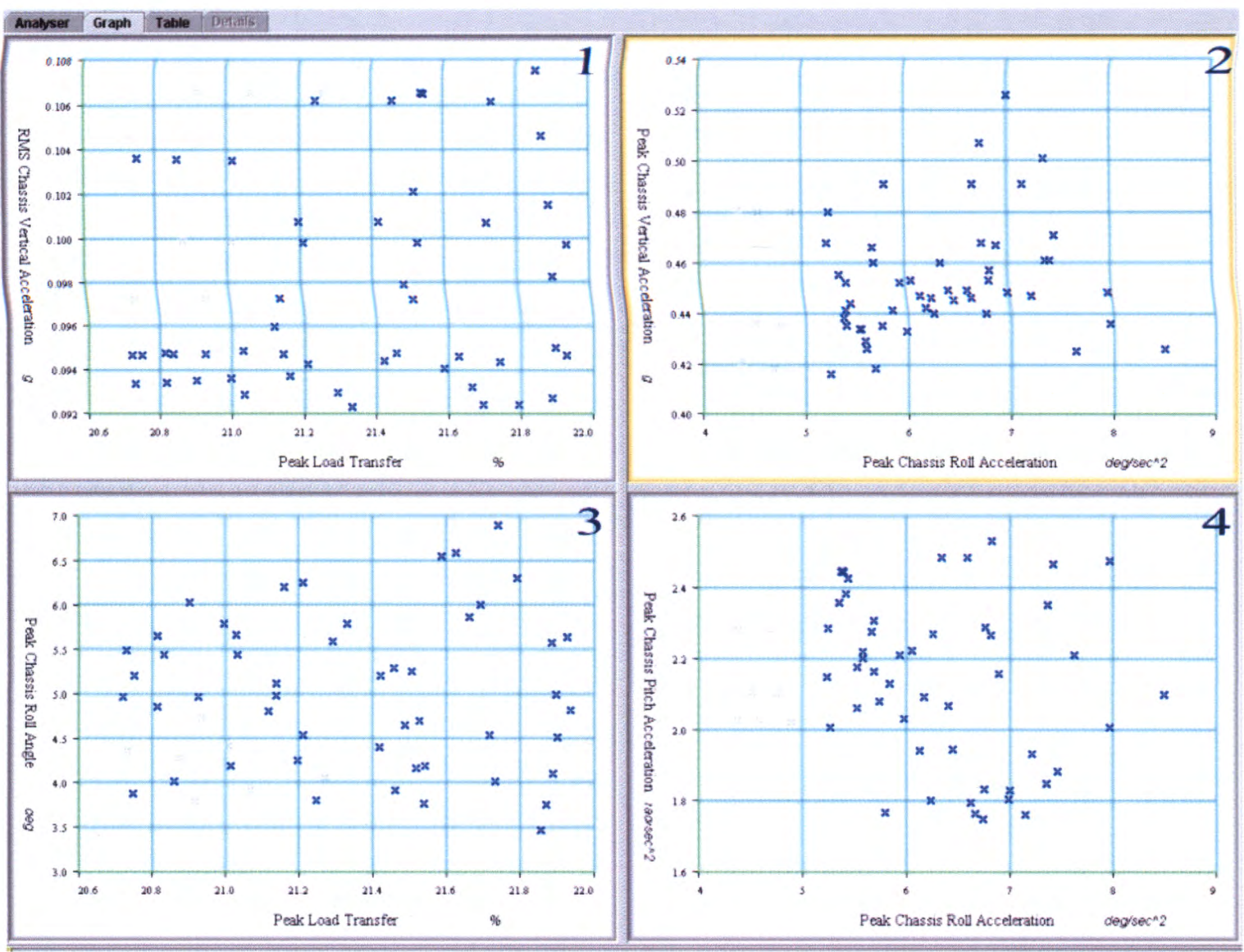

Figure 4.23: Viewer: User Selection based on Chassis Vertical Acceleration and Chassis Roll Acceleration for Intermediate Vehicle Weight

Figure 4.24 illustrates the selection made based on minimizing the peak roll angles experienced by the chassis on rough terrain. The peak chassis roll angles are kept under 4.2 deg which resulted in further reducing the design space from 7 configurations to 3 configurations. 

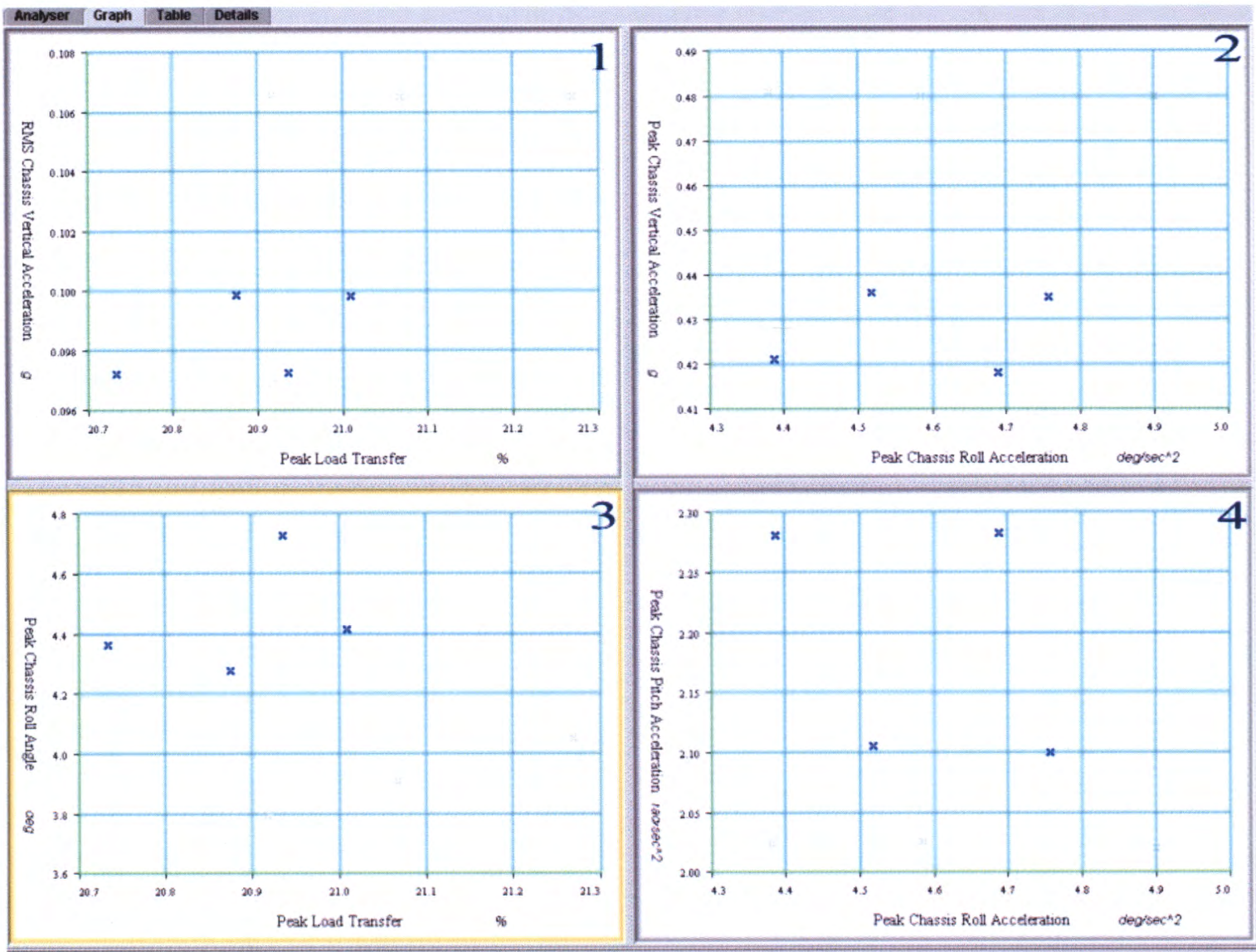

Figure 4.24: Viewer: User Selection based on Chassis Roll Angle and Peak Lateral Load Transfer for Intermediate Vehicle Weight

The remaining three configurations correspond to a tire pressure of $60 \mathrm{psi}$ and a damping factor of 0.25 . Now, since most of the performance measures are optimized, the final configuration is selected with the minimum chassis roll accelerations as illustrated in Figure 4.25 plot- 4 which also correspond to the configurations with the least load transfer. 


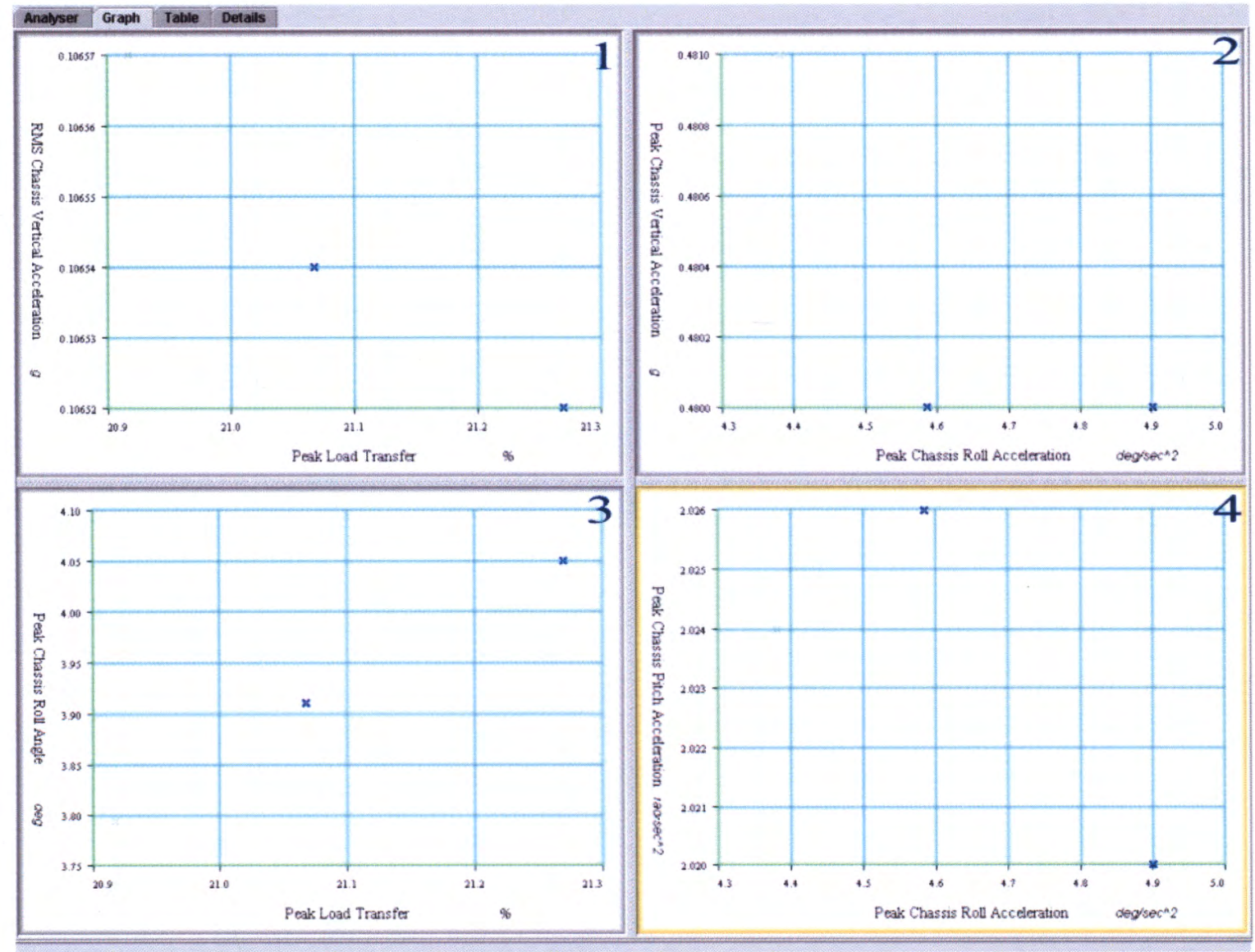

Figure 4.25: Viewer: User Selection based on Chassis Roll Acceleration for Intermediate Vehicle Weight

The final optimized configuration for the intermediate vehicle weight based on the selected hard constraints on the performance measures has the design parameters and measures as illustrated in Table 4.10. The final optimized configurations for different sprung masses are presented in Table 4.11. 


\begin{tabular}{|l|c|}
\hline \multicolumn{1}{|c|}{ Parameters } & Intermediate Vehicle Weight \\
\hline \multicolumn{1}{|c|}{ Tire Pressure } & $60 \mathrm{psi}$ \\
\hline Auxiliary Roll Stiffness & $+30 \%$ \\
\hline Damping Ratio & 0.25 \\
\hline \multicolumn{1}{|c|}{ Measures } & \\
\hline RMS Chassis Vertical Acceleration & $0.106 \mathrm{~g}$ 's \\
\hline Peak Chassis Vertical Acceleration & $0.481 \mathrm{~g}$ 's \\
\hline Peak Chassis Pitch Acceleration & $2.024 \mathrm{rad} / \mathrm{sec}^{2}$ \\
\hline Peak Chassis Roll Angle & $3.794 \mathrm{deg}$ \\
\hline & $0.139 \mathrm{~g}$ 's \\
\hline Peak Chassis Lateral Acceleration & $5.495 \mathrm{deg} / \mathrm{sec}^{2}$ \\
\hline Peak Chassis Yaw Rate & $4.382 \mathrm{deg} / \mathrm{sec}^{2}$ \\
\hline Peak Chassis Roll Accelerations & $20.918 \%$ \\
\hline Peak Percentage Load Transfer &
\end{tabular}

Table 4.10: Optimized Configuration for Intermediate Vehicle Weight

\begin{tabular}{|l|l|c|c|}
\hline Sprung Mass & $\begin{array}{c}\text { Curb Vehicle } \\
\text { Weight } \\
\text { (CVW) }\end{array}$ & $\begin{array}{c}\text { Intermediate } \\
\text { Vehicle } \\
\text { Weight }\end{array}$ & $\begin{array}{c}\text { Gross Vehicle } \\
\text { Weight } \\
\text { (GVW) }\end{array}$ \\
\hline Tire Pressure & 44 psi & $60 \mathrm{psi}$ & $72 \mathrm{psi}$ \\
\hline Auxiliary Roll Stiffness & $+30 \%$ & $+30 \%$ & $+30 \%$ \\
\hline Damping Ratio & 0.25 & 0.25 & 0.20 \\
\hline Performance Measures & & & \\
\hline RMS Chassis Vertical Acceleration & $0.124 \mathrm{~g}$ 's & $0.106 \mathrm{~g}$ 's & $0.086 \mathrm{~g}$ 's \\
\hline Peak Chassis Vertical Acceleration & $0.572 \mathrm{~g}$ 's & $0.481 \mathrm{~g}$ 's & $0.368 \mathrm{~g}$ 's \\
\hline Peak Chassis Pitch Acceleration & $2.11 \mathrm{rad} / \mathrm{sec}^{2}$ & $2.02 \mathrm{rad} / \mathrm{sec}^{2}$ & $2.15 \mathrm{rad} / \mathrm{sec}^{2}$ \\
\hline Peak Chassis Roll Angle & $2.92 \mathrm{deg}$ & $3.794 \mathrm{deg}$ & $3.259 \mathrm{deg}$ \\
\hline Peak Chassis Lateral Acceleration & $0.136 \mathrm{~g}$ 's & $0.139 \mathrm{~g}$ 's & $0.139 \mathrm{~g}$ 's \\
\hline Peak Chassis Yaw Rate & $5.43 \mathrm{deg} / \mathrm{sec}^{2}$ & $5.49 \mathrm{deg} / \mathrm{sec}^{2}$ & $5.51 \mathrm{deg} / \mathrm{sec}^{2}$ \\
\hline Peak Chassis Roll Accelerations & $6.36 \mathrm{deg} / \mathrm{sec}^{2}$ & $4.38 \mathrm{deg} / \mathrm{sec}^{2}$ & $6.22 \mathrm{deg} / \mathrm{sec}^{2}$ \\
\hline Peak Percentage Load Transfer & $16.97 \%$ & $20.92 \%$ & $23.02 \%$ \\
\hline
\end{tabular}

Table 4.11: Optimized Configuration for Different Sprung Masses 


\subsection{Summary}

In this chapter, we discussed the analysis, results and optimization of the cargo truck for different sprung masses. Appropriate tire pressure and suspension parameters are obtained for different loading conditions. It is important to note that selection of optimized configuration is dependent on the hard constraints a designer specifies after the dominance filtering of the design space. In the next chapter, conclusion and future work is discussed. 


\section{CHAPTER 5}

\section{CONCLUSION AND FUTURE WORK}

\subsection{Conclusion}

The motivation of this study is to demonstrate the work for design parameters optimization concentrating on the ride and handling of the MTV 5.0 Ton cargo truck for the U.S.Army. For very complex mechanical systems, like heavy duty trucks, we need more flexible and easy to use tools to explore different configurations of the vehicle. Exploring large design parameters variations in the vehicle helps us in narrowing down on optimum values for the components used on trucks. This study is focused on vehicle dynamics but similar work can be done in the other applicable areas (like for minimizing fuel consumption for the vehicle) using different tools available like MATLAB/Simulink etc. This research work is a continuation of the efforts done before in the area of optimization [21].

The method applied to improve the dynamic behavior of the vehicle included creating a MTV vehicle model for the vehicle with some modifications like incorporating air springs instead of leaf springs to provide improved ride for the passenger. This vehicle with air springs is then verified by doing a step steer analysis, constant radius cornering 
analysis and basic "sanity" checks. The next step is to identify the suspension and tire design parameters along with responses of interest for ride and handling maneuvers. Different configurations are generated by changing the values of the suspension and tire design parameters of the vehicle. Ride and handling metrics are defined to evaluate the design candidates. These generated configurations are then simulated for ride and handling maneuvers for a sprung mass and tire pressures combination. This was repeated for every sprung mass and tire pressures combination. Since six different tire pressures and three sprung masses ( CVW, Intermediate and GVW) are selected, the simulations were repeated for 18 times for the ride maneuver and 18 times for the handling maneuver, keeping the design parameters variations the same in each run. Dominance filtering is used to narrow down to the configurations of interest based on the selected criteria for ride and handling. The visualization environment provides two dimensional plots between performance measures and/or design parameters. These $2 \mathrm{D}$ plots are used to find the final optimized vehicle based on the selection criteria (constraints) for the vehicle. Appropriate tire pressures are found by following the design optimization process for the different loading (sprung mass) conditions. 
The final optimized configuration for different sprung masses is presented in Table 5.1.

\begin{tabular}{|l|l|c|c|}
\hline Sprung Mass & $\begin{array}{c}\text { Curb Vehicle } \\
\text { Weight } \\
\text { (CVW) }\end{array}$ & $\begin{array}{c}\text { Intermediate } \\
\text { Vehicle } \\
\text { Weight }\end{array}$ & $\begin{array}{c}\text { Gross Vehicle } \\
\text { Weight } \\
\text { (GVW) }\end{array}$ \\
\hline Tire Pressure & $44 \mathrm{psi}$ & $60 \mathrm{psi}$ & $72 \mathrm{psi}$ \\
\hline Auxiliary Roll Stiffness & $+30 \%$ & $+30 \%$ & $+30 \%$ \\
\hline Damping Ratio & 0.25 & 0.25 & 0.20 \\
\hline Performance Measures & & & \\
\hline RMS Chassis Vertical Acceleration & $0.124 \mathrm{~g}$ 's & $0.106 \mathrm{~g}$ 's & $0.086 \mathrm{~g}$ 's \\
\hline Peak Chassis Vertical Acceleration & $0.572 \mathrm{~g} \mathrm{~s}^{\mathrm{s}}$ & $0.481 \mathrm{~g}$ 's & $0.368 \mathrm{~g}$ 's \\
\hline Peak Chassis Pitch Acceleration & $2.11 \mathrm{rad} / \mathrm{sec}^{2}$ & $2.02 \mathrm{rad} / \mathrm{sec}^{2}$ & $2.15 \mathrm{rad} / \mathrm{sec}^{2}$ \\
\hline Peak Chassis Roll Angle & $2.92 \mathrm{deg}$ & $3.794 \mathrm{deg}$ & $3.259 \mathrm{deg}$ \\
\hline Peak Chassis Lateral Acceleration & $0.136 \mathrm{~g}$ 's & $0.139 \mathrm{~g}$ 's & $0.139 \mathrm{~g}$ 's \\
\hline Peak Chassis Yaw Rate & $5.43 \mathrm{deg} / \mathrm{sec}^{2}$ & $5.49 \mathrm{deg} / \mathrm{sec}^{2}$ & $5.51 \mathrm{deg} / \mathrm{sec}^{2}$ \\
\hline Peak Chassis Roll Accelerations & $6.36 \mathrm{deg} / \mathrm{sec}^{2}$ & $4.38 \mathrm{deg} / \mathrm{sec}^{2}$ & $6.22 \mathrm{deg} / \mathrm{sec}^{2}$ \\
\hline Peak Percentage Load Transfer & $16.97 \%$ & $20.92 \%$ & $23.02 \%$ \\
\hline
\end{tabular}

Table 5.1: Optimized Configuration for Different Sprung Masses

It can be seen in the above table that the values of the scale values for the optimized configuration for all sprung masses is $+30 \%$ for the auxiliary roll stiffness. This suggests that using anti roll bars of high roll stiffness improves the ride and handling characteristics of the truck. The damping of the truck with air suspension at curb and intermediate vehicle weight should be kept same as that of the truck with leaf spring but for the gross vehicle weight it should be reduced. Results showed that there is a tradeoff between ride and handling characteristics of the vehicle for a different tire pressure for a given sprung load. For lower tire pressures, least RMS values for chassis vertical acceleration are obtained. On the other hand, for higher tire pressures, the least peak 
lateral load transfers are obtained. If we just focus on improving the ride characteristics of the truck then we should go for very low tire pressures but that will provide worse handling characteristics for the vehicle. Instead, if we select higher tire pressures, worse ride (higher RMS chassis vertical acceleration) for the vehicle is obtained. This research study illustrated an approach to optimize the tire pressures (along with other design parameters) for a given sprung load.

Central Tire Inflation Systems (CTIS) can be conveniently used to control the tire pressures for the vehicle based on the terrain and loading conditions. Depending on the terrain such as snow, mud, sand and rocks, the tire inflations can be adjusted to provide the appropriate contact patch for the tires and good ride on a given terrain. 


\subsection{Future Work}

There are many areas still unexplored in this study. Some of them are discussed as future work in the following sections.

\subsubsection{Air Spring Stiffness as the Design Parameter}

The air spring stiffness for a given payload is kept constant in this research. It would be an appropriate design parameter to optimize for a given configuration of truck to optimize ride and handling of the truck.

\subsubsection{Optimizing the Damping and Spring Stiffness for a given Payload}

The method used in this research can be extended to use it for practical truck applications where depending on the payload a truck is carrying, a driver can conveniently find the right combination of air spring stiffness and damping for better ride and handling of the truck. This requires development of a tool which provides a convenient user interface to find suitable spring stiffnesses and damping for optimizing ride and handling of the given configuration of the truck. It can be automated so that when a user specifies the payload, damping and spring stiffnesses changes automatically to provide the best ride and handling possible for a given terrain.

\subsubsection{Leaf Spring Modeling using Auto/flex}

To model the leaf spring used on heavy duty trucks there are a few tools available in ADAMS to model them. ADAMS/Autoflex and Leaf Tool can be used to model leaf springs. The modeling of leaf springs requires extensive data 
for them from the manufacturer. An optimization study can be used to find the appropriate number of leafs and leaf spring stiffness for any given suspension.

\subsubsection{Powertrain and Driveline Modeling}

ADAMS/Engine can be used to model the engine used on the vehicles. Various components of the engine like a crank shaft, valve train, accessory drive and timing belt can be modeled using different modules available in ADAMS/ Engine. Engine and powertrain modeling includes the parts, joints etc. that provides power to the wheels in the vehicle. Complete modeling of the vehicle components provides a thorough insight in to the vehicle system.

\subsubsection{ADAMS/Ride}

ADAMS/Ride is a plug-in to ADAMS/Car which can be loaded in the ADAMS/Car environment. It provides an environment to study the ride characteristics of the vehicles in the frequency domain. Currently it is designed to analyze a vehicle with two axles and to expand its capability to include more that 2 axles requires a significant amount of work, time, knowledge and expertise. In the future versions of the ADAMS it may have flexibility to include more than 2 axles for the heavy duty trucks and should provide an excellent interface to study the ride of the vehicles in a convenient and easy to use environment.

\subsubsection{Flexible Chassis}

The chassis used on heavy duty trucks experience the phenomenon of 
beam bending because of the heavy varying loads acting on the truck. To study the handling of the truck, it is important that flexibility of selected components is taken in to account to reflect better overall dynamics of the vehicle. ADAMS provides an extended product called ADAMS/flex which can be used to model flexible bodies. It might lead to more complex vehicle models and require more computational power but it surely leads to better representation of the actual vehicle.

\subsection{Closure}

The ride and handling for heavy duty trucks is a complex issue and to find out smart ways to optimize them is a big challenge. There is always a tradeoff to be made between ride and handling characteristics for the vehicle. To be able to find appropriate tire pressures to optimize ride and handling for any given sprung load has vast applications in the automobile industry. Smart tools can be made using similar approaches as suggested in this thesis to obtain better dynamic response from the military or heavy duty trucks. 


\section{REFERENCES}

1. Gillespie, Thomas, Fundamental of Vehicle Dynamics, Society of Automotive Engineers, Inc., 1992.

2. Yi, Tong Y., Vehicle Dynamic Simulations Based on Flexible and Rigid Multibody Models, Society of Automotive Engineers, Inc., 2000.

3. El-Demeresh, S.M., Improvement of Trucks Ride Dynamics Using a Hydraulic Semi- Active Suspension System. Society of Automotive Engineers, Inc., 2002.

4. Ledesma, Ragnar, Ride Performance Comparison of Trailer Suspension Systems Using Computational Methods. Society of Automotive Engineers, Inc., 2002.

5. Nogueira, Felipe et. al, Tractor Air Suspension Design and Tuning, Society of Automotive Engineers, Inc., 2002.

6. Lee, Heui-bom et al., A study of ride analysis of medium trucks with varying the characteristics of suspension design parameters, Society of Automotive Engineers, Inc., 1997.

7. Ohta, Michiya et al., The influence of tire deformation on ride comfort of a truck, Society of Automotive Engineers, Inc., 1990.

8. Letherwood, Michael D. and Gunter, David D., Vehicle dynamics analysis of a heavy truck/trailer combination using simulation, Society of Automotive Engineers, Inc., 1999.

9. Gunter, David D., Modeling and simulation of a 6x6 military troop/cargo transport vehicle, Society of Automotive Engineers, Inc., 1998.

10. MSC-ADAMS Basic Full Simulation Product Guide by Mechanical Dynamics Inc., 2003.

11. ADAMS/Car Product Guide, Mechanical Dynamics Inc. 
12. John R. Josephson, B. Chandrasekaran, Mark Carroll, Naresh Iyer, Bryon Wasacz, Giorgio Rizzoni, Qingyuan Li, David A. Erb, An Architecture for Exploring Large Design Spaces, National Conference on AI (AAAI-98), American Association for Artificial Intelligence, 1998.

13. ADAMS/Insight Product Guide, Mechanical Dynamics Inc.

14. "Vehicle Dynamics Terminology," SAE 670e, Society of Automotive Engineers, Warrendale, PA

15. ADAMS/Tire Models Product Guide, Mechanical Dynamics Inc.

16. Woods, Robert L., and Lawrence, Kent L., Modeling and Simulation of Dynamic Systems, 1997, ISBN: 0-13-337379-1

17. Wong, J.Y, Theory of ground vehicles, 2001, ISBN: 0-471-35461-9

18. MSC-ADAMS/ Online guides

19. Visualization Environment developed by Aetion Technologies LLC (http://www.aetion.com) in collaboration with the Ohio State University (http://www.osu.edu).

20. DEPARTMENT OF TRANSPORTATION, National Highway Traffic Safety Administration (NHTSA), Rollover Resistance, 49 CFR Part 575, [Docket No. NHTSA-2001- 9663; Notice 3

21. Chandrasekaran, A.K., Vehicle Design Optimization Using Multibody Dynamic Simulation and Large Design Space Search Methods, Masters Thesis, The Ohio State University, 2002.

22. ADAMS/Car Templates Guide, Mechanical Dynamics Inc.

23. BMW website, $\underline{\text { http://www.bmw.com/ }}$

24. NHTSA website, http://www.nhtsa.dot.gov/cars/problems/rollover/pages/FAQs.htm

25. Stone, Richard and Ball, Jeffrey K., Automotive Engineering Fundamentals, 2004, ISBN: 0-7680-0987-1 
APPENDIX 


\section{ADAMS Code}

File: acarBS.cmd

!-- Code used to add the Generic Assembly option to New Menu in ADAMS ---! interface push_button create \&

push_button_name $=$.gui.main.aca_sta_mbar.file.new.generic_assembly $\&$ enabled $=$ yes \& documentation_text $=$ "Create a new generic assembly" \& units $=$ relative \& horiz_resizing $=$ scale_all $\&$ vert_resizing $=$ scale_all \& location $=0.0,0.0 \&$ label = "Generic Assembly..." \& commands = "interface dialog display dialog=.ACAR.dboxes.dbox_fil_ass_new_gen" \& default $=$ false

File: acarBS.cmd

!--- Code used to set minor role variable ---

variable set variable name $=$ ACAR. variables. minor roles \& string_value $=a n y$, front, front_tractor, rear_tractor, rear 


\section{Air Springs}

Force $=$ AKISPL $(($ trim length $-D M($ marker I, marker J)), (trim load $)$, splineID where;

$A K I S P L$ - is the ADAMS/Solver function that interpolates data using Akima's method. trim length - is the distance between the upper and lower spring seats when the suspension is at trim height. Trim length is a positive real value read from the air spring property file.

$D M$ (marker I, marker J) - is the distance between the upper and lower spring seats. trim load - is the load in the spring when the suspension is at trim height. The load corresponds to the trim load specified. If we select auto trim load, load corresponds to a differential equation. It is also the second independent variable in the three dimensional spline $(Z)$.

Diff function $=$ USER $(1117$, trim length, I marker, J marker $)$

where;

1117 - Branch ID.

trim length - The desired displacement, which can be modified using the vise property file editor.

I/ J marker - The air spring's I and J markers of the SFORCE. 